Article

\title{
An Extenics-Based Scheduled Configuration Methodology for Low-Carbon Product Design in Consideration of Contradictory Problem Solving
}

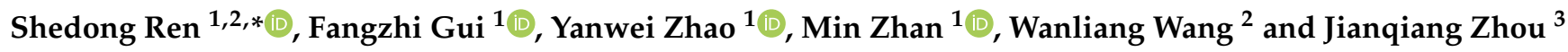 \\ 1 College of Mechanical Engineering, Zhejiang University of Technology, Hangzhou 310023, China; \\ guifangzhi@zjut.edu.cn (F.G.); ywz@zjut.edu.cn (Y.Z.); zm@zjut.edu.cn (M.Z.) \\ 2 College of Computer Science and Technology, Zhejiang University of Technology, Hangzhou 310023, China; \\ wangwlzjut@zjut.edu.cn \\ 3 College of Mechanical Engineering, Quzhou University, Quzhou 324000, China; zjqaydf@163.com \\ * Correspondence: renshedong@zjut.edu.cn
}

\section{check for}

updates

Citation: Ren, S.; Gui, F.; Zhao, Y.; Zhan, M.; Wang, W.; Zhou, J. An

Extenics-Based Scheduled

Configuration Methodology for

Low-Carbon Product Design in

Consideration of Contradictory

Problem Solving. Sustainability 2021,

13, 5859. https://doi.org/10.3390/

su13115859

Academic Editors: Barbara Motyl and Tracy Bhamra

Received: 11 March 2021

Accepted: 19 May 2021

Published: 23 May 2021

Publisher's Note: MDPI stays neutral with regard to jurisdictional claims in published maps and institutional affiliations.

Copyright: (c) 2021 by the authors. Licensee MDPI, Basel, Switzerland. This article is an open access article distributed under the terms and conditions of the Creative Commons Attribution (CC BY) license (https:/ / creativecommons.org/licenses/by/ $4.0 /)$.
Abstract: Low-carbon product design involves a redesign process that requires not only structural module modification, but more importantly, generating innovative principles to solve design contradictions. Such contradictions include when current design conditions cannot satisfy design requirements or there are antithetical design goals. On the other hand, configuration tasks in the reconfiguration process are interdependent, which requires a well-scheduled arrangement to reduce feedback information. This study proposes an effective configuration methodology for low-carbon design. Firstly, configuration tasks and configuration parameters are designated through quality characteristics, and the directed network along with the associated values of configuration tasks are transformed into the design structure matrix to construct the information flow diagram. Then, the Extenics-based problem-solving model is presented to address design contradictions: low-carbon incompatibility and antithetical problems are clarified and formulated with a basic-element model; extensible and conjugate analysis tools are used to identify problematic structures and provide feasible measures; the Gantt chart of measures execution based on the information flow diagram is constructed to reduce feedback and generate robust schemes with strategy models. The methodology is applied to the vacuum pump low-carbon design, the results show that it effectively solves contradictions with innovative design schemes, and comparative analysis verifies the performance of Extenics.

Keywords: low-carbon design; Extenics; requirements configuration; information flow diagram; contradictory problems

\section{Introduction}

To accommodate population growth and global economic development, sustainability research has become increasingly important to more efficiently use material resources and energy; on the other hand, the consumption of material resources and energy produces a large amount of greenhouse gas (GHG), especially from industrial production, which accelerates global warming and brings a significant threat to human survival [1,2]. The international academy for production engineering (CIRP) established the low carbon manufacturing working group in Paris, France, in 2008. It unified the research work about the design and manufacturing process with respect to energy conservation and emissions reduction and participated in launching a collaborative research project called CO2PE! [3]. Design decisions impact greatly on the manufacturability of the product in production, product quality and cost to society, and sustainability for the environment $[4,5]$. Lowcarbon design takes into account the low-carbon requirements and aims at reducing carbon emissions throughout the product lifecycle, and it has attracted heated research in both academia and industry [6-10]. 
In low-carbon product design, when low-carbon attributes are taken into account, this study makes the assumption that there are not predefined components that can be directly used to replace the problematic components, and thus designers need to break the original equilibrium design system in which all design attribute factors are well balanced and re-plan the design scheme to satisfy design targets. For instance, in order to reduce carbon emissions throughout the product lifecycle, designers could consider taking a low-carbon related strategy, modifying the structure parameter, adjusting the structure layout, and even adopting a new design principle; we call this procedure the configuration process. Furthermore, during the configuration process, designers should be aware of the following issues.

(1) Design contradictions commonly emerge from the configuration process for lowcarbon product design. Here, design contradiction is defined according to the Extenics theory [11], which comprises the incompatibility problem, that is, the objective condition cannot satisfy the subjective target, and the antithetical problem, namely, two subjective targets cannot be satisfied together under the current objective condition. Generally, in current configuration methods, such as the quality function deployment (QFD), the mapping of product function onto the components is not straightforward, and the function should be indirectly mapped onto the components by configuring quality characteristics (QCs). However, components interact with each other in many ways to deploy QCs, which results in the coupling properties between the QCs [12]. Thus, there is a phenomenon that, on the one hand, design conditions cannot satisfy the low-carbon demand, and on the other hand, the low-carbon performance characterized by QCs is improved while the other performance associated with the coupled QCs is weakened; these situations cause the design contradictions, namely the incompatibility problem and the antithetical problem, respectively.

(2) In order to accomplish the low-carbon reconfiguration tasks that are accompanied by design contradiction solving, designers need to go through multiple complex backtracking analysis processes. Tong and Sriram [13] described the function mapping process as an ill-structured problem and pointed out that the nature of product design is to gradually and clearly define the messy description of initial function configurations. In terms of lowcarbon configuration tasks (CTs), to accomplish the $\mathrm{CT}_{i}$, requires the input configuration parameters from the preceding $\mathrm{CTs}$, and $\mathrm{CT}_{i}$ also provides output configuration parameters for the subsequent CTs; consequently, there is a complex association network between CTs. For the coupled CTs, retrospective analysis is necessary, as the configuration tasks involve both qualitative and quantitative design objectives; the retrospective analysis process cannot be treated as an engineering optimization problem, and thus designers should coordinate the configuration parameters through multiple trial-and-error iterations [14,15]. Additionally, the potential design conflicts increase the complexity of the retrospective analysis process.

Consequently, low-carbon product design involves a redesign process that encompasses multiple complex configuration tasks with numbers of trial-and-error iterations to reconfigure the structural modules, and more importantly, the reconfiguration process is usually accompanied by design contradictions, which require innovative design strategies and ideas. The purpose of this study is to address the aforementioned two issues in lowcarbon product design by proposing a systematic Extenics-based scheduled configuration methodology. In the methodology, the information flow diagram (IFD) of configuration tasks is constructed to help designers reasonably arrange the configuration process and reduce the number of trial-and-error iterations in backtracking analysis; on the other hand, an effective design-contradiction-solving model is developed based on Extenics, which provides designers with innovative design strategies and ideas for addressing low-carbon design incompatibility and antithetical problems.

The rest of the paper is articulated as follows. Section 2 provides the literature review, including the low-carbon product design, and the contradictory problem-solving method Extenics. Section 3 is about the materials and methods of this paper; in Section 3.1, the 
low-carbon requirements are deployed with the QFD method, and the IFD of CTs is constructed based on the design structure matrix; in Section 3.2, the contradictory problemsolving model for low-carbon design based on Extenics is developed, which consists of problem clarification and formulation, extensible and conjugate analysis, and extension transformation; in Section 3.3, the outline of the combination of the scheduling model of CTs and the design-contradiction-solving method based on Extenics is illustrated. In Section 4, implementation of the proposed methodology to a case study of the vacuum pump low-carbon design and the comparative performance assessment are presented. Discussion is provided in Section 5, and conclusions are finally drawn along with the recommendations for further research in Section 6.

\section{Literature Review}

In this section, the literature review of the low-carbon product design is provided to reveal that it is urgent to develop an effective methodology to provide practicable strategies and solve design contradictions associated with the two issues described in the introduction section and then the literature review of design problem-solving method Extenics is introduced.

\subsection{Low-Carbon Product Design}

The product design process typically consists of product planning, conceptual design, embodiment design, and detailed design. Low-carbon product design is a redesign process that incorporates environmental impacts into the original design system with the goal of carbon emissions reduction, while satisfying the initial product functional performance and encouraging economic progress [16,17]. Related studies of low-carbon product design have been initiated and implemented by CIRP since 2008 [3], and now there are three main research branches under this area: (1) carbon emissions estimation throughout the entire life cycle of a product [18-20], (2) development of strategies and ideas for low-carbon product conceptual design [21-24], and (3) development of the constraint model and algorithm for low-carbon product optimization design $[25,26]$.

The carbon footprint (CFP), the sum of GHG emissions at each life cycle stage, is a widely accepted quantitative metric to evaluate the environmental impact of the product; this study adopts the CFP to estimate whether the new generation products are better than the previous generation products regarding low-carbon performance. The life cycle assessment method [27] and PAS 2050 framework [28] provide standards and specifications for CFP estimation by mapping the product bill of materials to the CFP life cycle inventory. With the CFP data, designers could identify the problematic structures that require environmental improvement. For instance, Song and Lee [29] developed a low-carbon design system based on g-BOM, which contains the embedded CFP data to help designers evaluate alternative parts. Zhang et al. [30] reported a CFP calculation approach for the connection characteristics between components to effectively identify the connection units with high carbon emissions. After the identification of problematic structures, measures should be taken to reconfigure these structures to realize the low-carbon target. If the measures for the problematic structures are only associated with material section and structure parameter optimization, an effective method is to construct the constraint optimization model or multi-objective optimization model to make a trade-off between the product CFP, functional performance, and cost [31,32]. For example, Zhang et al. [33] reported a hybrid low-carbon optimization model for structural components by integrating material selection, structure layout, and structure parameter optimization. Hu et al. [34] estimated the energy consumption in the manufacturing process based on the structural features at the product design stage to optimize structure parameters.

However, the low-carbon design problem cannot be always addressed by the optimization method; on the one hand, even if the optimal design parameters are obtained under the existing principle scheme, the carbon emissions reduction is not obvious; on the other hand, although the obtained design parameters in the new design scheme would 
improve the low-carbon performance, the conventional performance of the product would deteriorate, which makes the optimization result unacceptable. This is because although the low-carbon optimization method can solve the parametric design problem, it cannot solve the concept generation problem. As such, the low-carbon design problem requires design strategies and ideas to solve design contradictions and generate an innovative design scheme.

Low-carbon product conceptual design plays a critical role in the entire low-carbon product design stage; the new conceptual scheme can provide strategies and ideas for the product improvement, that is, the developed design scheme based on the strategies and ideas can satisfy the low-carbon requirements with the coordination of the design contradictions. For instance, Peng et al. [23] evaluated the hierarchical CFP information for direct structure design elements and indirect design elements, and innovative design strategies were proposed from the perspective of product structures, principle, function, and process to make product improvement associated with the low-carbon performance. However, the existing low-carbon product design literature is largely silent on the systematic methodology that provides strategies and ideas for conceptual scheme generation by solving contradictory problems. The purpose of the QFD method is to transform design needs into structural modules, and thus to improve product quality. By incorporating environmental aspects of a product into QFD as new design needs, a new set of eco-design tools have been generated, such as green QFD [35], QFD for the environment [36,37]. At an earlier time, Zhang et al. [35] proposed the green QFD method for product development or improvement, where the quality house, green house, and cost house are constructed to evaluate the product quality, environmental impacts, and cost of the design scheme, respectively. Devanathan et al. [38] integrated QFD and life cycle assessment methods to establish a function-environment impact matrix, which enables designers to know how the function of the product affects the environment in its life cycle at the design stage and identify the reconfiguration opportunities for problematic structures from the conventional and environmental perspectives. Nevertheless, the QFD method is not design problem solving oriented, and it cannot provide specific strategies for designers to solve the design contradictions. Sakao [39] thus proposed a QFD-centered design method for product ecodesign by introducing the TRIZ method to help designers generate improvement solutions to contradictory problems among the quality characteristics.

Moreover, during the configuration process for the low-carbon requirements, structures interact with each other to realize the functional requirements, which results in the coupling of properties between performance indicators. Therefore, when modifying the structural module or increasing a new one to enhance the low-carbon related indicators, possibly other satisfied performance indicators deteriorate, which causes design contradictions. On the other hand, as the coupled correlative relationship between configuration tasks, it is necessary to reasonably arrange the configuration process and reduce the number of trial-and-error iterations for the designers. Consequently, the development of an effective methodology to solve design contradictions emerging from the configuration process and provide practicable strategies for finding solutions would be a critical issue in low-carbon product design.

\subsection{Extenics-An Effective Contradictory Problem-Solving Methodology}

Real society is full of various contradictions, which are mainly reflected in the fact that the existing conditions cannot meet the needs of people's activities (for instance, using a scale with a range of $200 \mathrm{~kg}$ to weigh an elephant weighing several tons), and there is a conflicting relationship between the needs, which means the needs cannot be satisfied at the same time under the existing conditions (for example, establishing a conversion system to connect the left-driving road system and the right-driving road system at the border to meet the different traffic rules of the two countries) [40]. It is precisely because of dealing with various contradictions that human society has developed and formed valuable problem-solving methods [11,41]. 
Extenics is an effective contradictory problem-solving methodology put forward by professor Wen Cai in the 1980s. It contains the mathematical, philosophy, and engineering models with the goal to address two kinds of problems, the incompatibility problem that contradictions exist between the subjective target and the objective condition, and the antithetical problem that contradictions exist between two subjective targets [11]. For most contradictory problems, the treatment of quantitative relations among characteristic values cannot effectively contribute to problem solving. Instead, the object, characteristics, and values related to the contradiction should all be focused on, and by studying the relationship and changes between these three elements the reasonable solution to the contradiction could be obtained [40]. To this end, the concept of basic-element is proposed in Extenics, which integrates the object, characteristics, and values into a triple frame. This basic-element model is used to formally represent the matter, relationship, and affair action related to the contradiction, which is considered as the logical cell for the problem analysis and solving. Feng et al. [42] used the basic-element model to describe the feature information, connection information, and transformation information for the mechanical conceptual structure, and thus the design knowledge of the mechanical part could be formally stored, which facilitates the knowledge representation for the computer-aided design system. In the product modular design, Li et al. [43] adopted basic-element model to record the module history and the module family information and studied the extensibility and transformation of the basic-element.

On the basis of the basic-element model, the extension exploration for the basicelement is essential, consisting of the divergent, correlative, implication, opening-up, and conjugate analysis. These analytical methods provide multiple possibilities for the extension exploration from the perspective of the divergence, similarity, implication, combination and decomposition, and philosophical conjugate proprieties of the basic-element, which can stimulate people's creative thinking and enable them to put forward innovative solutions to contradictory problems [44-47].

After the extension exploration for all basic-elements associated with the contradictory problem, the acceptable basic-elements, namely the representation of the final scheme for the contradiction, could be obtained. From the initial basic-element to the acceptable basic-element, the extension transformation needs to be implemented to generate a specific solution strategy, which consists of the basic transformation, compound transformation, and the transforming bridge method. For example, Chen et al. [48] adopted the transforming bridge method to solve the design contradictions between the incorporated green attributes and the conventional design attributes for product green design. Olaru et al. [49] addressed the important contradictory problem of the precision and stability of the dynamic system by means of the extension transformation and dependent function. The creative ideas generated in Extenics mainly arise from the extensible and conjugate analysis for the basic-elements related to the contradiction. Another effective problem-solving method TRIZ theory offers an extensive series of analysis tools and knowledge base tools to solve conflicting problems. Thus, Extenics scholars carried out the research on integrating the TRIZ and Extenics to handle contradictions [50]; in these studies, the similarity between physical and technical contradictions in TRIZ and incompatibility and antithetical problems in Extenics was revealed, the TRIZ inventive principles were introduced into Extenics for conducting extension transformation [22,51].

The above steps of problem modeling, problem analysis, and problem solving form a systematic framework for contradictory problem solving by means of Extenics, which is used in product design, system control, architectural design, engineering management, and other fields $[11,52,53]$. In low-carbon product design, design contradictions are commonly emerging from the configuration process due to the consideration of low-carbon factors; this study employs Extenics to solve low-carbon design contradictions, which provides more methodology choices for designers in design problem solving for product development. Extenics classifies the contradiction into the incompatibility problem and the antithetical problem; however, in some specific domains, the current classification cannot clearly 
clarify the property of the contradiction. In low-carbon product design, the reason for the antithetical problem on the one hand is possibly that the two demand intervals of the core characteristic value corresponding to the two design goals have no common range; on the other hand, the reason is possibly that even if there is the common range of the two demand intervals of the core characteristic value, improving one design goal by modifying the core characteristic value will deteriorate the other design goal. The above two phenomena all belong to the antithetical problem in Extenics; however, the strategies for them should be different and more specific, which cannot be classified as the transforming bridge method. Therefore, when employing Extenics to solve contradictory problems in low-carbon product design, the contradictions should be clarified in detail and corresponding strategies should also be provided.

In addition, although Extenics provides a holistic framework for a single contradictory problem solving, in a complex low-carbon product design system, it is often necessary to handle the design contradictions in configuration tasks simultaneously or in parallel. Thus, designers need to reasonably schedule the configuration tasks, and accordingly make an arrangement for the execution of the strategy measures to the design contradictions. This paper constructs the information flow diagram of the configuration tasks for the low-carbon requirements, and then the Gantt chart of the execution of the measures to the design contradictions can be obtained, which effectively helps designers reduce the number of trial-and-error iterations in the configuration process and enhance the quality and efficiency of the low-carbon product design.

\section{Materials and Methods}

Low-carbon product design takes into account low-carbon attributes on the basis of the original design scheme and generates the new design scheme to reduce carbon emissions throughout the product life cycle. Based on the original design information, carbon emissions data of components could be obtained by means of the related evaluation method. Designers identify and reconfigure the problematic components with high carbon emissions by conducting corresponding configuration tasks from four levels, using low-carbon related strategies, modifying the structure parameters, adjusting the structure layout, and putting forward new functional principles. However, during the configuration process, design contradictions are emerging, and the configuration tasks require a well-scheduled arrangement to reduce the feedback information. This section presents a systematic low-carbon design configuration methodology, in which the information flow model is constructed to schedule the configuration tasks and the Extenics theory is introduced to solve design contradictions.

\subsection{A Scheduled Arrangement Model of CTs for Low-Carbon Requirements}

\subsubsection{Low-Carbon Requirements Analysis and the Potential Design Contradictions}

In low-carbon product design, environmental items should be considered as well as traditional targets. QFD is a useful design tool to collect customer requirements and deploy them to the actual design work by reusing configuration solutions to the traditional requirements and reconfiguring the structure modules to satisfy the newly added lowcarbon demands; in addition, the QFD method is also used to reveal the potential design conflicts associated with the QCs. Masui et al. [54] applied QFD to an eco-design project and investigated the general requirements and QCs that should be considered from an environmental point of view throughout the product life cycle. In our previous research work, we adopted the QFD method to identify the important design attributes with high relative weight and took them as the retrieval attributes to obtain the suitable similar product case for reuse and adaptation in a case-based reasoning system for vacuum pump low-carbon design [55]. In this paper, we select low-carbon related requirements and QCs and incorporate them into the low-carbon reconfiguration process for the vacuum pump; as illustrated in Figure 1, design requirements of the vacuum pump are mapped into QCs through QFD phase I. 


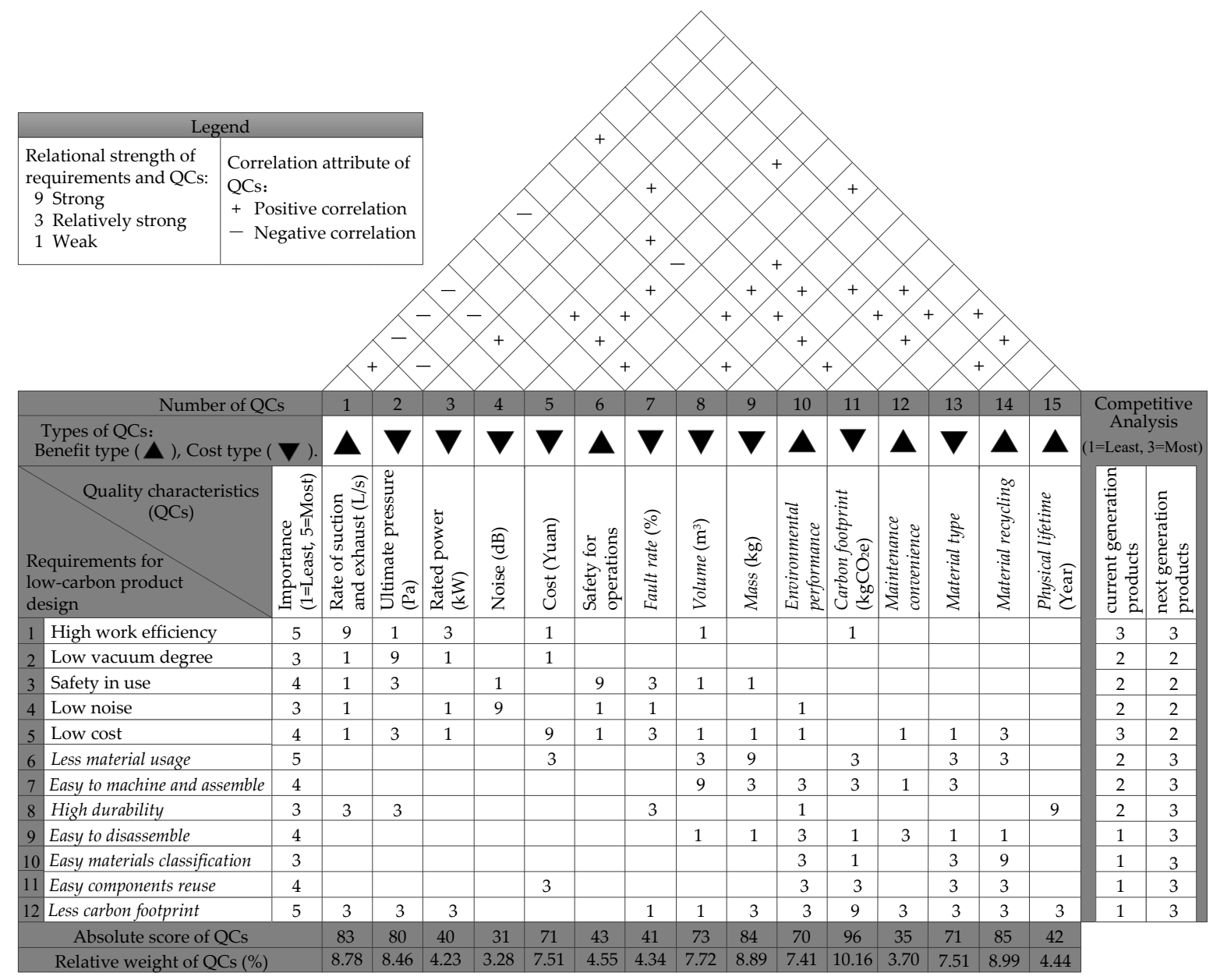

Figure 1. QFD phase I, mapping between the design requirements and QCs for the vacuum pump low-carbon design.

In Figure 1, italic items in the row of requirements and in the column of QCs are lowcarbon related needs and QCs. The importance of requirements is weighted based on the market survey, and the relational strength between requirements and QCs is determined by the designer; then, the absolute score and relative weight of each quality characteristic can be obtained. In competitive analysis, the competitiveness of current and next generation products is matched in strength associated with traditional requirements, such as the high work efficiency and low vacuum degree of the vacuum pump. However, the differences are obviously presented in terms of low-carbon requirements. So, how can the new generation product be developed? On the one hand, the prior configuration solutions to traditional requirements should be reused; on the other hand, low-carbon requirements need to be deployed. In addition, designers must notice the phenomenon that although low-carbon requirements are satisfied through reconfiguration tasks, the traditional performance may be deteriorated by analyzing the correlation of QCs.

The roof of the house of quality describes the correlation of QCs; in this paper, QCs are classified into two types, the benefit type, labeled with a regular triangle, and the cost type, labeled with an inverted triangle. Whether the correlation attribute is positive or negative between two QCs is dependent on the design expectation and the actual performance of QCs. For instance, $\mathrm{QC}_{1}<$ Rate of suction and exhaust $>$ belongs to benefit type, $\mathrm{QC}_{2}<$ Ultimate pressure $>$ belongs to cost type, when the designer expects to improve the performance of $\mathrm{QC}_{1}$, and the performance of $\mathrm{QC}_{2}$ gets better naturally; thus, the correlation attribute of $\mathrm{QC}_{1}$ and $\mathrm{QC}_{2}$ is positive, with the symbol "+". Nevertheless, $\mathrm{QC}_{3}<$ Rated power $>$ belongs to cost type; when $\mathrm{QC}_{1}$ is enhanced by adjusting $\mathrm{QC}_{3}$, the value of $\mathrm{QC}_{3}$ should be increased, which does not meet the low-carbon demand; thus, the 
correlation attribute of $\mathrm{QC}_{1}$ and $\mathrm{QC}_{3}$ is negative, with the symbol "-". The correlation matrix of QCs in the roof qualitatively reveals the potential contradictions between QCs; however, QFD does not provide specific strategies for design contradiction solving.

\subsubsection{Construction of the IFD for CTs}

The objective of design activities is to realize the functional performance characterized by QCs, and the property of each quality characteristic relies on the corresponding engineering characteristics (ECs), which are deployed through CTs. When new QCs are added and some related components should be modified, it is common to see the change propagation problem in engineering design as the coupled relationship of QCs [56]. Thus, it is crucial to reasonably arrange CTs in a scheduling mode to improve the design efficiency by reducing the number of trial-and-error iterations for configurations. In our research work, we extract the CTs, the mapping operations from QCs to ECs, as described in Equation (1), and construct the information flow model for all tasks gradually.

$$
\mathrm{QC}_{i} \Leftarrow \mathrm{CT}_{i}=\left[\mathrm{MA}_{i}\right]\{\mathrm{ECs}\}
$$

where $\mathrm{CT}_{i}$ denotes the configuration task $i$ for $\mathrm{QC}_{i}$, and $\left[\mathrm{MA}_{i}\right]$ denotes the configuration matrix between $\mathrm{QC}_{i}$ and ECs.

According to the relationship between CTs, which is associated with the input and output configuration parameters of each configuration task, the directed network of CTs can be generated, and the evaluation model for the associated value of each pair of correlated CTs is proposed as Equation (2).

$$
d_{i, j}\left(\mathrm{CT}_{i}, \mathrm{CT}_{j}\right)=\sum_{k=1}^{n} \omega_{k} \frac{\gamma_{j, k}}{\left(\gamma_{i, k}+\gamma_{j, k}\right)}
$$

where $d_{i, j}\left(\mathrm{CT}_{i}, \mathrm{CT}_{j}\right)$ denotes the associated value that $\mathrm{CT}_{i}$ depends on $\mathrm{CT}_{j}, i, j=1,2, \ldots$, $m, m$ is the number of CTs; $\gamma_{i, k}, \gamma_{j, k}$ denote the relational strength of $\mathrm{QC}_{i}$ and $\mathrm{EC}_{k}$, and $\mathrm{QC}_{j}$ and $\mathrm{EC}_{k}$ in QFD phase II, respectively; $\omega_{k}$ denotes the relative weight of $\mathrm{EC}_{k}, k=1$, $2, \ldots, n, n$ is the number of ECs; and given the condition that if $\gamma_{i, k}=0$ or $\gamma_{j, k}=0$, then $\gamma_{j, k} /\left(\gamma_{i, k}+\gamma_{j, k}\right)=0$.

The directed network of CTs to an activity-based DSM are mapped, as shown in Figure 2, taking six items as an example. DSM stores CTs along its diagonal, each configuration task to be completed in a row depends on the information of other tasks in the column, and the total sum of associated values stored in the upper-diagonal region is called feedback information, and thus the configuration process can be sequenced by reordering CTs such that feedback information is minimized. This paper adopts the variant feedback information estimation model as Equation (3) [57], and the genetic algorithm (GA) is implemented to obtain the optimal sequence of CTs, where the stopping criteria for the GA is that when the number of iterations reaches the maximum number of iterations allowed, the algorithm will stop, and the IFD of CTs can be generated.

$$
F I=\sum_{i=1}^{m-1} \sum_{j=i+1}^{m}(j-i) \cdot d_{i, j}\left(\mathrm{CT}_{i}, \mathrm{CT}_{j}\right)
$$

where $F I$ denotes the feedback information, $i, j$ denote the $i$-th row and $j$-th column in the DSM, respectively, and $m$ denotes the DSM size, corresponding to the number of CTs. 


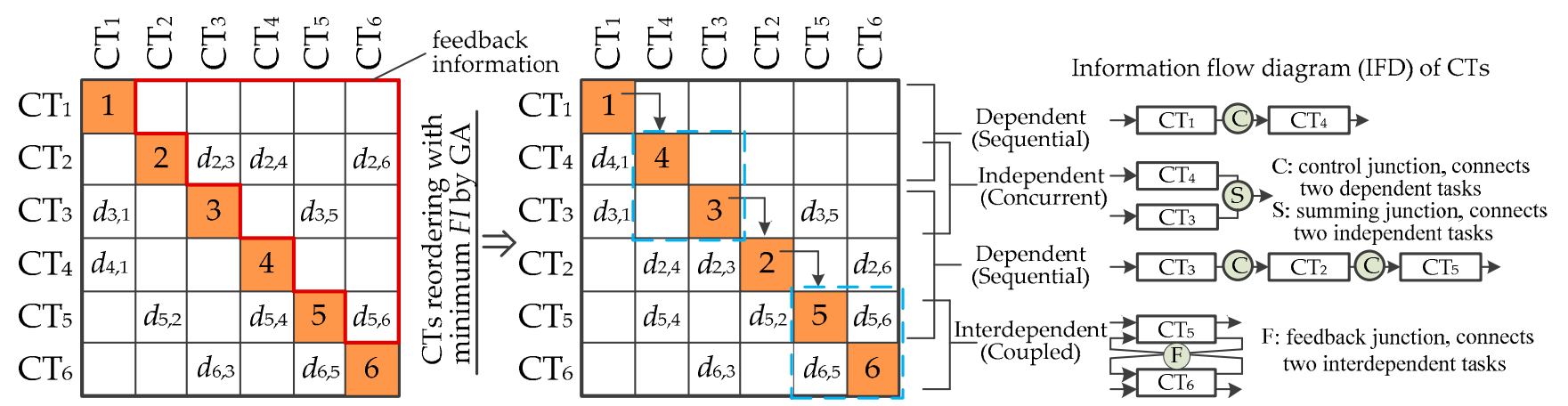

Figure 2. A reasonable sequence of CTs based on the DSM with minimum FI.

In the IFD, CTs are scheduled by three types of junctions: the control junction, labeled as symbol " $\mathrm{C}$ ", which connects two dependent CTs; the summing junction, labeled as symbol "S", which connects two independent CTs; and the feedback junction, labeled as symbol " $\mathrm{F}$ ", which connects two interdependent CTs. Accordingly, based on the IFD, CTs can be accomplished in a sequential and concurrent arrangement to improve the design efficiency.

The sequencing result in Figure 2 clearly indicates that $\mathrm{CT}_{1}$ should be completed first, and then $\mathrm{CT}_{4}$ and $\mathrm{CT}_{3}$ can be finished in a concurrent way, then $\mathrm{CT}_{2}, \mathrm{CT}_{5}$, and $\mathrm{CT}_{6}$ follow. In addition, $\mathrm{CT}_{5}$ and $\mathrm{CT}_{6}$ are coupled tasks, and $\mathrm{CT}_{3}$ and $\mathrm{CT}_{2}$ lack the necessary information provided by $\mathrm{CT}_{5}$ and $\mathrm{CT}_{6}$, respectively, when they are completed; thus, they still need to have some iterations. Although the IFD of CTs provides the reasonable arrangement to deploy the QCs when taking into account the low-carbon demands, designers require an effective problem-solving methodology to address the potential design conflicts during the configuration process. In the next section, we present the Extenics-based model to solve the design contradictions.

\subsection{Contradictory Problem Solving for Low-Carbon Product Design by Extenics}

The process of low-carbon requirement configuration goes along with the emerging design contradictions due to the coupling properties of the QCs. In this section, the contradictory problem-solving model based on Extenics is established, as shown in Figure 3. The framework of Extenics for design contradiction solving consists of the following six units: (1) representation of the design problem, (2) definition of the design contradiction, (3) extensible analysis, (4) conjugate analysis (5) extension transformation, and (6) evaluation of the solutions, and each unit contains $3-4$ sub-units. In the procedure, Unit 1 is used to formally describe the initial design problem, including the design goal and design condition; Unit 2 is used to identify the incompatibility and antithetical problem; extensible analysis and conjugate analysis are adopted in Unit 3 and Unit 4 to reveal the causes of the design contradiction and put forward the possible measures; based on the analysis result, Unit 5 is used to conduct the extension transformation to generate possible solutions to the design contradictions; and finally, Unit 6 focuses on the evaluation of the solutions and obtains the optimal design scheme. 
1.1 describe the attributes of the object with matter-element model $M$

1.2 describe the relationship between two objects with relation-element model $R$.

1.3 describe the expectation or the action to the object with affair-element model $A$.

1.4 describe the composite information of the object with compound-element model $Z$.

2.1 identify the incompatibility problem $(P)$, design goal $(g)$, design condition $(l), P=g^{*}$

2.2 identify the antithetical problem $(P)$, two design goals $\left(g_{1}\right.$ and $\left.g_{2}\right)$, and the design condition $(l), P=\left(\mathrm{g}_{1} \wedge \mathrm{g}_{2}\right)^{*} l$.

2.3 describe the design goal $g$ and design condition $l$ with the basic-element $M, R, A$ and the compound-element $Z$.

3.1 discover different attributes of one object, and find the objects with same attributes. 3.2 clarify the related factors of the object attribute that causes the design conflict.

3.3 reveal lower-level goals of the upper-level design goal by implication analysis.

3.4 increase the system functional attributes by accumulation and integration methods, reduce the system complexity through decomposition analysis.

4.1 analyze the material and nonmaterial parts of the object for the physical property 4.2 analyze the hard and soft parts of the object for the systematic property.

4.3 analyze the positive and negative parts of the object for the antithetic property.

4.4 analyze the apparent and latent parts of the object for the dynamic property.

5.1 conduct transformation operations for the problematic design goals and condition 5.2 address the incompatibility problem with the transformation strategies.

5.3 solve the antithetical problem with the transforming bridge method by establishing the connective transforming parts or separating transforming parts.

5.4 generate a set of possible solutions to the contradictory problem.

6.1 establish the dependent function model of each design attribute.

6.2 evaluate the solution based on the sum of the product of each attribute dependent

function value and its attribute weight.

6.3 obtain the final solution to the design contradiction.
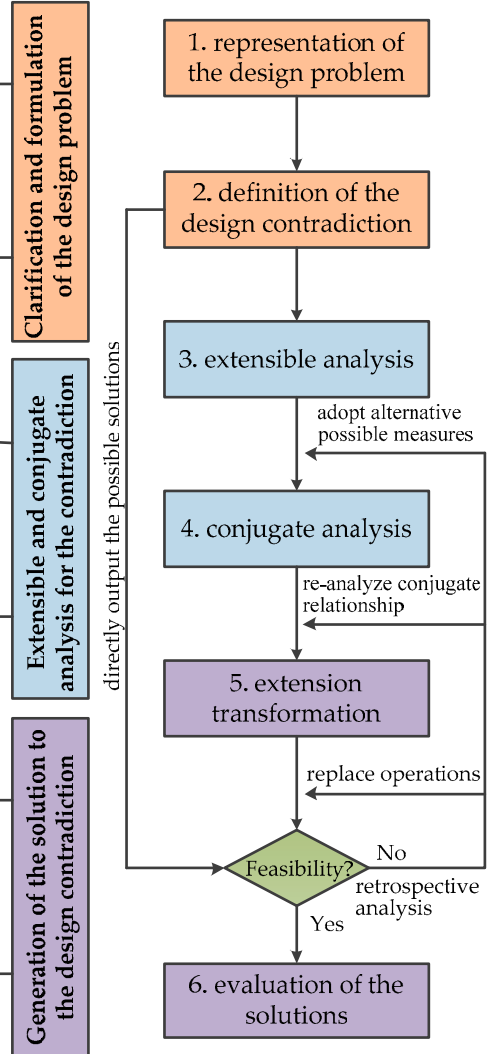

Figure 3. Framework of the design contradiction solving based on Extenics.

\subsubsection{Contradictory Problem Clarification and Formulation}

Extenics defines the basic-element and compound-element to describe attributes and relations of the objects, and this study redefines a low-carbon design basic-element model to formally represent the design knowledge of mechanical parts and design contradictions as follows.

The low-carbon design matter-element model of part $m$ describes its characteristics $c_{1}$, $c_{2}, \ldots, c_{n}$, and the corresponding values $v_{1}, v_{2}, \ldots, v_{n}$, with an ordered triple framework; item (a) in Table 1 is a case of a matter-element model that records the design information of the impeller.

The low-carbon design relation-element model describes the constraint relationship of parts, and item (b) in Table 1 describes the relationship between the impeller and shaft, where, $c_{1}, c_{2}$ denote the former item and latter item, and accordingly, $v_{1}, v_{2}$ are two related mechanical parts. $c_{3}, \ldots, c_{n}$ are attributes of the relationship, such as the constraint sensitivity, constraint type, etc. $v_{3}, \ldots, v_{n}$ are the values of the corresponding characteristics.

The low-carbon design affair-element model represents the design expectation or transformation rules. In Table 1, the expression "a" denotes the action and the dominating object. Additionally, the designer is considered as the acting object in default. $c_{1}, \ldots, c_{n}$ denote the receiving object (rece_obj), modification magnitude, constraints, etc. $v_{1}, \ldots, v_{n}$ are the values of the corresponding characteristics. Item (c) in Table 1 records the adaptation knowledge of the impeller for CFP reduction.

The low-carbon design compound-element model is used to represent composite information, item (d) in Table 1 describes the design information of the transmission component, where $O$ can represent the matter $\mathrm{m}$, relation $\mathrm{r}$, or affair action a. 
Table 1. Low-carbon design basic-element model for knowledge representation.

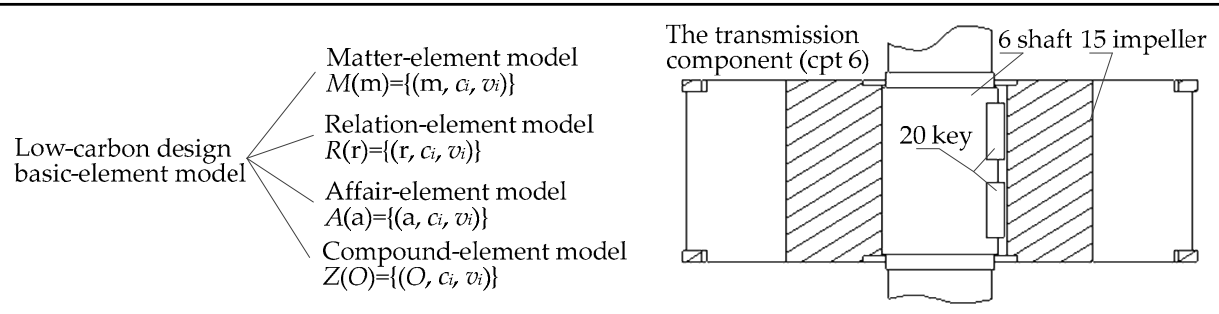

(a) matter-element model of the impeller.

m: impeller (part 15).

$M(m)=\left[\begin{array}{ccc}\mathrm{m}, & \text { material, } & \text { copper } \\ & \vdots & \vdots \\ \text { mass, } & 50.52 \mathrm{~kg} \\ \mathrm{CFP}, & 705.59 \mathrm{kgCO}_{2} \mathrm{e}\end{array}\right]$

(c) affair-element model of the shaft to reduce CFP.

$\mathrm{a}_{1}$ : reduce CFP.

$A\left(a_{1}\right)=\left[\begin{array}{ccc}\mathrm{a}_{1}, & \text { rece_obj, } & \text { part } 6 \\ & \text { material, } & 45 \# \\ \text { diameter, } & 40 \mathrm{~mm} \\ \vdots & \vdots \\ & \text { constraint, } & \text { stress }\end{array}\right]$ (b) relation-element model of the shaft and impeller.

r: assembly relationship (part 6 and part 15).

$R(r)=\left[\begin{array}{cc}\mathrm{r}, \quad \begin{array}{c}\text { the former item, } \\ \text { the latter item, }\end{array} & \text { part } 6 \\ \vdots & \vdots \\ \text { connection type, } & \text { key connection }\end{array}\right]$

(d) compound-element model of transmission components. $O$ : transmission component (cpt 6).

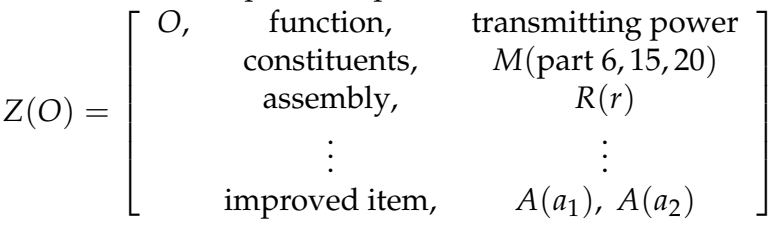

Based on the basic-element model, this study clarifies and formalizes the incompatibility and antithetical problems in low-carbon design. The low-carbon design incompatibility problem (LCD-IP) refers to the contradiction that current design conditions cannot satisfy low-carbon requirements. Supposing that design problem $P$, design goal $g$, and design condition $l$, then $P$ can be described as below.

$$
Z(g)=\left[\begin{array}{ccc}
g, & c_{1}, & v_{1}=c_{1}(g) \\
\vdots & \vdots \\
c_{i}, & v_{i}=c_{i}(g) \\
\vdots & \vdots \\
c_{m}, & v_{m}=c_{m}(g)
\end{array}\right], \quad Z(l)=\left[\begin{array}{ccc}
l, & c_{1}, & v_{1}=c_{1}(l) \\
\vdots & \vdots \\
c_{j}, & v_{j}=c_{j}(l) \\
\vdots & \vdots \\
c_{n}, & v_{n}=c_{n}(l)
\end{array}\right]
$$

where symbol " $*$ " denotes that design goal $g$ depends on the design condition $l ; v_{i}$, in the compound-element model of design goal $g$, denotes a certain value or a range of the value that should be satisfied for $c_{i}$, and it can also be described as $c_{i}(g) . v_{j}$, in the compoundelement model of design condition $l$, denotes the actual value of $c_{j}$. The characteristic that reflects the performance of the design goal is defined as the core characteristic, and there can be one or more core characteristics in a basic-element model. When value $c_{j}(l)$ of the core characteristic $c_{j}$ in the design condition cannot meet the corresponding value $c_{i}(g)$ of the core characteristic $c_{i}$ in the design goal, then it causes the design contradiction. On this condition, $P$ belongs to the LCD-IP, described as $P=g \uparrow l$.

For the low-carbon design antithetical problem (LCD-AP), this paper classifies it into two types; LCD-AP(I): two design goals cannot be satisfied simultaneously by the design conditions; LCD-AP(II): modify the design conditions to satisfy or improve one design goal; however, the performance of the other design goal deteriorates. Equation (5) describes the 
problem $P$ associated with two design goals, and when $P$ is consistent with either of the above two cases, then $P$ is an antithetical problem and described as $P=\left(g_{1} \hat{g_{2}}\right) \uparrow l$.

$$
P=\left(g_{1} \wedge g_{2}\right) * l
$$

where symbol "^" denotes the logical And, design goals $g_{1}, g_{2}$, and design condition $l$ can also be represented in a compound-element model.

We take an example to illustrate those two types of LCD-AP in Figure 4. Assume that $g_{1}$ and $g_{2}$ are both cost type design goals and are reflected by one core characteristic $c_{i}, c_{j}$, respectively, and the corresponding core characteristic of design condition $l$ is $c_{k}$. Suppose that the value of characteristic $c_{i}$ is $c_{i}\left(g_{1}\right)=\left[l_{a 1}, l_{b 1}\right]$, and the value of characteristic $c_{j}$ is $c_{j}\left(g_{2}\right)=\left[l_{c 1}, l_{d 1}\right]$, then $c_{i}\left(g_{1}\right) \cap c_{j}\left(g_{2}\right)=\varnothing$. If the value of characteristic $c_{k}$ satisfies $c_{k}(l)=l_{x 1} \in c_{i}\left(g_{1}\right)$, at this design condition, $g_{1}$ and $g_{2}$ cannot be satisfied together; thus, $P$ belongs to the LCD-AP(I).

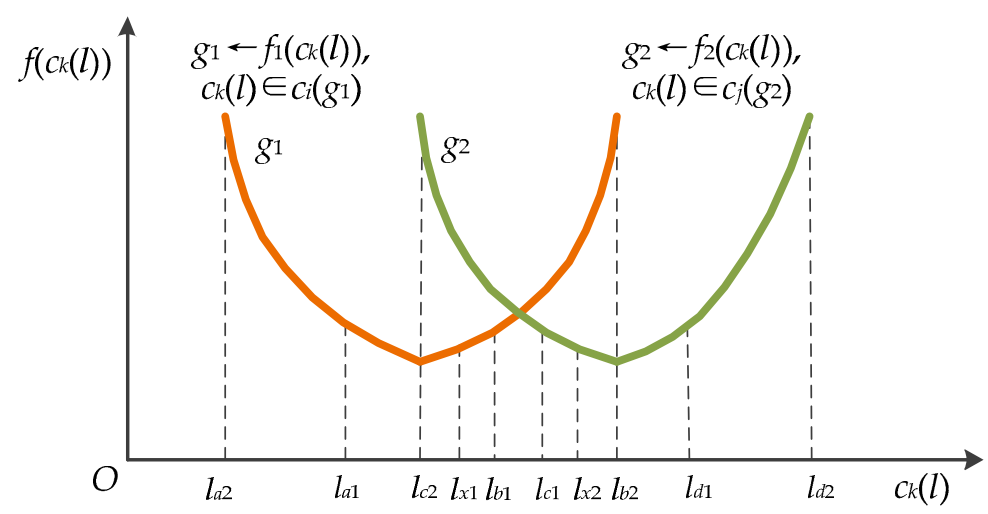

Figure 4. An example to illustrate two types of LCD-AP.

The designer can change the range of $c_{i}\left(g_{1}\right)$ and $c_{j}\left(g_{2}\right), c_{i}\left(g_{1}\right)=\left[l_{a 2}, l_{b 2}\right], c_{j}\left(g_{2}\right)=\left[l_{c 2}, l_{d 2}\right]$, then $c_{i}\left(g_{1}\right) \cap c_{j}\left(g_{2}\right)=\left[l_{c 2}, l_{b 2}\right]$. If the designer wants to improve the performance of $g_{2}$, such as set $c_{j}\left(g_{2}\right)=\left[l_{c 1}, l_{b 2}\right]$, then $c_{i}\left(g_{1}\right) \cap c_{j}\left(g_{2}\right)=\left[l_{c 1}, l_{b 2}\right]$. The designer can modify the design condition $c_{k}(l)$ from $l_{x 1}$ to $l_{x 2}, l_{x 2} \in\left[l_{c 1}, l_{b 2}\right]$. At this condition, although the performance of $g_{2}$ is enhanced, the performance of $g_{1}$ is badly deteriorated; thus, $P$ belongs to the LCD-AP(II).

The most intuitive difference between LCD-IP and LCD-AP is that LCD-IP only involves one design goal, while LCD-AP involves two design goals. LCD-IP is the basic contradictory problem in Extenics, which is addressed through extension transformation to generate strategies. Generally, LCD-IP and LCD-AP can be transformed into each other; LCD-AP can be considered as two coupled LCD-IPs with two design goals that cannot be satisfied together; while if the design goal in LCD-IP can be decomposed into sub-goals that with opposite property, then the original LCD-IP would be considered as LCD-AP. This paper makes the assumption that the complex design contradiction with more than two design goals can be decomposed into the incompatibility and antithetical problems, and for coupled design problems, retrospective analysis is required. For design contradiction solving, it is crucial to find core characteristics and corresponding components that cause the conflict. In Extenics, extensible and conjugate analysis tools are provided to help designers comprehensively understand design goals and conditions and put forward possible measures.

\subsubsection{Extensible and Conjugate Analysis}

(1) Extensible analysis

The inconsistency between low-carbon requirements and design conditions results in the contradictory problems, namely the LCD-IP and LCD-AP; the extensible analysis method for the design goal and condition provides possible measures to solve design 
contradictions, comprising divergent analysis, correlative analysis, implication analysis, and opening-up analysis.

Divergent analysis is used to expand the object $O$ and the characteristics $\left\{c_{i}\right\}$ in the compound-element model, which is summarized as two principles. The principle "one object and multiple characteristics", described as $Z(O)=(O, c, v) \dashv\left\{\left(O, c_{1}, v_{1}\right),\left(O, c_{2}, v_{2}\right), \ldots\right.$, $\left.\left(O, c_{n}, v_{n}\right)\right\}$, requires the designer to be clear about all characteristics of the research object, as different characteristics can reflect certain performances required in design tasks. The principle "multiple objects and one common characteristic", described as $Z(O)=(O, c, v) \dashv\left\{\left(O_{1}\right.\right.$, $\left.\left.c, v_{1}\right),\left(O_{2}, c, v_{2}\right), \ldots,\left(O_{n}, c, v_{n}\right)\right\}$, indicates that if one object is not applicable in a design task, then objects with the common characteristics can be employed.

Correlative analysis contains the analysis of characteristics in a compound-element model and in different compound-element models, expressed as $c_{i}(Z(O))=f\left[c_{j}(Z(O))\right]$, $c_{i}\left(Z\left(O_{1}\right)\right)=f\left[c_{j}\left(Z\left(O_{2}\right)\right)\right]$, respectively. Where $f[\cdot]$ denotes the correlative function, if $c_{i}, c_{j}$ are correlated, then it can be labeled as $c_{i}(Z(O)) \sim c_{j}(Z(O)), c_{i}\left(Z\left(O_{1}\right)\right) \sim c_{j}\left(Z\left(O_{2}\right)\right)$. In design tasks, the functional performance is reflected by the predominant characteristics and the correlated characteristics; thus, it is essential to clearly understand the relationship between characteristics to facilitate the design contradiction solving.

Implication analysis is mainly for design goals, expressed as $Z\left(g_{2}\right) \Rightarrow Z\left(g_{1}\right)$. It indicates if $g_{2}$ is satisfied, then $g_{1}$ can be completed. $g_{1}$ and $g_{2}$ are called the upper-level design goal and lower-level design goal, respectively. Accordingly, if the upper-level design goal is difficult to complete, then it can be divided into several lower-level design goals. When lower-level design goals are completed, the upper-level design goal is accomplished.

Combination and decomposition are two common means used in opening-up analysis; the former contains the accumulation method, expressed as $Z(O)=Z\left(O_{1}\right) \oplus Z\left(O_{2}\right)$, namely, putting two objects together to obtain two kinds of functions, and the integration method, expressed as $Z(O)=Z\left(O_{1}\right) \otimes Z\left(O_{2}\right)$, namely, integrating two objects to achieve one certain requirement function or to reinforce the original functional performance. Decomposition analysis is the inverse process of the integration analysis expressed as $(O, c, c(O)) / /\left\{\left(O_{1}, c\right.\right.$, $\left.\left.c\left(O_{1}\right)\right),\left(O_{2}, c, c\left(O_{2}\right)\right), \ldots,\left(O_{n}, c, c\left(O_{n}\right)\right)\right\}$, which simplifies the complex design system.

(2) Conjugate analysis

Extensible analysis of the design goals and conditions provides possible approaches to solve the contradictory problems; conjugate analysis, another powerful analysis tool in Extenics, focuses on four pairs of conjugate parts, namely the nonmaterial-material part, soft-hard part, negative-positive part, and latent-apparent part, as illustrated in Figure 5. In this paper, the conjugate analysis method is implemented to generate robust design schemes for low-carbon design from the viewpoint of the physical property, systematic property, antithetic property, and dynamic property.

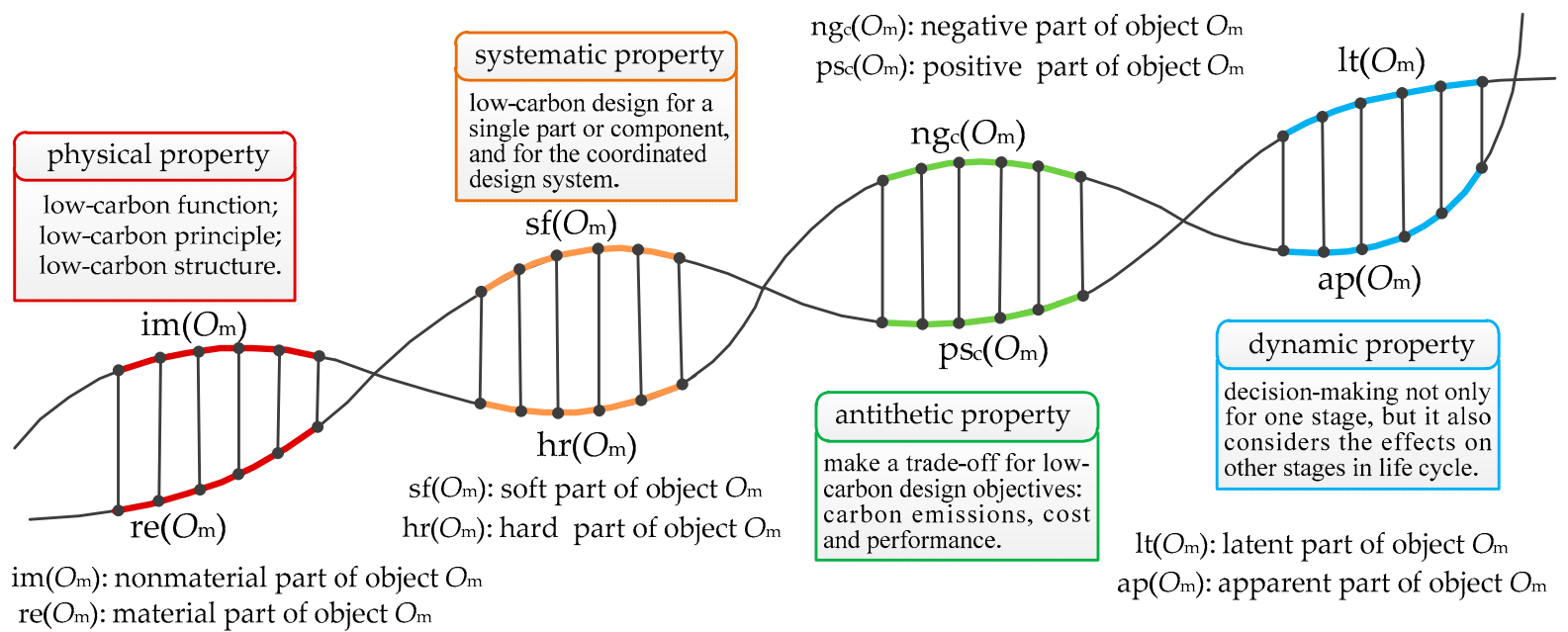

Figure 5. Conjugate analysis of four pairs of conjugate parts for low-carbon product design. 
In terms of the physical property of matter, all matters are composed of a physical part and a non-physical part; the former is referred to as the material part of matter, expressed as $\mathrm{re}\left(\mathrm{O}_{\mathrm{m}}\right)$, and the latter is referred to as the nonmaterial part of matter, expressed as $\operatorname{im}\left(O_{\mathrm{m}}\right)$. For instance, the structural entity of the component is the material part, and its functional performance belongs to the nonmaterial part. Designers pay more attention to reduce CFP on the structures; however, if a new principle to realize the same function can be applied with less CFP, this design scheme may be more acceptable. Thus, the estimation of the low-carbon property of function and its principles is also important to facilitate the layout of structural entities from the perspective of the nonmaterial part of the product [23,38]. In addition, the systematic design approach, e.g., presented by Pahl and Beitz, could be used to generate alternative feasible alternative principles for each function [58].

When considering a matter's structure from the systematic property, components as a whole are referred to as the hard part, expressed as $\mathrm{hr}\left(O_{\mathrm{m}}\right)$, and the relations between the matter and its components and other matters are referred to as the soft part, expressed as $\operatorname{sf}\left(O_{\mathrm{m}}\right)$. It reminds designers of the fact that it should not be limited to a single part or component for CFP reduction, but consider the low-carbon effect of the entire product system, as good coordination in a design system can make up for the weakness of local quality in design tasks.

The positive value of the characteristic is referred to as the positive part about the characteristic, expressed as $\mathrm{ps}_{\mathrm{c}}\left(\mathrm{O}_{\mathrm{m}}\right)$, and the negative part is that the value is negative, expressed as $\operatorname{ng}_{\mathrm{c}}\left(O_{\mathrm{m}}\right)$. In low-carbon design, new functional principles and alternative modules are adopted to reduce carbon emissions, but this also increases the product cost and affects its functional performance; thus, designers should make a trade-off for the design objectives, i.e., carbon emissions, cost, and functional performance.

The matter's latent parts are referred to as the latent part, expressed as $\operatorname{lt}\left(O_{\mathrm{m}}\right)$, and apparent parts are referred to as its apparent part, expressed as ap $\left(O_{\mathrm{m}}\right)$. The latent-apparent conjugate analysis indicates that decision-making for one stage in the life cycle produces obvious efforts, but it will cause latent effects for other stages, which may be positive or negative. For instance, at the raw material stage, cast iron is selected as the material for the impeller with a lower price and carbon emission factor. However, the physical lifetime of the impeller made of cast iron is limited, and the cost and carbon emissions for maintenance at the use stage are higher than those of the impeller made of copper.

Here, we take the design problem of a disposable lunch box as an example to explain the application of extensible and conjugate analysis. There is a disposable lunch box made of plastic, as shown in Figure 6. However, the customer requires a disposable lunch box that is environmentally friendly; obviously, the current design scheme cannot satisfy the requirement.

Based on the basic-element model, the design information of the original lunch box can be described as $Z(O)$, where object $O$ denotes the lunch box made of plastic, as depicted in Figure 6.

We first designate the design goal $g$ <design a disposable lunch box that is environmentally friendly $>$, and the upper-level design goal can be divided into lower-level design goals with the implication analysis; $g_{1}<$ the lunch box can hold different kinds of food $>, g_{2}$ $<$ the lunch box is not harmful to the environment in the disposal stage $>, g_{3}<$ the price of the lunch box is acceptable $>, g_{4}<$ the lunch box is light and solid $>$, and $g_{5}<$ the lunch box has long store time>.

To achieve design goal $g_{2}$, we can make a divergent analysis for the material associated with the design information $Z(O)$. Rather than the plastic, there are alternatives: the fullydegradable materials derived from starch and plant fiber, paper pulp, stainless steel, aluminum, etc.; thus, we can obtain possible measures, that is, the $\mathrm{Z}\left(\mathrm{O}_{1}\right), \mathrm{Z}\left(\mathrm{O}_{2}\right) \mathrm{Z}\left(\mathrm{O}_{3}\right) \ldots$, as shown in Figure 6.

To achieve design goal $g_{1}$, opening-up analysis can be implemented for the chambers, that is, redesigning the shape and size of the chamber to satisfy $g_{1}$, for example, changing the shape of chamber 1 or combining chamber 1 and chamber 2 to hold some special food. 
We take $Z\left(O_{1}\right)$ as an example, and new possible measures are generated, the $Z\left(O_{11}\right), Z\left(O_{12}\right)$, $\mathrm{Z}\left(\mathrm{O}_{13}\right) \ldots$, as shown in Figure 6.

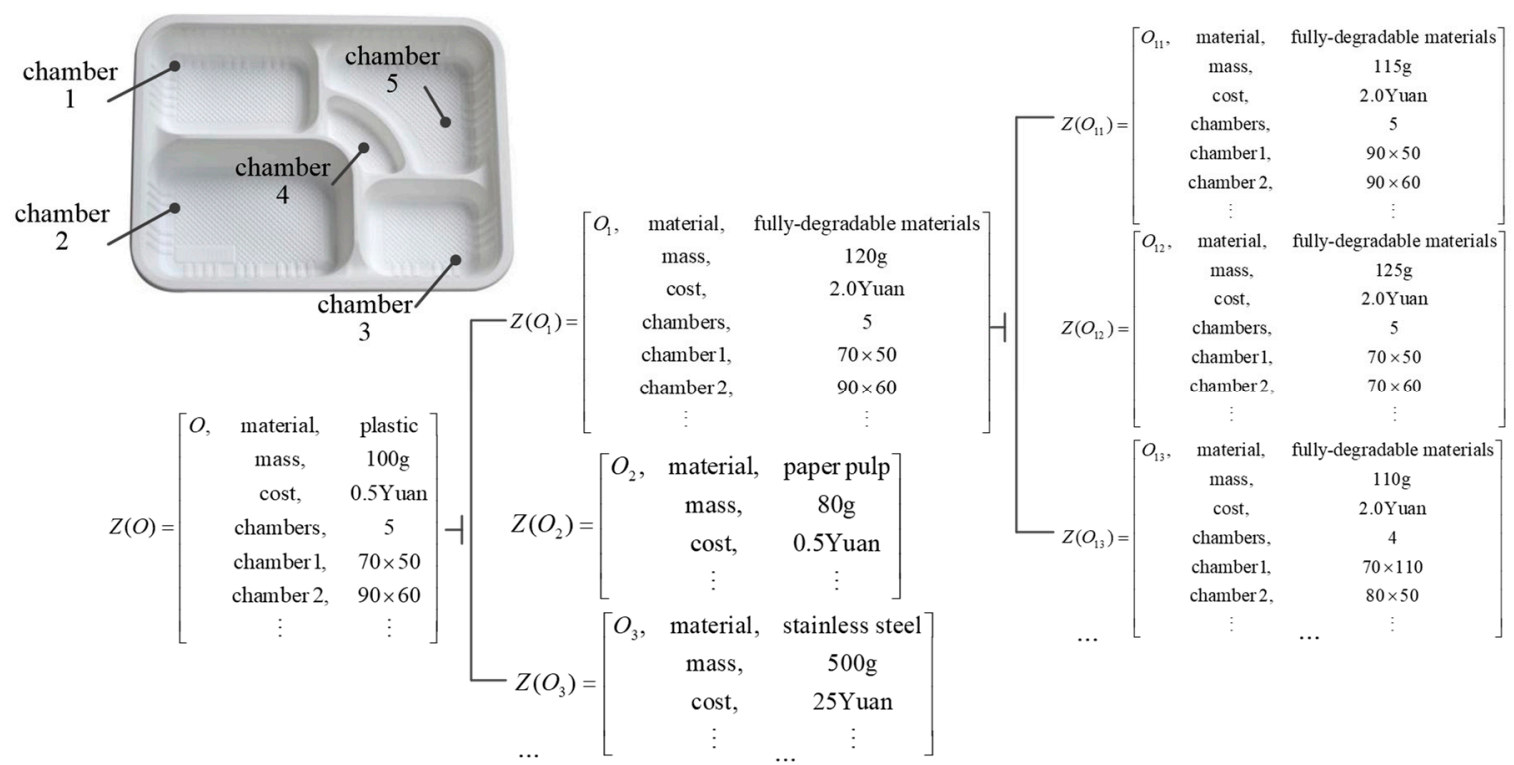

Figure 6. An example of extensible analysis of the disposable lunch box design for the environment.

After obtaining all possible measures, designers should estimate each measure from the physical, systematic, antithetic, and dynamic properties' perspective to generate robust design schemes with the conjugate analysis tool.

\subsubsection{Extension Transformation for the Generation of Design Schemes}

Extension transformation determines the transformation strategy to solve design contradictions according to the extensible and conjugate analysis, and it provides specific operations, consisting of substitution, increasing/decreasing, expansion/contraction, decomposition, and duplication. Generally, it always adopts multiple operations simultaneously or successively to solve a contradictory problem, and all transformation operations could be represented with the basic-element model to record the adaptation knowledge.

For the LCD-IP, if the design goal is complex, lower-level design goals can be obtained through implication analysis. To address sub-goals, three steps are included: identifying the core characteristics and components of the design condition; taking extensible and conjugate analysis for the design contradiction; and implementing extension transformation to objects, characteristics, or characteristic values that cause the contradiction.

For the antithetical problem, in Extenics, the transforming bridge method with the thought of "reciprocal indifference and proper place" is proposed, which indicates that the antithetical parties can be satisfied with different manners by constructing the connective transforming parts or separating transforming parts. According to the transforming bridge method, this study presents the strategy models for these two types of antithetical problems, as illustrated in Figure 7.

LCD-AP(I) in item a depicts that design goal $g_{1}$ and $g_{2}$ both locate at the low score line with the poor performance, and they cannot simultaneously reach the high score line with the good performance, which is similar to the description in Figure 4 , where the values $c_{i}\left(g_{1}\right), c_{j}\left(g_{2}\right)$ of the core characteristic $c_{i}, c_{j}$ locate at $\left[l_{a 1}, l_{b 1}\right],\left[l_{c 1}, l_{d 1}\right]$, respectively, and there is no common design area to satisfy the design goals together. The strategy for LCD-AP(I) is to generate a common design area by constructing the connective transforming part as shown in item $\mathrm{a}_{2}$; then, two design goals can be achieved. LCD-AP(II) in item $\mathrm{b}_{1}$ depicts that design goal $g_{2}$ is improved while the related design goal $g_{1}$ deteriorates, the similar description in Figure 4 is that $c_{i}\left(g_{1}\right), c_{j}\left(g_{2}\right)$ locate at the common design interval $\left[l_{c 2}, l_{b 2}\right]$, where two core characteristics $c_{i}, c_{j}$ present the opposite property. The strategy for LCD- 
$\mathrm{AP}(\mathrm{II})$ is to form the design border area by constructing the separating transforming part as shown in item $\mathrm{b}_{2}$; thus, $g_{1}$ and $g_{2}$ do not interfere with each other, and when $g_{2}$ reaches the high score line, $g_{1}$ also can be realized.

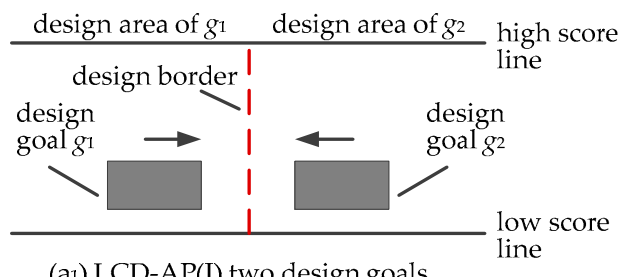

(a1) LCD-AP(I) two design goals cannot be satisfied together

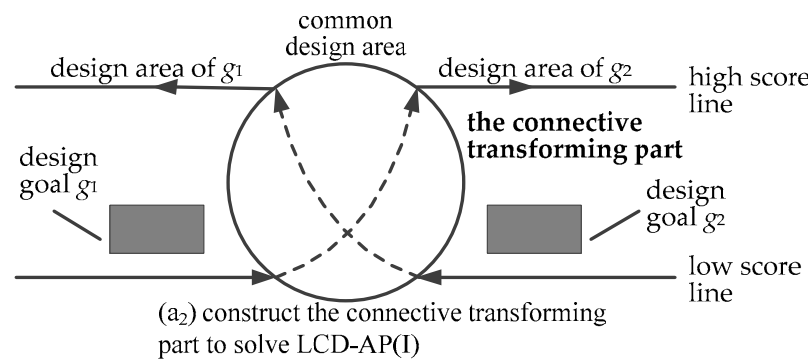

part to solve LCD-AP(I)

(a) LCD-AP(I) and its strategy model
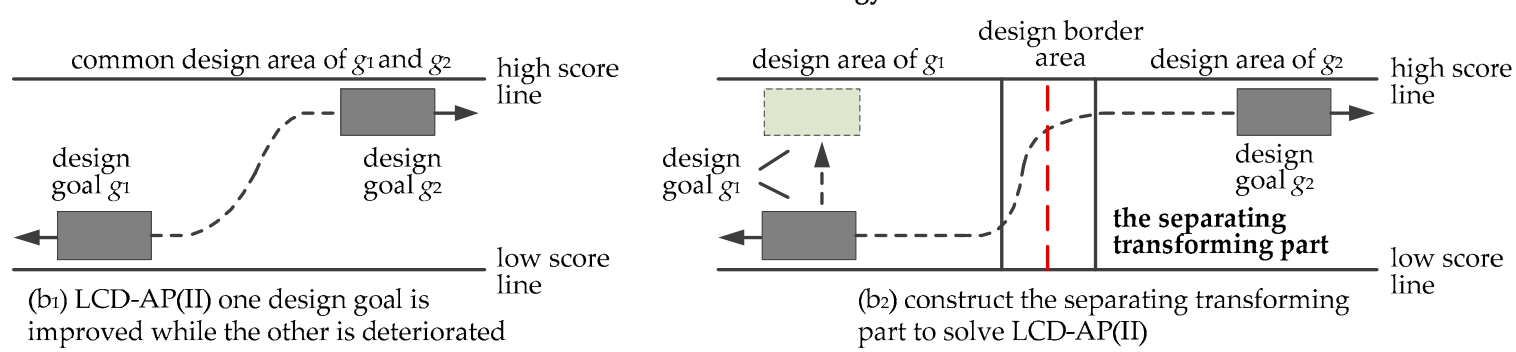

(b) LCD-AP(II) and its strategy model

Figure 7. Strategy models for LCD-AP based on the transforming bridge method.

\subsection{Outline of Proposed Extenics-Based Scheduled Configuration Methodology}

Integrating the IFD of CTs for deploying the low-carbon demands and the Extenicsbased contradictory problem-solving model, the proposed methodology in support of low-carbon product design is depicted in Figure 8, and the implementation steps are elaborated as below.

Step 1. Low-carbon requirements analysis and configuration

Designers collect the design requirements and convert them into the QCs through QFD phase I as illustrated in Figure 1, and for low-carbon demands, it is necessary to add low-carbon related QCs. Consequently, designers also need to modify the existing ECs or add new ECs to meet QCs by synthesizing and designating corresponding CTs in QFD phase II. On the other hand, the adaptation for the structure modules may impact the original functional performance, and thus, it is essential to identify the potential design conflicts arising from the inclusion of the low-carbon demands.

Step 2. Construction of the IFD for CTs

CTs are determined according to the QCs by analyzing the input configuration parameters for configuration task $\mathrm{CT}_{i}$ and the output configuration parameters that $\mathrm{CT}_{i}$ can provide for other $\mathrm{CTs}$, establishing the directed network of the CTs, and calculating the associated values $d_{i, j}\left(\mathrm{CT}_{i}, \mathrm{CT}_{j}\right), d_{j, i}\left(\mathrm{CT}_{j}, \mathrm{CT}_{i}\right)$ of two interdependent $\mathrm{CT}_{i}$ and $\mathrm{CT}_{j}$ based on Equation (2). Transforming the directed network of CTs into an activity-based DSM, the genetic algorithm is used to generate the optimal sequence of CTs with the goal to minimize the feedback in the configuration process.

Step 3. Design contradictions clarification and formulation

For newly added CTs, it is necessary to identify the low-carbon design incompatibility problem LCD-IP and low-carbon design antithetical problem LCD-AP(I) and LCD-AP(II), and the design goal and design condition of each contradictory problem can be represented with the basic-element model, which facilitates further extensible and conjugate analysis.

Step 4. Extensible and conjugate analysis for design contradictions

The implication analysis for the design goal is implemented to obtain lower-level sub goals; the divergent analysis, correlative analysis, and opening-up analysis for the design 
condition are conducted to reveal the problematic structures that cause the design conflict, and possible measures to solve the contradiction are put forward. The conjugate analysis is then employed to evaluate the feasibility of the possible measures. In addition, extensible and conjugate analysis can also reveal the potential antithetical problems and update the preliminary design contradictions.

Step 5. Generation of the design scheme based on extension transformation

Transformation operations are used to modify the problematic structures based on extensible and conjugate analysis, and to address antithetical problems LCD-AP(I) and LCD-AP(II), two strategy models are proposed, as illustrated in Figure 7. On the other hand, the implementation of extension transformation also needs to follow the arrangement of CTs by constructing the Gantt chart of measures execution for design contradiction solving.

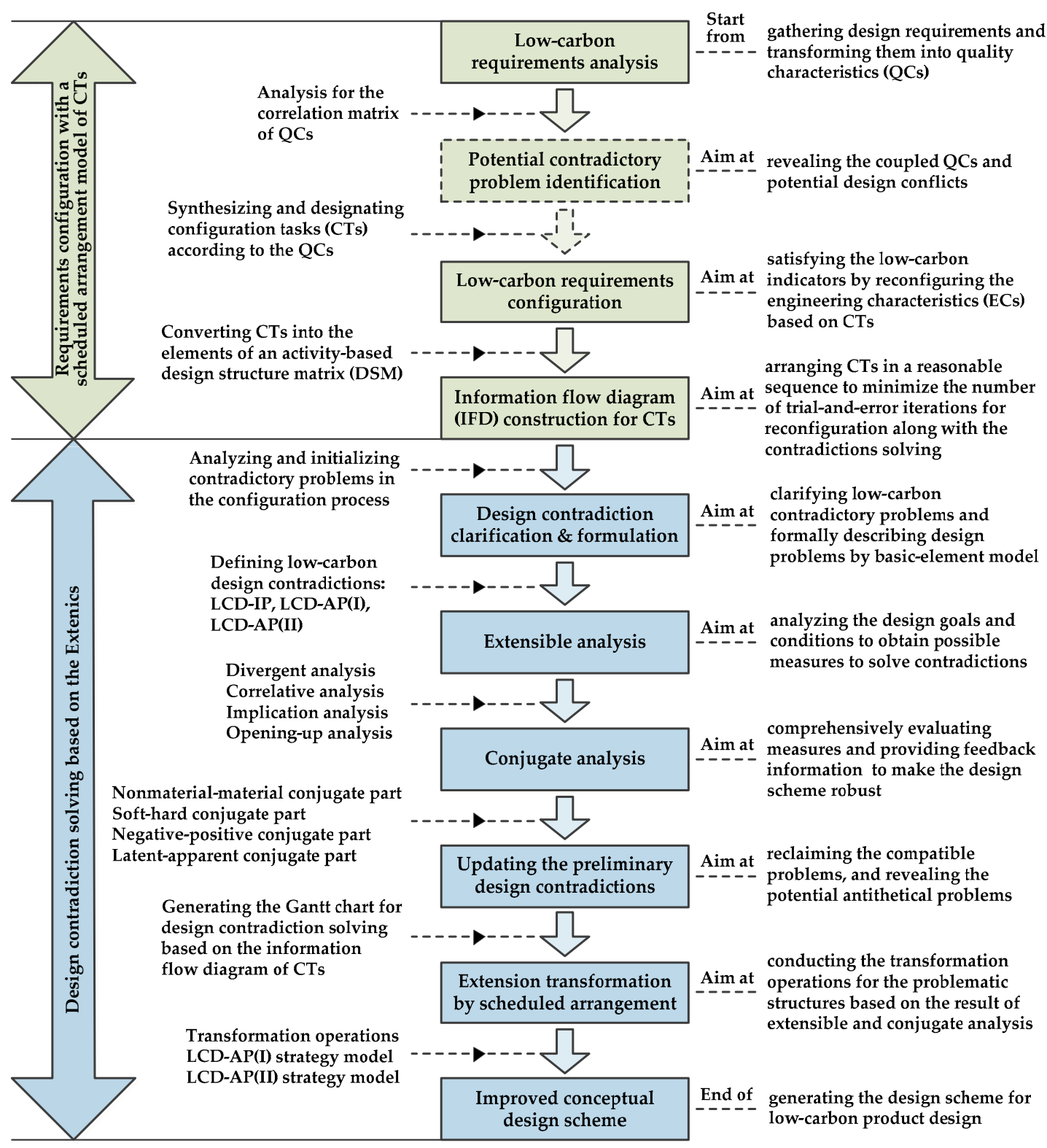

Figure 8. Framework of the Extenics-based scheduled configuration model for low-carbon product design.

\section{Results-A Case Study of Vacuum Pump Low-Carbon Design}

This section exhibits a detailed case study to demonstrate the applicability of the proposed Extenics-based scheduled configuration methodology. This case study focuses 
on the environmental improvement of the traditional vacuum pump by reconfiguring the problematic structural modules with high carbon emissions. This case study is an academic example and a work by a team that consists of one assistant researcher and two undergraduates majoring in product design and three experts who have at least three years of product design and development work experience. According to the framework of the proposed methodology as illustrated in Figure 8, the implementation results are elaborated as below; and we also make the comparative study between the Extenics and other methods in design contradiction solving.

\subsection{Implementation of Extenics-Based Scheduled Configuration Methodology for Vacuum Pump Low-Carbon Design}

4.1.1. Requirements Configuration and the IFD of CTs for Vacuum Pump Low-Carbon Design

The vacuum pump is widely used in the industry field to provide a required working pressure environment. Existing design schemes of the vacuum pump are mainly for satisfying functional performance requirements, such as the high rate of suction and exhaust and low ultimate pressure, and there is a lack of the low-carbon performance consideration throughout the product life cycle. In the case study, the SK-15 vacuum pump is taken as an academic example, and in Table 2, it enumerates the components and CFP information of parts; the estimation model for CFP is based on the PAS 2050 framework adopted in our previous research work [31].

Table 2. Components (cpts) and CFP information of the vacuum pump/unit $\mathrm{kgCO}_{2} \mathrm{e}$.

\begin{tabular}{|c|c|c|c|c|c|c|c|}
\hline & \multirow{2}{*}{ Components and Parts } & \multicolumn{5}{|c|}{ CFP of Parts at Each Life Cycle Stage } & \multirow{2}{*}{ CFP_Part } \\
\hline & & RM & Mfg & Dist. & Use & EoL & \\
\hline \multirow{5}{*}{ cpt1 } & (18) bearing seat $\times 2$ & 117.37 & 123.16 & 1.09 & 65.04 & 4.35 & 311.01 \\
\hline & (19) bearing $\times 2$ & 45.81 & 9.55 & 0.52 & 180.76 & 0.29 & 236.92 \\
\hline & (21) front bearing seat gland & 35.66 & 37.74 & 0.33 & 40.50 & 1.29 & 115.52 \\
\hline & (5) rear bearing seat gland & 24.09 & 26.47 & 0.22 & 40.50 & 0.89 & 92.18 \\
\hline & (22) gland washer $\times 2$ & 1.59 & 1.88 & 0.01 & 41.72 & 0.002 & 45.20 \\
\hline \multirow{2}{*}{ cpt2 } & (1) pump cover $\times 2$ & 1298.03 & 1282.15 & 12.03 & 180.76 & 1.45 & 2774.43 \\
\hline & (17) pump cover gland $\times 2$ & 18.62 & 21.25 & 0.17 & 40.50 & 0.70 & 81.25 \\
\hline cpt3 & (12) suction and exhaust disc $\times 2$ & 90.52 & 101.22 & 0.42 & 52.77 & 0.144 & 245.08 \\
\hline \multirow{5}{*}{ cpt4 } & (11) profiling seal ring $\times 2$ & 1.72 & 2.07 & 0.34 & 44.96 & 1.15 & 50.24 \\
\hline & (9) sealing packing $\times 2$ & 4.72 & 0.40 & 0.26 & 78.13 & 6.29 & 89.80 \\
\hline & (8) sealing gland $\times 2$ & 10.05 & 11.28 & 0.53 & 133.62 & 0.01 & 155.50 \\
\hline & (10) front bushing $\times 2$ & 4.81 & 5.64 & 0.04 & 76.75 & 0.01 & 87.25 \\
\hline & (7) rear bushing $\times 2$ & 13.36 & 15.68 & 0.12 & 111.77 & 0.01 & 140.94 \\
\hline \multirow{3}{*}{ cpt5 } & (2) pump body & 559.54 & 559.78 & 5.19 & 110.63 & 0.47 & 1235.60 \\
\hline & (13) seal ring $\times 2$ & 1.17 & 1.17 & 0.19 & 36.96 & 0.62 & 40.12 \\
\hline & (14) tightening bolt $\times 6$ & 6.30 & 0.15 & 1.53 & 25.90 & 0.10 & 33.99 \\
\hline \multirow{3}{*}{ cpt6 } & (6) transmission shaft & 105.64 & 11.96 & 2.15 & 110.63 & 0.16 & 230.55 \\
\hline & (15) impeller & 298.88 & 292.91 & 2.97 & 110.63 & 0.19 & 705.59 \\
\hline & (20) connection key $\times 2$ & 0.91 & 4.49 & 0.43 & 53.46 & 0.005 & 59.29 \\
\hline cpt7 & $\begin{array}{l}\text { (24) suction and exhaust pipeline } \\
\times 2\end{array}$ & 187.01 & 196.00 & 1.73 & 180.76 & 0.64 & 566.15 \\
\hline
\end{tabular}

The shaded mechanical parts are self-produced parts, and the figure in the bracket in front of each part is the number in the assembly drawing. RM, Mfg, Dist., Use, and EoL denote five life cycle stages, namely, raw material stage, manufacturing stage, distribution stage, use stage, and end of life stage.

In QFD phase I, the mapping relationship between design requirements and QCs for the vacuum pump has been established as illustrated in Figure 1, where it should update the existing CTs or add new CTs to satisfy the low-carbon related QCs. Additionally, each configuration task is not independent; to accomplish the $\mathrm{CT}_{i}$, designers require the input configuration parameters from the preceding $\mathrm{CTs}$, and also $\mathrm{CT}_{i}$ provides the output configuration parameters for the subsequent CTs; consequently, there is a complex association network between CTs, as illustrated in Figure 9. On the basis of the CTs, the QCs of the vacuum pump for low-carbon design are transformed into components, namely the engineering characteristics ECs; the information of CTs and configuration parameters are described in Table 3. 


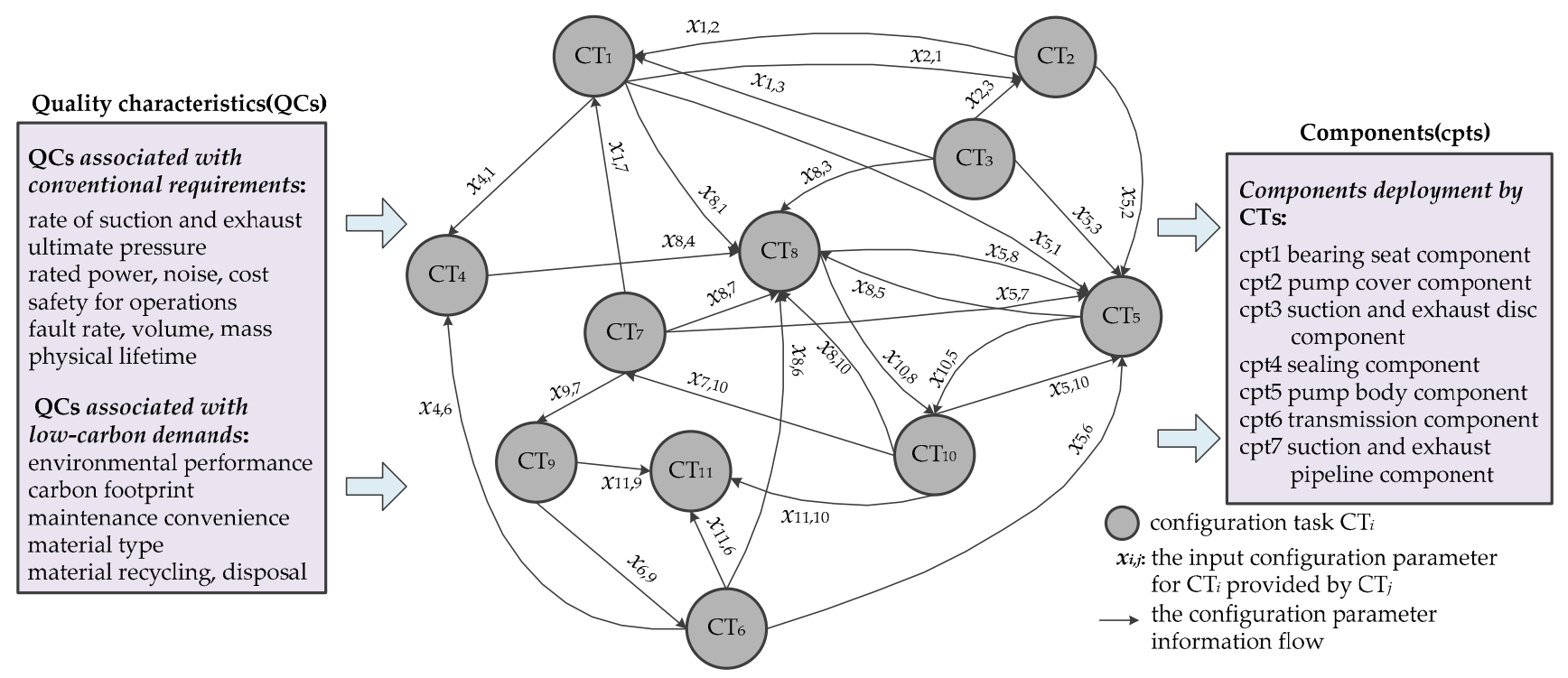

Figure 9. The directed network of CTs.

The mapping relationship between QCs and components in Figure 9 can be converted into the QFD phase II as illustrated in Figure 10, and according to the configuration parameters, experts are asked to evaluate the relational strength between each $\mathrm{QC}_{i}$ and the $\mathrm{EC}_{k}$, namely, the $k$-th component cpt $k$, by providing the score $\gamma_{i, k}$, where " 1 " indicates the relation is weak, " 3 " shows the relation is relatively strong, and " 9 " shows the relation is strong, and then the relative weight $\omega_{k}$ of $\mathrm{EC}_{k}$ can be obtained. Subsequently, based on the Equation (2), the associated values $d_{i, j}\left(\mathrm{CT}_{i}, \mathrm{CT}_{j}\right)$ and $d_{j, i}\left(\mathrm{CT}_{j}, \mathrm{CT}_{i}\right)$ of two correlated CTs are calculated, and then the directed network of CTs along with the associated values can be represented by the activity-based DSM, as depicted in Figure 11a.

For instance, $\mathrm{CT}_{1}$ and $\mathrm{CT}_{2}$ are interdependent configuration tasks; then, $d_{1,2}\left(\mathrm{CT}_{1}, \mathrm{CT}_{2}\right)$, which denotes the associated value that $\mathrm{CT}_{1}$ depends on $\mathrm{CT}_{2}$, is calculated as below:

$d_{1,2}\left(\mathrm{CT}_{1}, \mathrm{CT}_{2}\right)=\sum_{k}\left(\omega_{k} \cdot \gamma_{2, k} /\left(\gamma_{1, k}+\gamma_{2, k}\right)\right)$

$=0.163 \times 9 /(3+9)+0.146 \times 9 /(3+9)+0.145 \times 3 /(3+3)+0.227 \times 1 /(9+1)+$ $0.103 \times 1 /(1+1)=0.378$

and $d_{2,1}\left(\mathrm{CT}_{2}, \mathrm{CT}_{1}\right)$, which denotes the associated value that $\mathrm{CT}_{2}$ depends on $\mathrm{CT}_{1}$, is calculated as below:

$d_{2,1}\left(\mathrm{CT}_{2}, \mathrm{CT}_{1}\right)=\sum_{\mathrm{k}}\left(\omega_{k} \cdot \gamma_{1, k} /\left(\gamma_{1, k}+\gamma_{2, k}\right)\right)$

$=0.163 \times 3 /(3+9)+0.146 \times 3 /(3+9)+0.145 \times 3 /(3+3)+0.227 \times 9 /(9+1)+$ $0.103 \times 1 /(1+1)=0.406$.

The optimal sequence scheme of CTs is obtained with a GA-DSM algorithm, as shown in Figure 11b, and then the IFD of CTs of the vacuum pump is generated, as shown in Figure 12.

Figure 12 indicates that $\mathrm{CT}_{3}, \mathrm{CT}_{10}$, and $\mathrm{CT}_{7}$ can be firstly deployed together; to complete $\mathrm{CT}_{10}$, it should predefine the input parameters $x_{10,5}, x_{10,8}$, and configuration task $\mathrm{CT}_{7}$ depends on the configuration parameter $x_{7,10}$ from $\mathrm{CT}_{10} \cdot \mathrm{CT}_{1}$ and $\mathrm{CT}_{2}, \mathrm{CT}_{9}$ and $\mathrm{CT}_{6}$ can be deployed together, $\mathrm{CT}_{1}$ and $\mathrm{CT}_{2}$ are two interdependent tasks, and $\mathrm{CT}_{1}$ still depends on the configuration parameters $x_{1,3}, x_{1,7}$ from $\mathrm{CT}_{3}$ and $\mathrm{CT}_{7}$, respectively, $\mathrm{CT}_{2}$ relies on the configuration parameter $x_{2,3} ; \mathrm{CT}_{9}$ and $\mathrm{CT}_{6}$ are two dependent tasks, $\mathrm{CT}_{9}$ requires the configuration parameter $x_{9,7}$ from $\mathrm{CT}_{7}$, and $\mathrm{CT}_{6}$ requires the configuration parameter $x_{6,9}$ from $\mathrm{CT}_{9} . \mathrm{CT}_{11}, \mathrm{CT}_{4}, \mathrm{CT}_{8}$, and $\mathrm{CT}_{5}$ can be deployed together, $\mathrm{CT}_{11}$ depends on the parameters $x_{11,6}, x_{11,9}$, and $x_{11,10}$ from $\mathrm{CT}_{6}, \mathrm{CT}_{9}$, and $\mathrm{CT}_{10}$, respectively; $\mathrm{CT}_{4}$ depends on the parameters $x_{4,1}$ and $x_{4,6}$ from $\mathrm{CT}_{1}$ and $\mathrm{CT}_{6} ; \mathrm{CT}_{8}$ and $\mathrm{CT}_{5}$ are interdependent tasks; $\mathrm{CT}_{8}$ still needs the configuration parameters $x_{8,1}, x_{8,3}, x_{8,4}, x_{8,6}, x_{8,7}$, and $x_{8,10} ; \mathrm{CT}_{5}$ still needs the configuration parameters $x_{5,1}, x_{5,2}, x_{5,3}, x_{5,6}, x_{5,7}$, and $x_{5,10}$; in addition, the output parameters $x_{10,8}$ and $x_{10,5}$ from $\mathrm{CT}_{8}$ and $\mathrm{CT}_{5}$ are taken as the feedback information for $\mathrm{CT}_{10}$. 
The IFD of the CTs facilitates the reconfiguration process in an appropriate sequential and concurrent arrangement for the vacuum pump low-carbon design; however, as there are interdependent configuration tasks in the flow diagram, namely $\mathrm{CT}_{1}$ and $\mathrm{CT}_{2}, \mathrm{CT}_{8}, \mathrm{CT}_{5}$, and $\mathrm{CT}_{10}$, it still needs some iterations to adjust and balance the configuration parameters.

Table 3. Description of the configuration tasks and configuration parameters.

\begin{tabular}{|c|c|c|}
\hline Configuration Task $\mathrm{CT}_{i}$ & Input Parameter $x_{i, j}$ & Output Parameter $x_{j, i}$ \\
\hline $\begin{array}{l}\mathrm{CT}_{1} \text { configuration for suction and } \\
\text { exhaust module }\end{array}$ & $\begin{array}{l}x_{1,2} \text { ultimate pressure; } x_{1,3} \text { rated power } \\
x_{1,7} \text { volume of the working chamber }\end{array}$ & $x_{2,1}, x_{4,1}, x_{5,1}, x_{8,1}$ \\
\hline $\begin{array}{l}\mathrm{CT}_{2} \text { configuration for ultimate } \\
\text { pressure module }\end{array}$ & $x_{2,1}$ rate of the suction and exhaust; $x_{2,3}$ rated power & $x_{1,2}, x_{5,2}$ \\
\hline $\mathrm{CT}_{3}$ rated power determination & & $x_{1,3}, x_{2,3}, x_{5,3}, x_{8,3}$ \\
\hline $\mathrm{CT}_{4}$ noise control & $\begin{array}{l}x_{4,1} \text { effect of the pumping rate to the noise } \\
x_{4,6} \text { noise stems from the mechanical faults }\end{array}$ & $x_{8,4}$ \\
\hline $\mathrm{CT}_{5}$ cost control & $\begin{array}{l}x_{5,1} \text { cost with different pumping rates } \\
x_{5,2} \text { cost with different ultimate pressure needs } \\
x_{5,3} \text { cost with different rated power needs } \\
x_{5,6} \text { cost of faults diagnosis and maintenance } \\
x_{5,7} \text { cost of mechanical parts } \\
x_{5,8} \text { cost of the environmental measures } \\
x_{5,10} \text { cost of materials of parts and the recycling }\end{array}$ & $x_{8,5}, x_{10,5}$ \\
\hline $\begin{array}{l}\mathrm{CT}_{6} \text { consideration of fault rate and } \\
\text { operation safety }\end{array}$ & $x_{6,9}$ maintenance and faults resolution for components & $x_{4,6}, x_{5,6}, x_{8,6}, x_{11,6}$ \\
\hline $\mathrm{CT}_{7}$ control the volume and mass & $x_{7,10}$ materials of the parts & $x_{1,7}, x_{5,7}, x_{8,7}, x_{9,7}$ \\
\hline $\begin{array}{l}\mathrm{CT}_{8} \text { consideration of } \mathrm{CFP}, \\
\text { environmental impact }\end{array}$ & $\begin{array}{l}x_{8,1} \text { rate of suction and exhaust } \\
x_{8,3} \text { rated power } \\
x_{8,4} \text { noise of the product } \\
x_{8,5} \text { cost for the environmental demands } \\
x_{8,6} \text { fault rate of the components } \\
x_{8,7} \text { materials usage of the parts } \\
x_{8,10} \text { material types, recycling and disposal methods }\end{array}$ & $x_{5,8}, x_{10,8}$ \\
\hline $\begin{array}{l}\mathrm{CT}_{9} \text { consideration of the } \\
\text { maintenance convenience }\end{array}$ & $x_{9,7}$ volume and mass of the parts & $x_{6,9}, x_{11,9}$ \\
\hline $\begin{array}{l}\mathrm{CT}_{10} \text { material selection, recycling, } \\
\text { and disposal }\end{array}$ & $\begin{array}{l}x_{10,5} \text { cost constraint for material selection, recycling, and } \\
\text { disposal } \\
x_{10,8} \text { environmental demands for material selection, } \\
\text { recycling and disposal }\end{array}$ & $x_{5,10}, x_{7,10}, x_{8,10}, x_{11,10}$ \\
\hline $\begin{array}{l}\mathrm{CT}_{11} \text { determination of product } \\
\text { physical lifetime }\end{array}$ & $\begin{array}{l}x_{11,6} \text { fault rate of the components } \\
x_{11,9} \text { maintenance convenience for the parts } \\
x_{11,10} \text { service life of materials for the parts }\end{array}$ & \\
\hline
\end{tabular}




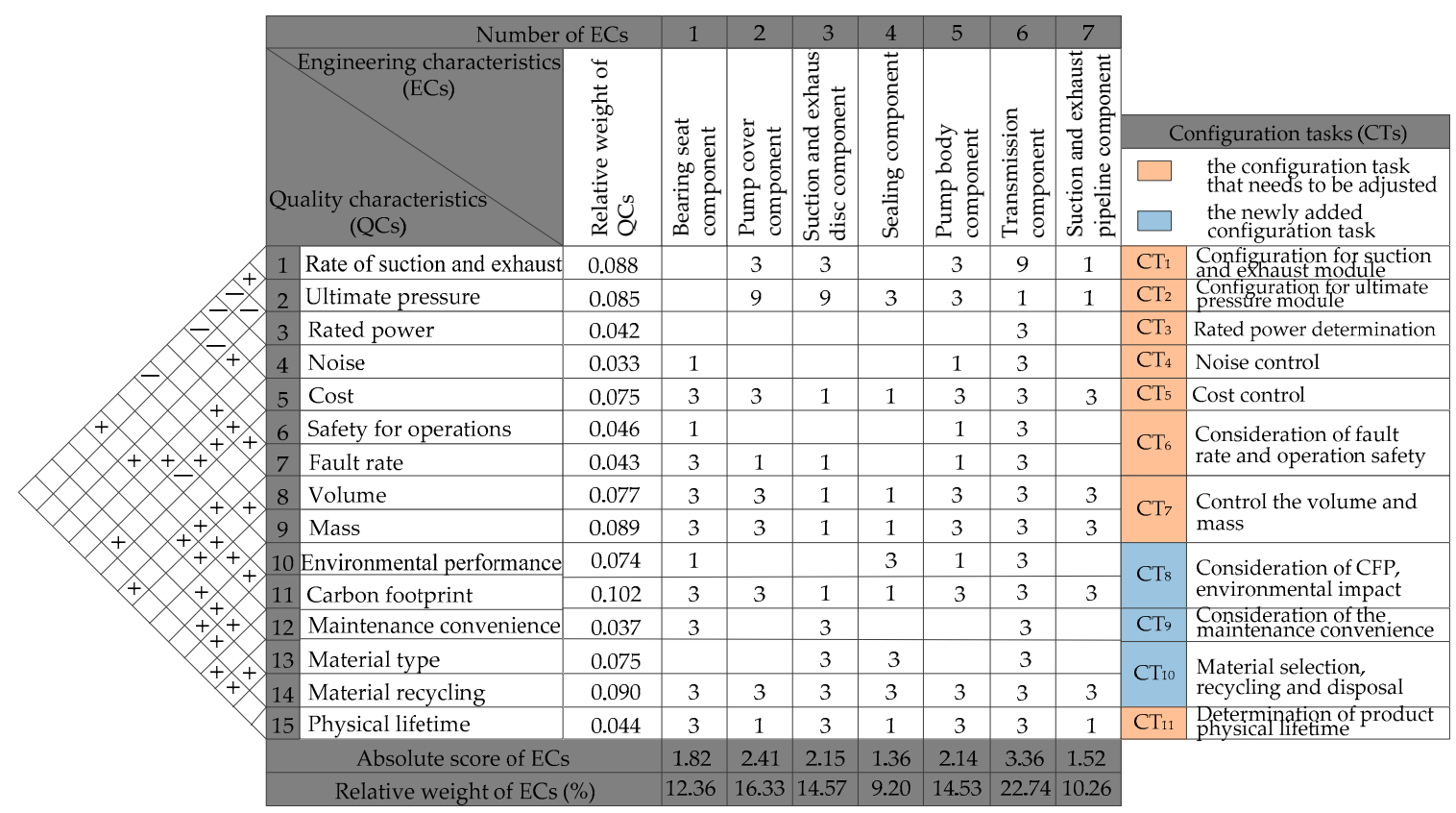

Figure 10. QFD phase II, mapping between QCs and ECs for the vacuum pump low-carbon design.

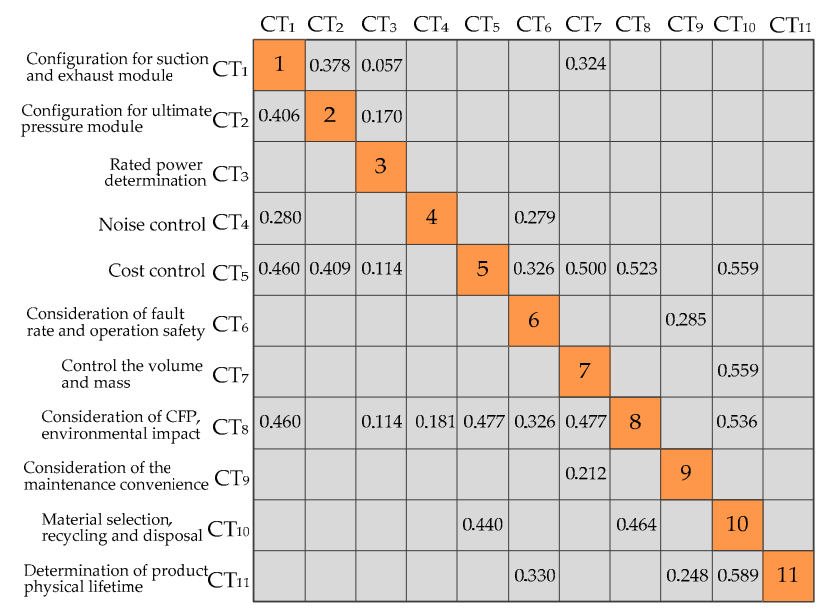

(a)

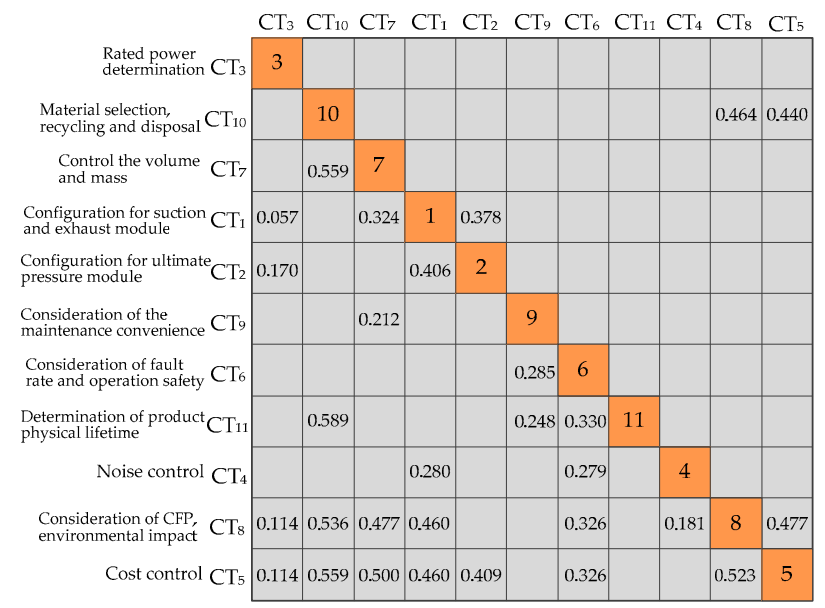

(b)

Figure 11. Sequencing for the configuration tasks (CTs) of the vacuum pump: (a) correlation representation of CTs with DSM and (b) the optimal sequence of CTs.

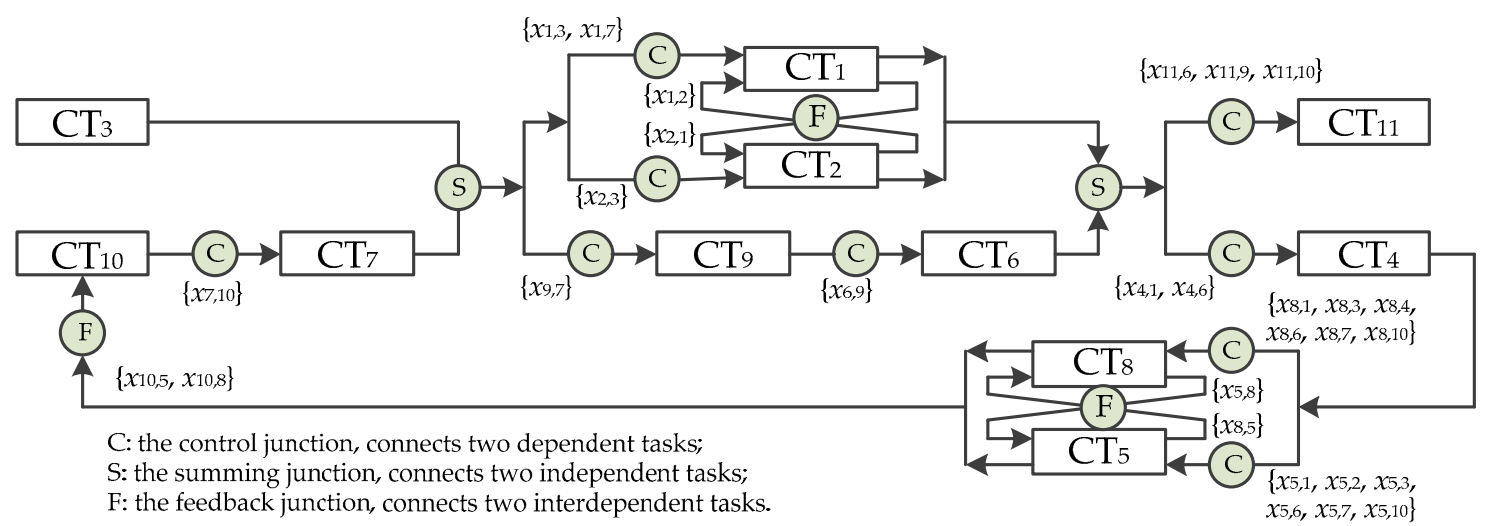

Figure 12. The information flow diagram (IFD) of CTs for vacuum pump low-carbon design. 


\subsubsection{Design Contradiction Clarification and Formulation for Vacuum Pump Low-Carbon Design}

The IFD of CTs of the vacuum pump provides instructions for designers to conduct the CTs in a reasonable order. In this section, contradictory problems associated with the newly added design tasks $\mathrm{CT}_{8}, \mathrm{CT}_{9}$, and $\mathrm{CT}_{10}$ are clarified and formulated with the basic-element model.

For the configuration task $\mathrm{CT}_{8}<$ consideration of CFP and environmental impact $>$, the design goal $g<$ reduce the carbon footprint of the vacuum pump $>$ is extracted, and it can be divided into three sub-goals by implication analysis, that is, $g_{1}<$ reduce the volume and mass of the vacuum pump $>, g_{2}<$ reduce the power consumption $>$, and $g_{3}<$ improve the reusability and adaptability of parts $>$. Design goal $g_{1}$ can be further divided into six sub-goals $g_{11}-g_{16}$, which aim at reducing the volume and mass of parts with high carbon emissions as estimated in Table 2; they are the pump cover, pump body, impeller, suction and exhaust pipeline, bearing seat, and transmission shaft. Accordingly, the design information of each part is taken as the design condition $l_{11}-l_{16}$, and then we can obtain six potential incompatibility problems $P_{11}-P_{16}$ as described in Table 4 .

Design goal $g_{2}$ of $\mathrm{CT}_{8}$ is divided into two sub-goals, namely $g_{21}<$ reduce the inner power consumption $>$ and $g_{22}<$ improve the work efficiency>; the corresponding design problems $P_{21}$ and $P_{22}$ are described in Table 4 . The inner power consumption is caused by the over-compressed air in the working chamber of the vacuum pump; the effective solution is to make the exhaust pressure adjustable, and thus the over-compressed air can be discharged through the suction and exhaust disc (part12) timely. The method to improve the work efficiency is mainly to enhance the rate of suction and exhaust, which is related to the working volume composed of the volume of the pump body and pump cover; in addition, increasing the number of impellers can also promote the work efficiency.

Design goal $g_{3}$ comprises $g_{31}<$ improve the reusability of parts> and $g_{32}<$ improve the adaptability of parts $>$. In design condition $l_{31}$, part1, part6, part15, and part24 can be reused by remanufacturing in the end of life stage; however, part2, part12, and part18 are not designed for reuse. In terms of design goal $g_{32}$, the adaptability of part12 and part24 is expected to be improved; the exhaust pressure cannot be adjusted in the current design scheme of part12 when the input pressure is changed, which leads to the inner power consumption; and although part24 can be reused by remanufacturing, the dimensions of part24 are fixed, which makes it difficult to be adapted for reuse to the series SK vacuum pumps. Thus, here we take $P_{31}$ and $P_{32}$ as design contradictions in Table 4.

In the configuration task $\mathrm{CT}_{9}$, the design goal $g<$ maintenance of parts in use stage $>$ is extracted, and it contains two sub-goals $g_{1}<$ maintenance of the continuous working parts $>$ and $g_{2}<$ maintenance of the sealing parts $>$; the corresponding design problems $P_{1}$ and $P_{2}$ are described in Table 5. For $g_{1}$, we expect to enhance the maintenance for the continuous working parts, that is, the transmission shaft (part6), impeller (part15), bearing seat (part18), and the bearing (part19), and in the actual maintenance work, the worker provides the lubrication for the part19, makes the crack detection for part15 and part18, and implements the tolerance detection for part6; all these maintenance measures can reduce the fault rate in the use stage. For $g_{2}$, the maintenance work is focused on the sealing component parts; during the maintenance, the sealing packing (part9) and profiling seal ring (part11) are replaced if they are loosened, and the rear bushing (part7), sealing gland (part8), and front bushing (part10) are usually needed to adjust the assembly gap, as the parts are easy to wear out during the working process; the maintenance for the sealing parts can effectively guarantee the ultimate pressure of the vacuum pump, which reduces the energy consumption. The design problems $P_{1}$ and $P_{2}$ of $C_{9}$ in Table 5 are not the contradictory problems, as the current maintenance conditions can satisfy the design requirements. 
Table 4. Description of design problems of the configuration task $\mathrm{CT}_{8}$.

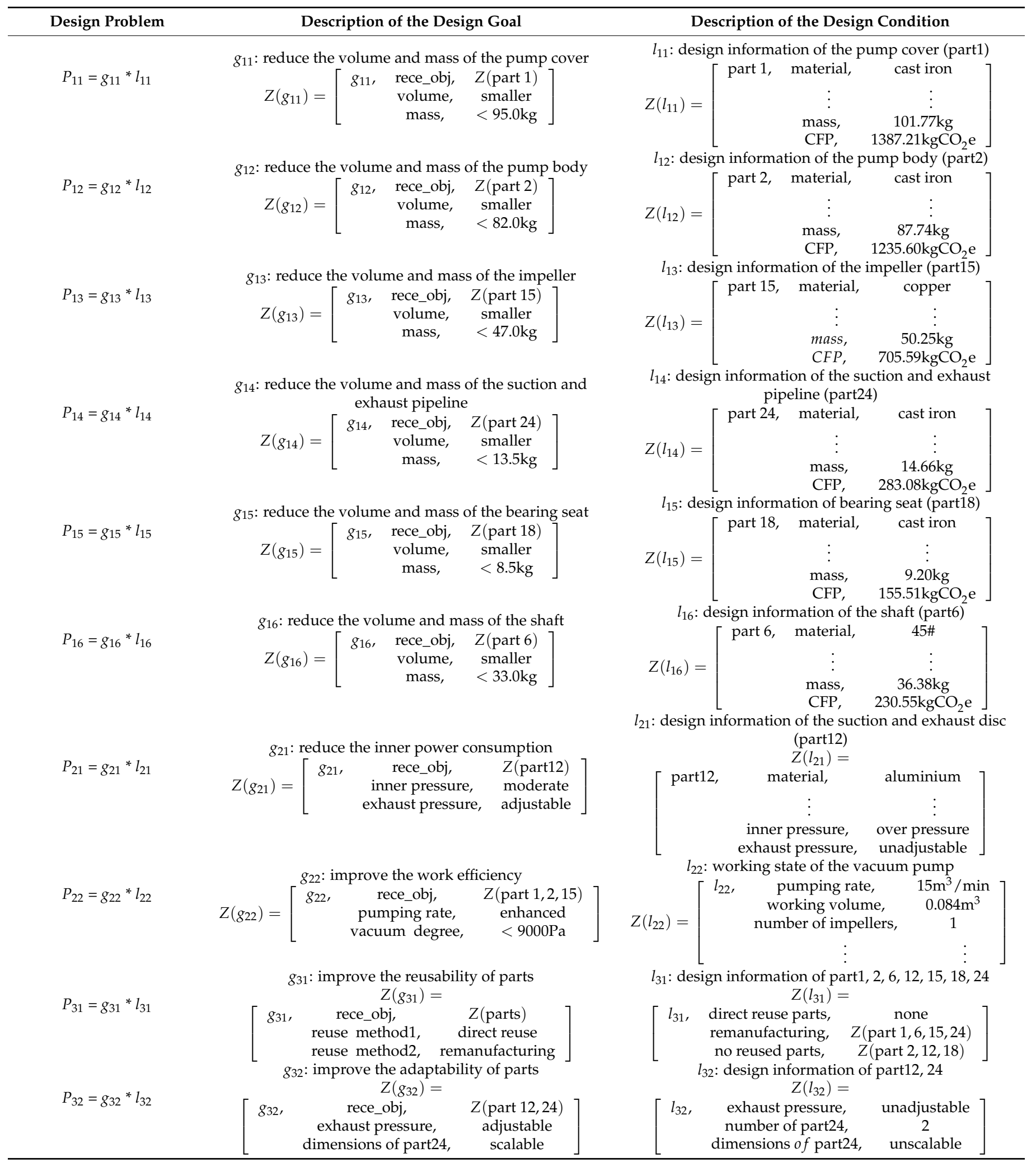


Table 5. Description of design problems of the configuration task $\mathrm{CT}_{9}$.

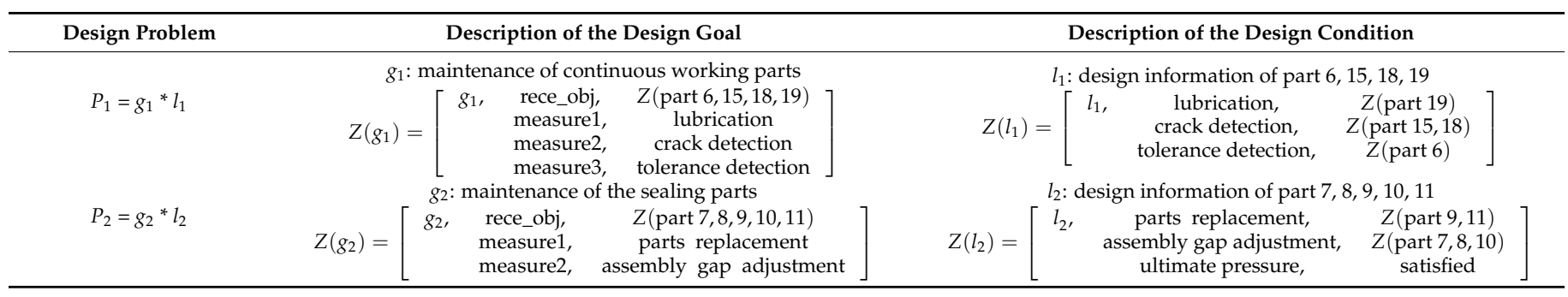

In the configuration task $\mathrm{CT}_{10}$, the design goal $g<$ material selection, the recycling and disposal methods $>$ is extracted, and it is divided into two sub-goals, $g_{1}<$ select suitable materials for the parts $>$ and $g_{2}<$ improve the recycling and disposal methods $>$; the design problems are described in Table 6. The material of the part determines its mechanical properties, cost, carbon emission factor, and the recycling and disposal methods in the end of life stage. The material selection for the transmission shaft and the impeller should be carefully considered, as the transmission component greatly affects the physical lifetime of the vacuum pump. In the current design scheme, the materials of the transmission shaft and impeller are 45\# and copper, respectively, which cannot ensure that the selection is the optimal scheme with minimum carbon emissions throughout the product lifecycle; thus, we take the $P_{11}$ and $P_{12}$ of $\mathrm{CT}_{10}$ in Table 6 as the potential design contradictions. For $g_{2}$, considering the recycling measures for parts, we require that part2, part12, and part18 can be reused by remanufacturing rather than material recycling, as mentioned in $g_{31}$ of $\mathrm{CT}_{8}$ associated with the reusability of the parts; for the disposal measures, part9 is disposed of with landfill, and part11 and part13 are disposed of with incineration, which satisfies the low-carbon demands; thus, we only take $P_{21}$ as the design contradiction in terms of the design goal $g_{2}$.

Table 6. Description of design problems of the configuration task $\mathrm{CT}_{10}$.

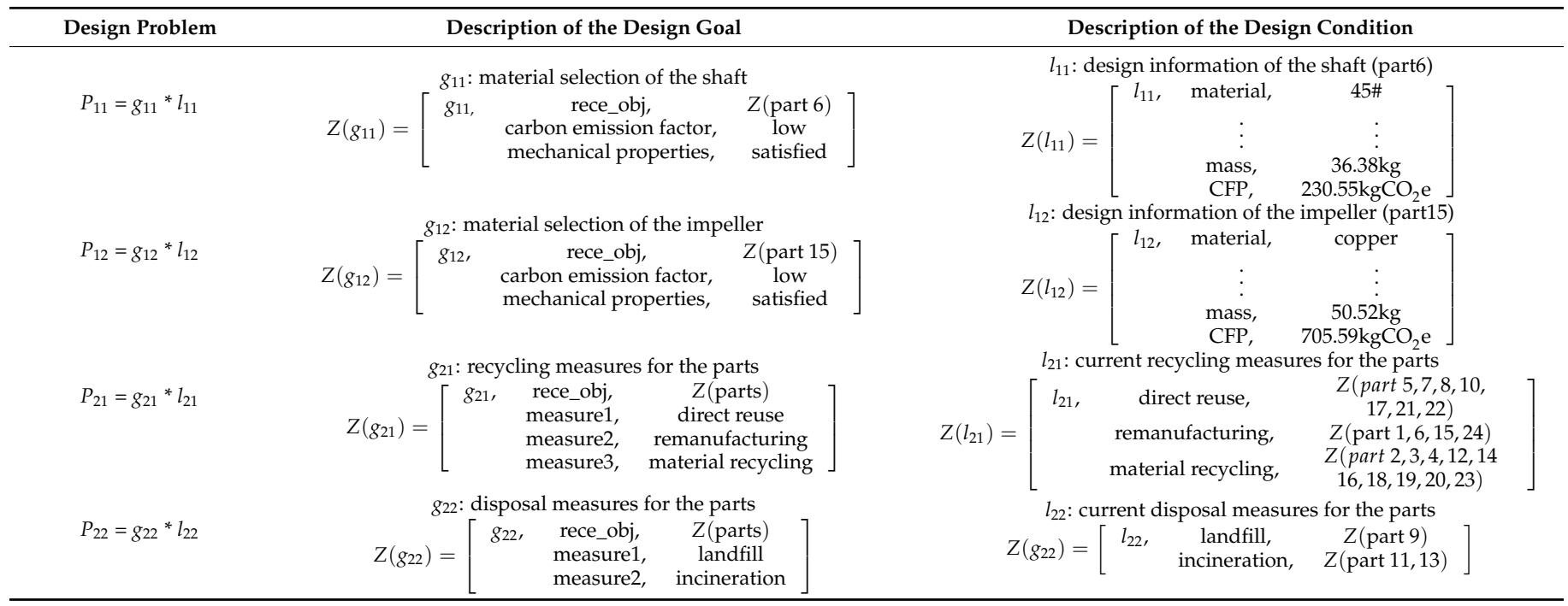

Finally, the design problems of the newly added configuration tasks $\mathrm{CT}_{8}, \mathrm{CT}_{9}$, and $\mathrm{CT}_{10}$ are concluded in Table A1 in Appendix A. However, to accomplish these three tasks, designers require the input design information from other $\mathrm{CTs}$, and $\mathrm{CT}_{8}, \mathrm{CT}_{9}$, and $\mathrm{CT}_{10}$ could also provide output configuration parameters; thus, when dealing with design problems of $\mathrm{CT}_{8}, \mathrm{CT}_{9}$, and $\mathrm{CT}_{10}$, the configuration parameters associated with the other related CTs also need to be adjusted. 


\subsubsection{Extensible and Conjugate Analysis for Design Contradictions}

Since the preliminary contradictory problems associated with $\mathrm{CT}_{8}$ and $\mathrm{CT}_{10}$ are clarified, it is necessary to make the extensible and conjugate analysis for the design contradictions to put forward feasible measures, as illustrated in Figures 13 and 14.

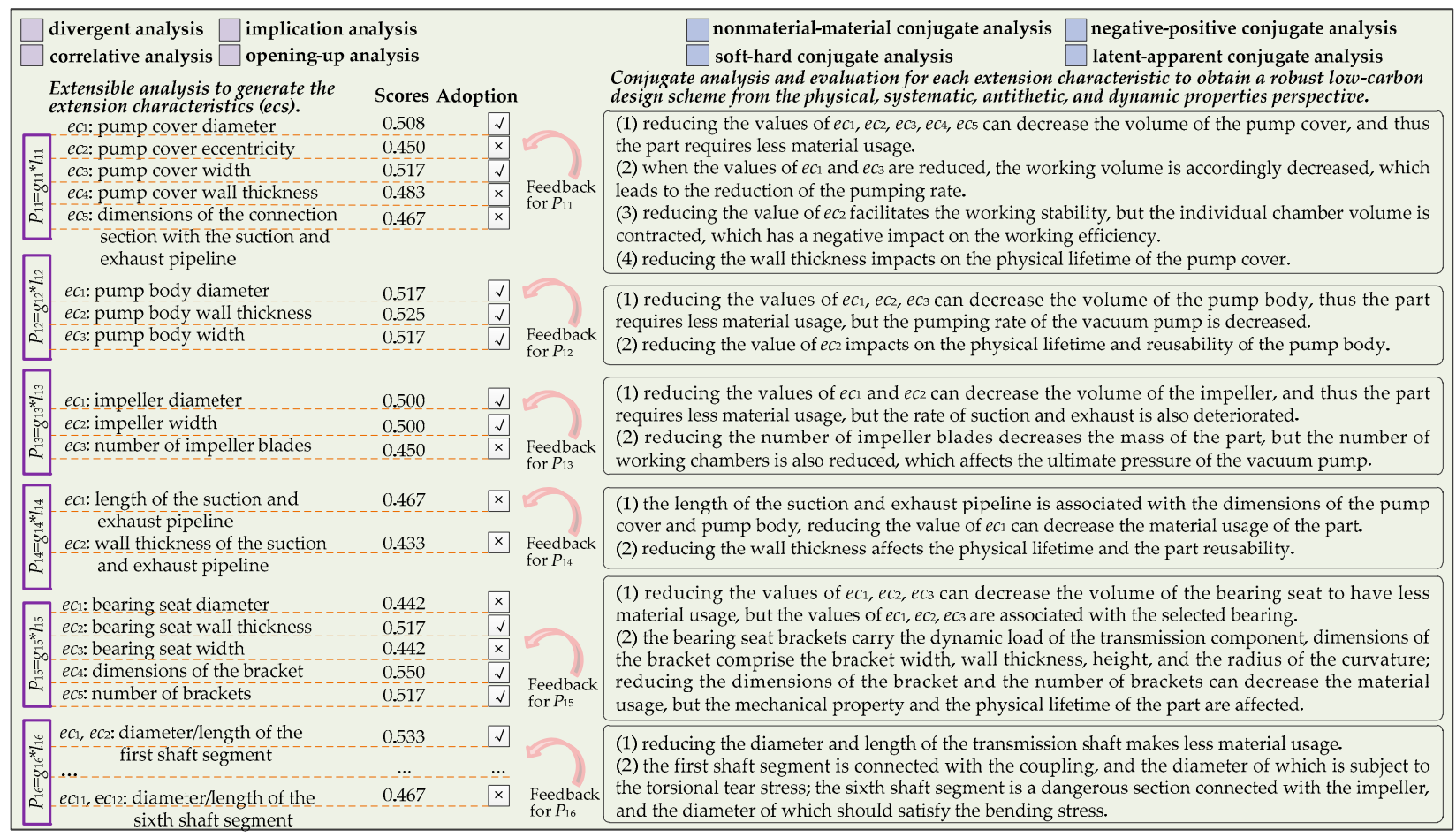

Figure 13. Extensible and conjugate analysis for $P_{11}-P_{16}$ of $\mathrm{CT}_{8}$.

Based on the extensible analysis for the design condition of each contradictory problem, the extension characteristics (ecs) are generated, which are viewed as the possible measures to solve the design contradictions. For example, for the contradictory problem $P_{11}$ of $\mathrm{CT}_{8}$, in order to satisfy the design goal $g_{11}$, namely, to reduce the volume and mass of the pump cover, there are five extension characteristics provided based on the extensible analysis, $e c_{1}<$ pump cover diameter $>, e c_{2}<$ pump cover eccentricity $>, e c_{3}<$ pump cover width $>, e c_{4}<$ pump cover wall thickness $>$, and $e c_{5}<$ dimensions of the connection section with the suction and exhaust pipeline $>$. Thus, modifying the values of these extension characteristics can provide possible measures to solve $P_{11}$. Take contradictory problem $P_{21}$ of $\mathrm{CT}_{8}$ as another example; there are three extension characteristics generated based on the extensible analysis, as depicted in Figure 14, and thus redesigning the location of the exhaust port, increasing the number of exhaust ports, and adding the pressure-adjusting component are the possible measures to solve $P_{21}$.

When implementing the extensible analysis for design conditions, the design constraints are not fully considered, which would be able to radiate innovative solutions. Thus, the possible extension characteristics may not be the feasible measures; in this paper, each extension characteristic is evaluated qualitatively and quantitatively by means of the conjugate analysis, which takes into account the functional performance, cost, and low-carbon environmental impact of the design solution from the physical, systematic, antithetic, and dynamic properties perspectives. Due to the space limitations, in this section, we only provide the quantitative evaluation result for the extension characteristics of the $P_{21}, P_{22}$, $P_{31}$, and $P_{32}$ of the $\mathrm{CT}_{8}$, as shown in Table 7 , where eight conjugate parts are taken as the evaluation indicators. The material part considers the complexity of the design structure, and the nonmaterial part indicates the corresponding functional performance, cost, and carbon emissions; the hard part considers the compatibility of the structural layout, and 
the soft part indicates the coordination of overall functional performance; the positive part estimates the positive effect taken from the design solution, and the negative part reveals its negative effect; the apparent part analyzes the obvious or current benefits, and the latent part considers the long-term benefits to the society and environment.

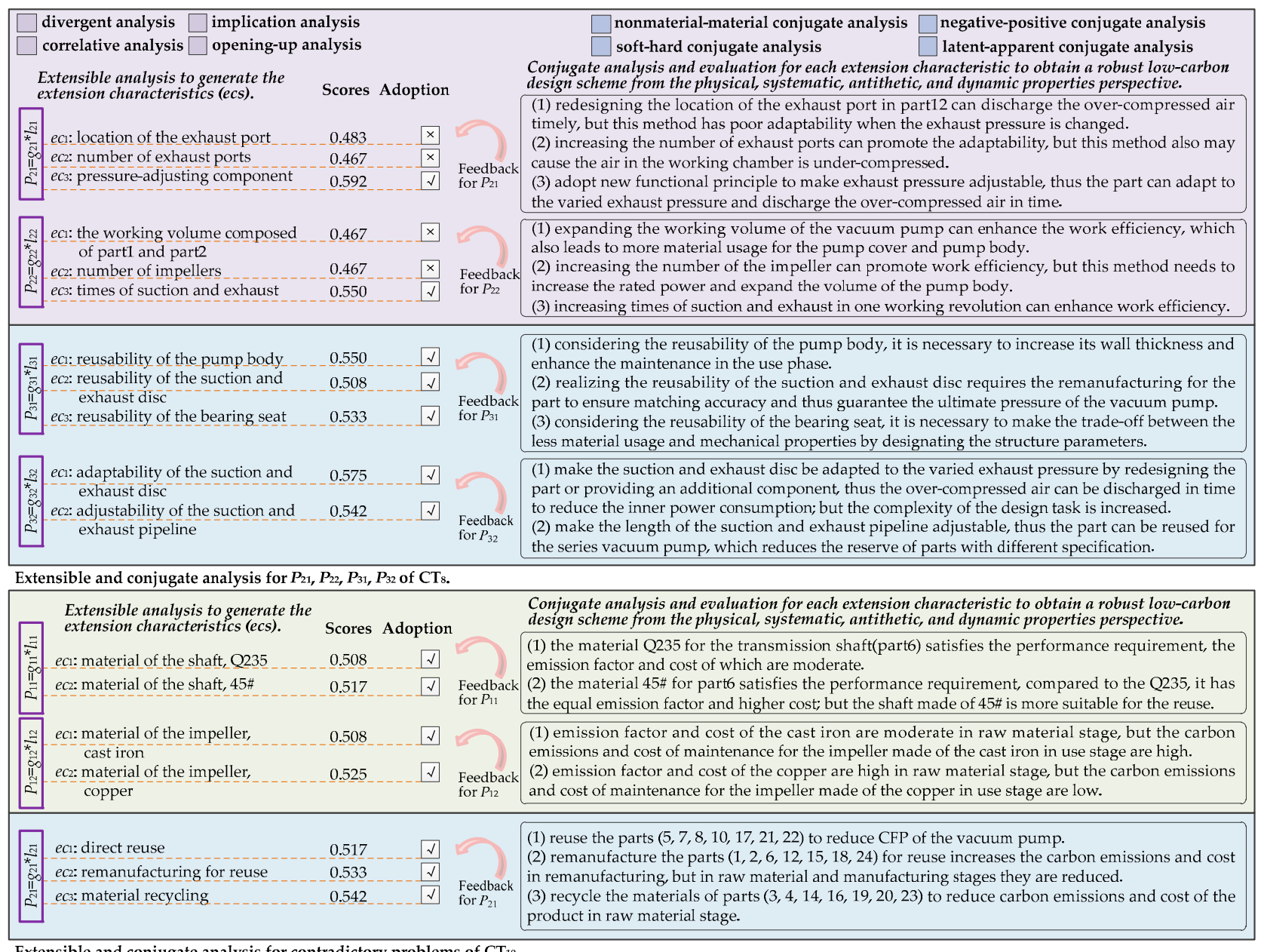

Figure 14. Extensible and conjugate analysis for $P_{21}, P_{22}, P_{31}$, and $P_{32}$ of $\mathrm{CT}_{8}$ and for contradictory problems of $\mathrm{CT}_{10}$.

According to the evaluation indicators, each extension characteristic is estimated by three experts, and the mean scores are used to calculate the total score, where the weight of each evaluation indicator is equal to 0.125 . In addition, the evaluation scale for the negative part of $e c_{i}$ should be explained; for example, when the evaluation for the negative part of $e c_{i}$ is very good (VG), it indicates that taking this measure $\left(e c_{i}\right)$ to solve the problem only has a slight negative effect. Finally, the qualitative and quantitative evaluation results based on the conjugate analysis are taken as the feedback information to determine whether the extension characteristic should be adopted, and thus to obtain the robust design solution, as depicted in Figures 13 and 14.

In addition, based on the conjugate analysis, the design contradictions about the incompatibility problems are further studied. Figures 13 and 14 conclude that $P_{11}, P_{12}$, and $P_{22}$ of $\mathrm{CT}_{8}$ can be summarized as an antithetical problem $P_{01}$, as reducing the volume of the pump cover and pump body will deteriorate the work efficiency, while improving work efficiency will inevitably increase the volume of parts. $P_{01}$ can be described as below:

$$
P_{01}=\left(\left(g_{11}, g_{12}\right) \wedge g_{22}\right) \uparrow l_{01}
$$

where $P_{01}$ belongs to the LCD-AP(II). 
Table 7. Evaluation for extension characteristics (ecs) of $P_{21}, P_{22}, P_{31}$, and $P_{32}$ of the $\mathrm{CT}_{8}$ based on the conjugate parts.

\begin{tabular}{|c|c|c|c|c|c|c|c|c|c|c|}
\hline & & \multicolumn{2}{|c|}{ Physical Property } & \multicolumn{2}{|c|}{ Systematic Property } & \multicolumn{2}{|c|}{ Antithetic Property } & \multicolumn{2}{|c|}{ Dynamic Property } & \multirow[b]{2}{*}{ Score } \\
\hline & & Material Part & $\begin{array}{c}\text { Nonmaterial } \\
\text { Part }\end{array}$ & Hard Part & Soft Part & Positive Part & $\begin{array}{c}\text { Negative } \\
\text { Part }\end{array}$ & $\begin{array}{l}\text { Apparent } \\
\text { Part }\end{array}$ & Latent Part & \\
\hline \multirow{3}{*}{$P_{21}$} & $e c_{1}$ & $\begin{array}{c}\mathrm{M}, \mathrm{M}, \mathrm{M} \\
\text { Mean }=0.50\end{array}$ & $\begin{array}{c}\mathrm{P}, \mathrm{M}, \mathrm{P} \\
\text { Mean }=0.37\end{array}$ & $\begin{array}{c}\mathrm{G}, \mathrm{M}, \mathrm{M} \\
\text { Mean }=0.57\end{array}$ & $\begin{array}{c}\text { G,M,M } \\
\text { Mean }=0.57\end{array}$ & $\begin{array}{c}\mathrm{M}, \mathrm{M}, \mathrm{M} \\
\text { Mean }=0.50\end{array}$ & $\begin{array}{c}\mathrm{M}, \mathrm{M}, \mathrm{M} \\
\text { Mean }=0.50\end{array}$ & $\begin{array}{c}\text { M,G,M } \\
\text { Mean }=0.57\end{array}$ & $\begin{array}{c}\text { M,P,VP } \\
\text { Mean }=0.30\end{array}$ & 0.483 \\
\hline & $e c_{2}$ & $\begin{array}{c}\mathrm{M}, \mathrm{M}, \mathrm{M} \\
\text { Mean }=0.50\end{array}$ & $\begin{array}{c}\mathrm{P}, \mathrm{M}, \mathrm{M} \\
\text { Mean }=0.43\end{array}$ & $\begin{array}{c}\text { M,G,M } \\
\text { Mean }=0.57\end{array}$ & $\begin{array}{c}\mathrm{G}, \mathrm{M}, \mathrm{M} \\
\text { Mean }=0.57\end{array}$ & $\begin{array}{c}\mathrm{M}, \mathrm{M}, \mathrm{M} \\
\text { Mean }=0.50\end{array}$ & $\begin{array}{c}\mathrm{P}, \mathrm{M}, \mathrm{P} \\
\text { Mean }=0.37\end{array}$ & $\begin{array}{c}\text { M,M,P } \\
\text { Mean }=0.43\end{array}$ & $\begin{array}{c}\text { M,P,P } \\
\text { Mean = } 0.37\end{array}$ & 0.467 \\
\hline & $e c_{3}$ & $\begin{array}{c}\text { M,M,G } \\
\text { Mean = } 0.57\end{array}$ & $\begin{array}{c}\text { G,G,VG } \\
\text { Mean }=0.77\end{array}$ & $\begin{array}{c}\mathrm{M}, \mathrm{M}, \mathrm{M} \\
\text { Mean }=0.50\end{array}$ & $\begin{array}{c}\text { M,M,G } \\
\text { Mean = } 0.57\end{array}$ & $\begin{array}{c}\text { G,M,G } \\
\text { Mean = } 0.63\end{array}$ & $\begin{array}{c}\text { M,M,M } \\
\text { Mean = } 0.50\end{array}$ & $\begin{array}{c}\mathrm{G}, \mathrm{M}, \mathrm{M} \\
\text { Mean }=0.57\end{array}$ & $\begin{array}{c}\text { G,M,G } \\
\text { Mean = } 0.63\end{array}$ & 0.592 \\
\hline \multirow{3}{*}{$P_{22}$} & $e c_{1}$ & $\begin{array}{c}\text { M,M,M } \\
\text { Mean = } 0.50\end{array}$ & $\begin{array}{c}\text { M,M,G } \\
\text { Mean }=0.57\end{array}$ & $\begin{array}{c}\mathrm{P}, \mathrm{M}, \mathrm{P} \\
\text { Mean }=0.37\end{array}$ & $\begin{array}{c}\mathrm{P}, \mathrm{M}, \mathrm{P} \\
\text { Mean }=0.37\end{array}$ & $\begin{array}{c}\text { M,M,G } \\
\text { Mean }=0.57\end{array}$ & $\begin{array}{c}\text { M,P,P } \\
\text { Mean }=0.37\end{array}$ & $\begin{array}{c}\text { M,M,P } \\
\text { Mean }=0.43\end{array}$ & $\begin{array}{c}\text { M,M,G } \\
\text { Mean }=0.57\end{array}$ & 0.467 \\
\hline & $e c_{2}$ & $\begin{array}{c}\mathrm{M}, \mathrm{P}, \mathrm{M} \\
\text { Mean }=0.43\end{array}$ & $\begin{array}{c}\mathrm{G}, \mathrm{M}, \mathrm{G} \\
\text { Mean }=0.63\end{array}$ & $\begin{array}{c}\text { M,P,P } \\
\text { Mean }=0.37\end{array}$ & $\begin{array}{c}\text { M,P,M } \\
\text { Mean }=0.43\end{array}$ & $\begin{array}{c}\mathrm{G}, \mathrm{M}, \mathrm{M} \\
\text { Mean = } 0.57\end{array}$ & $\begin{array}{c}\text { M,P,P } \\
\text { Mean }=0.37\end{array}$ & $\begin{array}{c}\mathrm{P}, \mathrm{M}, \mathrm{P} \\
\text { Mean }=0.37\end{array}$ & $\begin{array}{c}\text { M,G,M } \\
\text { Mean = } 0.57\end{array}$ & 0.467 \\
\hline & $e c_{3}$ & $\begin{array}{c}\mathrm{M}, \mathrm{M}, \mathrm{M} \\
\text { Mean }=0.50\end{array}$ & $\begin{array}{c}\text { G,M,G } \\
\text { Mean }=0.63\end{array}$ & $\begin{array}{c}\text { M,P,M } \\
\text { Mean }=0.43\end{array}$ & $\begin{array}{c}\text { M,M,G } \\
\text { Mean = } 0.57\end{array}$ & $\begin{array}{c}\text { G,M,G } \\
\text { Mean = } 0.63\end{array}$ & $\begin{array}{c}\text { M,P,M } \\
\text { Mean }=0.43\end{array}$ & $\begin{array}{c}\text { M,M,G } \\
\text { Mean = } 0.57\end{array}$ & $\begin{array}{c}\text { G,M,G } \\
\text { Mean = } 0.63\end{array}$ & 0.550 \\
\hline \multirow{3}{*}{$P_{31}$} & $e c_{1}$ & $\begin{array}{c}\text { M,G,M } \\
\text { Mean = } 0.57\end{array}$ & $\begin{array}{c}\text { M,G,M } \\
\text { Mean }=0.57\end{array}$ & $\begin{array}{c}\text { M,G,M } \\
\text { Mean }=0.57\end{array}$ & $\begin{array}{c}\text { M,G,M } \\
\text { Mean = } 0.57\end{array}$ & $\begin{array}{c}\text { M,G,G } \\
\text { Mean = } 0.63\end{array}$ & $\begin{array}{c}\text { M,M,P } \\
\text { Mean }=0.43\end{array}$ & $\begin{array}{c}\text { M,M,P } \\
\text { Mean }=0.43\end{array}$ & $\begin{array}{c}\text { G,G,M } \\
\text { Mean }=0.63\end{array}$ & 0.550 \\
\hline & $e c_{2}$ & $\begin{array}{c}\text { M,M,M } \\
\text { Mean = } 0.50\end{array}$ & $\begin{array}{c}\text { M,M,M } \\
\text { Mean = } 0.50\end{array}$ & $\begin{array}{c}\text { M,M,M } \\
\text { Mean = } 0.50\end{array}$ & $\begin{array}{c}\text { M,M,M } \\
\text { Mean = } 0.50\end{array}$ & $\begin{array}{c}\text { G,M,M } \\
\text { Mean = 0.57 }\end{array}$ & $\begin{array}{c}\text { M,M,M } \\
\text { Mean = } 0.50\end{array}$ & $\begin{array}{c}\text { M,M,P } \\
\text { Mean = } 0.43\end{array}$ & $\begin{array}{c}\text { G,M,M } \\
\text { Mean }=0.57\end{array}$ & 0.508 \\
\hline & $e c_{3}$ & $\begin{array}{c}\mathrm{G}, \mathrm{M}, \mathrm{M} \\
\text { Mean }=0.57\end{array}$ & $\begin{array}{c}\text { M,M,M } \\
\text { Mean = } 0.50\end{array}$ & $\begin{array}{c}\text { G,M,M } \\
\text { Mean }=0.57\end{array}$ & $\begin{array}{c}\mathrm{M}, \mathrm{M}, \mathrm{M} \\
\text { Mean }=0.50\end{array}$ & $\begin{array}{c}\text { G,M,G } \\
\text { Mean }=0.63\end{array}$ & $\begin{array}{c}\text { M,M,P } \\
\text { Mean }=0.43\end{array}$ & $\begin{array}{c}\mathrm{G}, \mathrm{M}, \mathrm{M} \\
\text { Mean }=0.57\end{array}$ & $\begin{array}{c}\mathrm{M}, \mathrm{M}, \mathrm{M} \\
\text { Mean }=0.50\end{array}$ & 0.533 \\
\hline \multirow{2}{*}{$P_{32}$} & $e c_{1}$ & $\begin{array}{c}\text { M,M,G } \\
\text { Mean = } 0.57\end{array}$ & $\begin{array}{c}\text { G,G,G } \\
\text { Mean }=0.70\end{array}$ & $\begin{array}{c}\mathrm{M}, \mathrm{M}, \mathrm{M} \\
\text { Mean = } 0.50\end{array}$ & $\begin{array}{c}\text { M,G,M } \\
\text { Mean = } 0.57\end{array}$ & $\begin{array}{c}\text { G,M,G } \\
\text { Mean = } 0.63\end{array}$ & $\begin{array}{c}\text { M,P,M } \\
\text { Mean }=0.43\end{array}$ & $\begin{array}{c}\text { G,M,M } \\
\text { Mean = } 0.57\end{array}$ & $\begin{array}{c}\text { G,M,G } \\
\text { Mean = } 0.63\end{array}$ & 0.575 \\
\hline & $e c_{2}$ & $\begin{array}{c}\text { G,M,M } \\
\text { Mean }=0.57\end{array}$ & $\begin{array}{c}\text { G,M,M } \\
\text { Mean =0.57 }\end{array}$ & $\begin{array}{c}\text { M,M,M } \\
\text { Mean }=0.50\end{array}$ & $\begin{array}{c}\text { M,M,M } \\
\text { Mean = } 0.50\end{array}$ & $\begin{array}{c}\mathrm{G}, \mathrm{G}, \mathrm{M} \\
\text { Mean }=0.63\end{array}$ & $\begin{array}{c}\text { M,M,P } \\
\text { Mean = } 0.43\end{array}$ & $\begin{array}{c}\text { M,M,M } \\
\text { Mean }=0.50\end{array}$ & $\begin{array}{c}\mathrm{G}, \mathrm{G}, \mathrm{M} \\
\text { Mean }=0.63\end{array}$ & 0.542 \\
\hline
\end{tabular}

Evaluation scale: Very good (VG) 0.9, Good (G) 0.7, Moderate (M) 0.5, Poor (P) 0.3, Very poor (VP) 0.1.

For the incompatibility problem $P_{21}$ of $\mathrm{CT}_{8}$, design goal $g_{21}<$ reduce the inner power consumption $>$ can be replaced with $g_{211}<$ reduce the air pressure $>$ when the air in the working chamber is over-compressed, and $g_{212}<$ increase the air pressure $>$ when the air pressure of the working chamber does not satisfy the exhaust pressure. Thus, $P_{21}$ is actually an antithetical problem, and it can be redefined as:

$$
P_{02}=\left(g_{211} \wedge g_{212}\right) \uparrow l_{21}
$$

where $P_{02}$ belongs to the LCD-AP(I). $P_{01}$ and $P_{02}$ are all added to Table A1 in Appendix A.

4.1.4. Generation of the Design Scheme Based on Extension Transformation for Vacuum Pump Low-Carbon Design

According to the extensible and conjugate analysis for the design contradictions of $\mathrm{CT}_{8}$ and $\mathrm{CT}_{10}$, sixteen feasible measures are obtained to solve the low-carbon design problems. As the coupling relationship is caused by the input and output configuration parameters between $C T s$, measures corresponding to the $\mathrm{CT}_{8}$ and $\mathrm{CT}_{10}$ should be mapped to related CTs. Ultimately, based on the IFD of CTs depicted in Figure 12, all measures for the design contradictions can be scheduled with a Gantt chart in Figure 15 to clearly describe the order of the execution.

In the Gantt chart, the material selection of the shaft and impeller associated with the $P_{11}$ and $P_{12}$ of $\mathrm{CT}_{10}$ is first determined, and then measures for $P_{21}$ of $\mathrm{CT}_{10}$ concerned with the parts designed for direct reuse, reuse by remanufacturing, and material recycling are implemented; these measures also require the modification information of the dimensions of the parts involved in the $\mathrm{CT}_{7}$. Based on the conjugate analysis, the measure of increasing the times of suction and exhaust is adopted to enhance the work efficiency of the vacuum pump for $P_{22}$; however, $P_{22}, P_{11}$, and $P_{12}$ of $\mathrm{CT}_{8}$ cause the antithetical problem $P_{01}$; thus, they should be addressed together. In the Gantt chart, it can be seen that the design contradictions $P_{11}-P_{16}$ of $\mathrm{CT}_{8}$ associated with the structural modifications of the parts are all mapped onto the $\mathrm{CT}_{7}$, and the modifications for the dimensions of the pump cover, pump body, and shaft precede the modifications for the impeller, suction and exhaust pipeline, and bearing seat, as the latter parts require the design information from the 
former parts; at the same time, measures of improving the reusability of the pump body (measure 8 ), bearing seat (measure 14), and the adaptability of the suction and exhaust pipeline (measure 12) are implemented accordingly. Measure 15 is to design a pressureadjusting component for the suction and exhaust disc to solve the $P_{21}$ of $\mathrm{CT}_{8}$, which is considered as the antithetical problem $P_{02}$, and measure 15 is also related to the $\mathrm{CT}_{1}$ and $\mathrm{CT}_{2}$ concerned with the rate of suction and exhaust, and the ultimate pressure. Measure 16 is finally conducted for the suction and exhaust disc; it is necessary to redesign the structure to fix the newly added pressure-adjusting component and consider reusability and adaptability to reduce the environmental impact in the use stage and end of life stage.

\begin{tabular}{|c|c|c|c|c|c|c|c|c|c|c|c|c|c|c|c|c|c|c|}
\hline \multirow{2}{*}{\multicolumn{2}{|c|}{$\begin{array}{l}\text { Scheduled configuration tasks and } \\
\text { Measures for the design withe consumed time } t \\
\text { contradictions associated with the CTS }\end{array}$}} & \multicolumn{5}{|c|}{$\begin{array}{l}\mathrm{CT}_{3} \\
\mathrm{CT}_{10}\end{array}$} & \multicolumn{3}{|c|}{$\mathrm{CT}_{7}$} & \multicolumn{5}{|c|}{$\begin{array}{l}\mathrm{CT}_{1}, \mathrm{CT}_{2} \\
\mathrm{CT} \mathrm{T}_{9}, \mathrm{CT}_{0}\end{array}$} & \multicolumn{4}{|c|}{$\begin{array}{c}\mathrm{CT}_{11} \\
\mathrm{CT}_{4}, \mathrm{CT}_{\mathrm{s}}, \mathrm{CT}_{5} \\
\end{array}$} \\
\hline & & \begin{tabular}{|l|l|}
$t_{1}$ & $t_{2}$ \\
\end{tabular} & $t_{3}$ & $t_{4}$ & $t_{5}$ & $t_{0}$ & $t_{7}$ & $t_{s}$ & \begin{tabular}{|l|l|l|}
$t_{10}$ & $t_{11}$ & $t_{12}$ \\
\end{tabular} & \begin{tabular}{|l|l|}
$t_{13}$ & $t_{14}$ \\
\end{tabular} & $t_{15}$ & $t_{10}$ & $t_{17}$ & $t_{18}$ & $t_{19}$ & \begin{tabular}{|l|l|}
$t_{20}$ & $t_{21}$ \\
\end{tabular} & $t_{22}$ & \begin{tabular}{|l|l}
$t_{23}$ & $t_{24}$
\end{tabular} \\
\hline 1 & material selection of the shaft, impeller & \multicolumn{17}{|c|}{$P_{11}, P_{12}$ of $C_{10}$} \\
\hline 2 & parts designed for direct reuse & & \multicolumn{6}{|c|}{$P_{21}$ of $\mathrm{CT}_{10}$} & & & & & & & & & & \\
\hline 3 & $\begin{array}{l}\text { parts designed for reuse by } \\
\text { remanufacturing }\end{array}$ & & \multicolumn{6}{|c|}{$P_{21}$ of $\mathrm{CT}_{10}$} & & & & & & & & & & \\
\hline 4 & parts designed for material recycling & & \multicolumn{6}{|c|}{$P_{21}$ of $\mathrm{CT}_{10}$} & & & & & & & & & & \\
\hline 5 & $\begin{array}{l}\text { get a scheme to increase the times of suction } \\
\text { and exhaust in one working revolution }\end{array}$ & & & & & & \multicolumn{8}{|c|}{$P_{22}$ of $\mathrm{CT}_{\mathrm{s}}$} & & & & \\
\hline 6 & modify the dimensions of the pump cover & & & & & & \multicolumn{3}{|c|}{$P_{11}$ of $\mathrm{CT}_{8}$} & & & & & & & & & \\
\hline 7 & modify the dimensions of the pump body & & & & & & \multicolumn{3}{|c|}{$P_{12}$ of $C T_{s}$} & & & & & & & & & \\
\hline 8 & improve the reusability of the pump body & & & & & & \multicolumn{5}{|c|}{$P_{31}$ of $\mathrm{CT}_{\mathrm{s}}$} & & & & & & & \\
\hline 9 & modify the dimensions of the shaft & & & & & & \multicolumn{3}{|c|}{$P_{16}$ of $\mathrm{CT}_{8}$} & & & & & & & & & \\
\hline 10 & modify the dimensions of the impeller & & & & & & & & $P_{13}$ of $\mathrm{CT}_{8}$ & & & & & & & & & \\
\hline 11 & $\begin{array}{l}\text { modify the dimensions of the suction } \\
\text { and exhaust pipeline }\end{array}$ & & & & & & & & $P_{14}$ of $\mathrm{CT}_{8}$ & & & & & & & & & \\
\hline 12 & $\begin{array}{l}\text { enhance the adaptability of the suction } \\
\text { and exhaust pipeline }\end{array}$ & & & & & & & & $P_{32}$ of $\mathrm{CT}_{8}$ & & & & & & & & & \\
\hline 13 & $\begin{array}{l}\text { modify the number and dimensions of } \\
\text { the bracket of the bearing seat }\end{array}$ & & & & & & & & $P_{15}$ of $\mathrm{CT}_{8}$ & & & & & & & & & \\
\hline 14 & improve the reusability of the bearing seat & & & & & & & & $P_{31}$ of $\mathrm{CT}_{8}$ & & & & & & & & & \\
\hline 15 & design the pressure adjusting component & & & & & & & & $P_{21}$ of $\mathrm{CT}_{8}$ & & & & & & & & & \\
\hline 16 & $\begin{array}{l}\text { improve the reusability and adaptability } \\
\text { of the suction and exhaust disc }\end{array}$ & & & & & & & & $P_{21}, P_{31}, P_{32}$ & of $\mathrm{CT}_{8}$ & & & & & & & & \\
\hline
\end{tabular}

Figure 15. The Gantt chart of measures execution for design contradiction solving.

(1) Solutions to the incompatibility problems

To solve the incompatibility problems, design conditions should be modified to satisfy the design goals based on the inspiration of the measures. For example, the incompatibility problems $P_{15}<$ how to reduce the volume and mass of the bearing seat $>$ and $P_{31}<$ how to improve the reusability of parts $>$; measure 13 can modify the dimensions of the brackets of the bearing seat, that is, the bracket width, wall thickness, height, and the curvature radius of the bracket, and adjust the number of brackets to reduce the volume and mass of the bearing seat. However, when considering the reusability of the bearing seat, designers should make a trade-off between the structure dimensions and physical lifetime, and the optimization algorithm could be applied to obtain the optimal design parameters; measures to solve $P_{31}$ also include measure 8 and measure 16, namely, improving the reusability of the pump body and the suction and exhaust disc.

However, in terms of the antithetical problems, modifying the design parameters to solve one incompatibility problem will cause another design conflict, which requires innovative ideas to generate the feasible design scheme. This study adopts the proposed strategy models for LCD-AP to solve the antithetical problems $P_{01}$ and $P_{02}$ as below.

(2) Solution to the antithetical problem $P_{01}$ (LCD-AP(II))

$P_{01}$ is a conflicting problem between design goals $\left(g_{11}\right.$ and $\left.g_{12}\right)$ and $g_{22}$ of $\mathrm{CT}_{8}$. To solve $P_{01}$, Figure 16a illustrates the work principle of the SK-15 vacuum pump. It is a variable capacity vacuum pump, which realizes air suction, compression, and exhaust by changing 
the working chamber volumes. When the impeller makes a revolution, each working chamber volume changes from small to large and back to small, and the air sucked from the suction port can be discharged from the exhaust port. Thus, the vacuum pump completes the air suction and exhaust process once a revolution, and increasing the pump volume can promote the work efficiency to some extent, but the design goals $g_{11}$ and $g_{12}$ deteriorate.

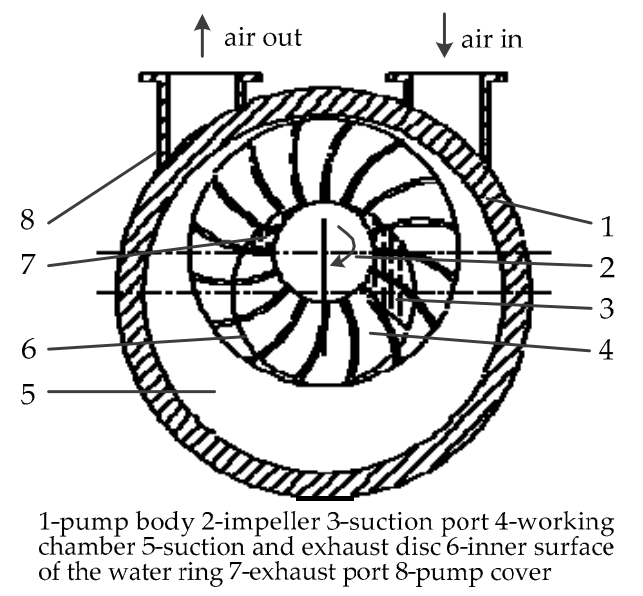

(a)

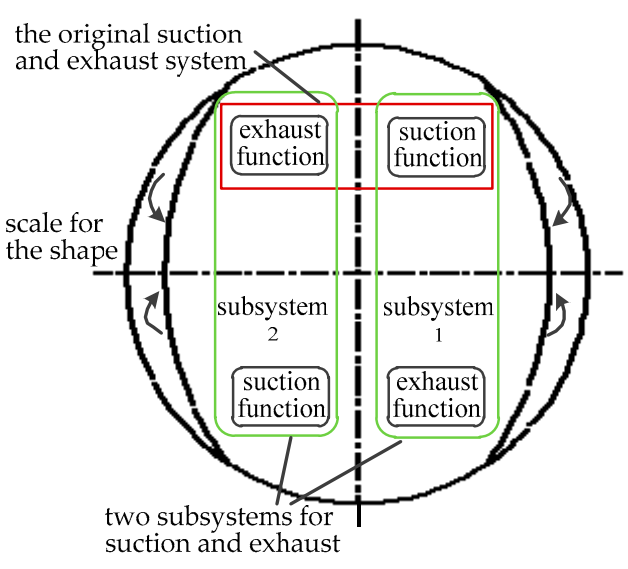

(b)

Figure 16. Principle scheme to solve the antithetical problem $P_{01}$ : (a) work principle of the vacuum pump and (b) principle scheme for adaptation.

According to the result of extensible and conjugate analysis, we adopt the measure of increasing the times of suction and exhaust in one working revolution, and the antithetical problem $P_{01}$ is transformed to get a new design scheme that can realize the function of increasing the times of air suction and exhaust. Inspired by the strategy model for LCDAP(II) in Figure $7\left(b_{2}\right)$, a novel principle scheme for the adaptation of the SK-15 vacuum pump is put forward, as illustrated in Figure 16b. In the new principle scheme, the original suction and exhaust system is replaced by two subsystems, and each subsystem has the air suction function and air exhaust function. Therefore, the vacuum pump can obtain the ability of air suction and exhaust twice in one revolution of the impeller, which improves the work efficiency. Meanwhile, the pump volume can also be appropriately reduced by changing its shape.

Figure 17a illustrates the new conceptual design scheme to solve $P_{01}$; the crosssectional shape of the pump body and pump cover is redesigned to be a similar ellipse, and a new pair of suction and exhaust ports are added to the suction and exhaust disc, and the air passages on the pump cover are also redesigned accordingly. Thus, when the impeller makes a revolution, the vacuum pump can suck and exhaust the air twice to enhance the work efficiency. Furthermore, the working chambers with variable volumes are naturally constructed by an oval-shaped cavity; thus, the impeller is not required to be installed in an eccentric mode and it can make the stress load well-balanced.

(3) Solution to the antithetical problem $P_{02}$ (LCD-AP(I))

Antithetical problem $P_{02}$ comes from the design goal of reducing the inner power consumption caused by the over-compressed air and the design goal of enhancing the adaptability of the suction and exhaust disc to the different requirements for the exhaust pressure. The measure provided for $P_{02}$ based on the extensible and conjugate analysis is to add a pressure-adjusting component for the suction and exhaust disc, which can reduce the air pressure of the working chamber when it is too high and continue to compress the air when the pressure is insufficient. As shown in Figure 17b, a pair of simple and effective pressure-adjusting components composed of the rubber ball valves and the fixing plates with hole slots are designed and installed in the front of each exhaust port. When the working chamber pressure is higher than the exhaust pressure, the air in the working 
chamber can be pre-exhausted through the passages of the rubber ball valves, and when the air pressure of the working chamber does not reach the exhaust pressure, the rubber ball valves will not work, and finally the air is smoothly discharged from the exhaust port. For the different exhaust pressure requirements, we can adjust the location of the rubber ball valves installed in the hole slots of the fixing plates to improve the adaptability of the suction and exhaust disc. In this process, the pressure-adjusting component acts as a connective transforming part corresponding to the strategy model for LCD-AP(I) in Figure $7\left(\mathrm{a}_{2}\right)$, and it successfully solves the conflicting problem that the working chamber pressure needs to be reduced when the air is over-compressed and the working chamber pressure also needs to be increased when the air is under-compressed.

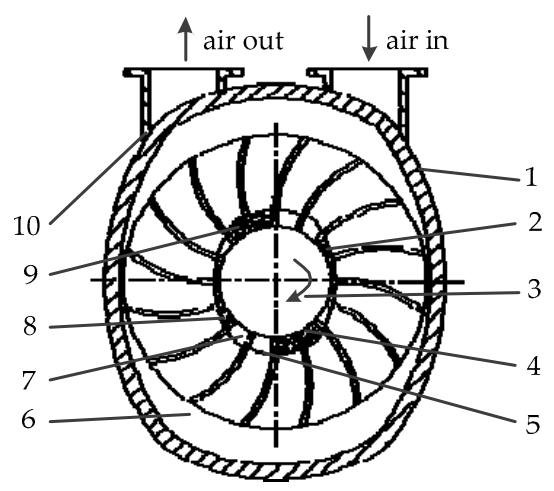

1-pump body 2-exhaust port2 3-impeller 4-suction port1 5-inner surface of the water ring 6-suction and exhaust disc 7 -working chamber 8-exhaust port1 9-suction port2 10-pump cover

(a)

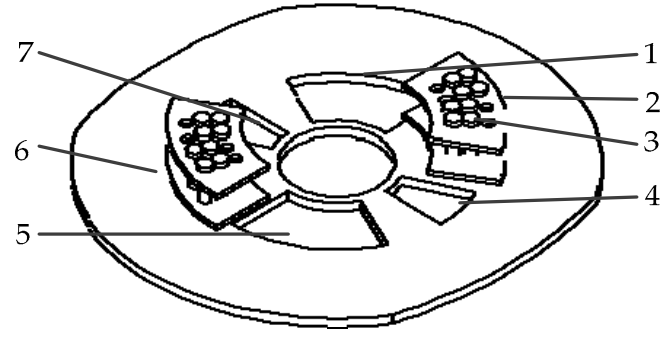

1-suction port2 2-fixing plate with hole slots 3-rubber ball valves 4-exhaust port2 5-suction port1 6-the suction and exhaust disc 7-exhaust port1

\section{(b)}

Figure 17. Solutions to antithetical problems of the vacuum pump: (a) the new conceptual scheme for $P_{01}$ and (b) the new conceptual scheme for $P_{02}$.

Based on the measures for the incompatibility problems and the antithetical problems, the adaptations for components of the SK-15 vacuum pump are provided, as described in Table 8.

Figure 18 presents a comparison result of the CFP information at each life cycle stage of parts before and after adaptation. It demonstrates that the CFP of the improved parts is lower than that of the original parts, especially at the use stage due to the improvement of the suction and exhaust efficiency of the vacuum pump. Additionally, the pre-sale stage is analyzed as well; the CFP information of the pre-sale stage is the sum of the CFP of the raw material stage, manufacturing stage, and distribution stage, which is located at the interval of the Dist. stage, where the CFP of the original parts and improved parts at the pre-sale stage are 5454.0 and $4865.6 \mathrm{kgCO}_{2} \mathrm{e}$, respectively. Figure 18 also reveals that measures such as reducing the volume and mass of parts, selecting appropriate materials, and optimizing structure parameters can help to reduce the CFP of the vacuum pump. 
Table 8. Adaptations for components (cpts) of the SK-15 vacuum pump.

\begin{tabular}{l} 
The Original Design Scheme \\
\hline (1) bearing seat wall thickness is $20 \mathrm{~mm}$; \\
(2) dimensions of the bracket of the bearing seat: the \\
bracket width is $36 \mathrm{~mm}$, the wall thickness is $8 \mathrm{~mm}$; \\
(3) number of the bracket is three; \\
(4) the bearing seat is designed for material recycling. \\
(1) the cross-sectional shape of the pump cover is a circle; \\
(2) the pump cover diameter is $480 \mathrm{~mm}$, the width is \\
124 mm; \\
(3) the eccentricity of the pump cover is $30 \mathrm{~mm}$.
\end{tabular}

\begin{tabular}{|c|c|}
\hline cpt3 & $\begin{array}{l}\text { (1) the suction and exhaust disc has one suction port and } \\
\text { one exhaust port; } \\
\text { (2) there is no pressure-adjusting component applied; } \\
\text { (3) the suction and exhaust disc is designed for material } \\
\text { recycling. }\end{array}$ \\
\hline cpt4 & the shape of the profiling seal ring is a circle. \\
\hline cpt5 & $\begin{array}{l}\text { (1) the cross-sectional shape of the pump body is a circle; } \\
\text { (2) the pump body diameter is } 480 \mathrm{~mm} \text {, the wall thickness } \\
\text { is } 30 \mathrm{~mm} \text {; the width is } 235 \mathrm{~mm} \text {; } \\
\text { (3) the pump body is designed for material recycling. }\end{array}$ \\
\hline
\end{tabular}

(1) the impeller material is copper, the diameter is $400 \mathrm{~mm}$, cpt6 the width is $235 \mathrm{~mm}$;

(2) the material of the shaft is $45 \#$, diameter of the first shaft segment is $60 \mathrm{~mm}$.

the length of the suction and exhaust pipeline is fixed, cpt7 which depends on the length of the pump cover and pump body. the bearing seat stands the dynamic load of the transmission component; it should make a trade-off between the size reduction and the mechanical demand: the bearing seat wall thickness is $16 \mathrm{~mm}$; the bracket width is $40 \mathrm{~mm}$, bracket wall thickness is $15 \mathrm{~mm}$, the number of brackets is two; the bearing seat is redesigned for reuse.

adaptation for the pump cover: the cross-sectional shape is similar to an ellipse, the diameter is $540 \mathrm{~mm}$, the width is $156 \mathrm{~mm}$, the eccentricity is zero; air passages are redesigned to satisfy the function of suction and exhaust twice in one working revolution.

the suction and exhaust disc is modified to improve its reusability and adaptability: it has two pairs of suction and exhaust ports to meet the requirement of suction and exhaust twice in one working revolution; the pressure-adjusting component is designed to reduce the inner power consumption; the part is redesigned for reuse. the profiling seal ring is replaced by an oval-shaped one. adaptation for the pump body: the cross-sectional shape is similar to an ellipse, the diameter is $540 \mathrm{~mm}$, the wall thickness is $16 \mathrm{~mm}$, the width is $210 \mathrm{~mm}$; the pump body is redesigned for reuse by remanufacturing. adaptation for the impeller and the shaft: the material of the impeller is still copper, the diameter is $450 \mathrm{~mm}$, the width is $210 \mathrm{~mm}$; the material of the shaft is still 45\#, diameter of the first shaft segment is $40 \mathrm{~mm}$.

the length of the suction and exhaust pipeline can be adjusted, it can be reused for the series vacuum pumps.

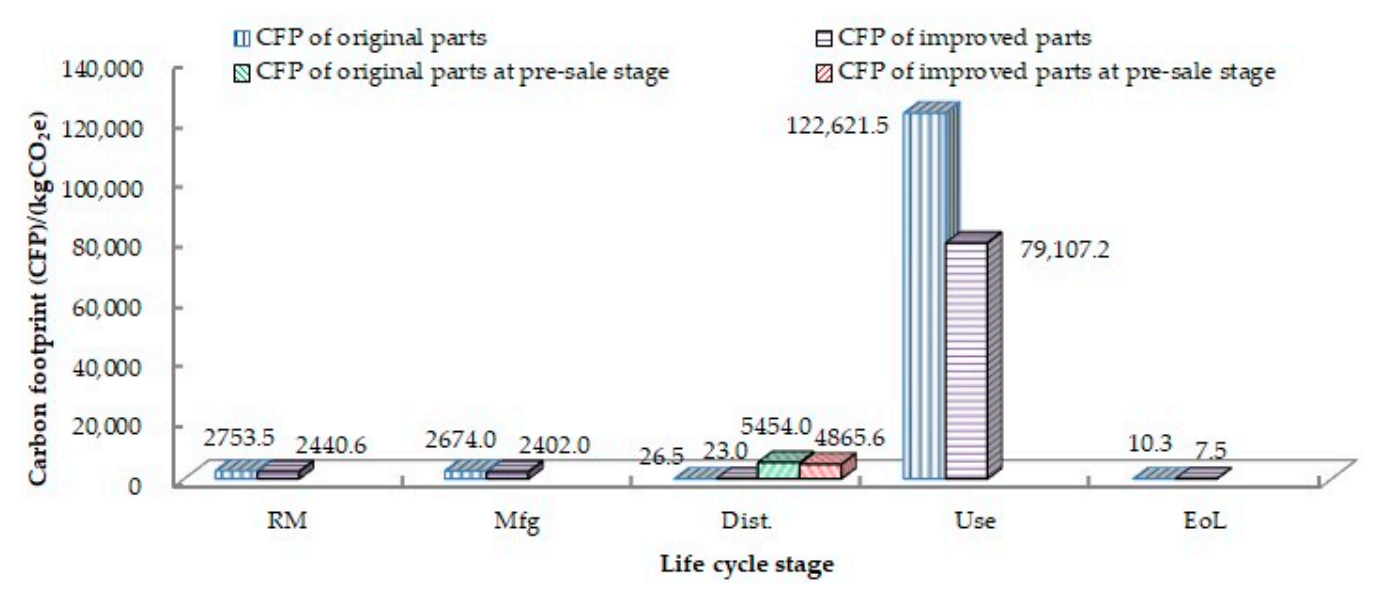

Figure 18. CFP information of vacuum pump parts before and after adaptation.

\subsection{Comparative Performance Assessment against Other Design Problem-Solving Methods}

TRIZ (Theory of Inventive Problem Solving, a Russian acronym), pioneered by Altshuller and his colleagues in the mid-1940s, is another systematic method and widely used to solve contradictions in creative problem solving [59,60]. The eco-design strategy wheel is a strategy-oriented ideation mechanism with environment-related guidelines to 
inspire designers to put forward design ideas for products throughout their whole life cycle [61]. This section conducted a comparative study between the Extenics and TRIZ and the eco-design strategy wheel, and accordingly, the commonly used evaluation indicators were selected [61,62], namely the two process-based criteria: the number of ideas and the variety of ideas generated, which implies the exploration of the design space, and two result-based criteria: the novelty (are the ideas original and unusual?) and the quality (are the ideas feasible and satisfying the design specifications?).

To conduct the comparative study, we recruited twenty students majoring in product design; students all volunteered to join our study, and they were all beginners and had the same level of design experience. Students were divided into four groups by lottery: the no-method aided group, eco-design strategy wheel group, TRIZ group, and Extenics group. The comparative study was a team study; five students in each group were trained in the corresponding method, and they worked together to solve design problems; on the day of the test, the task of low-carbon design for the vacuum pump was assigned; for example, the design for the vacuum pump required less material usage, low carbon emissions, easy reuse for the components, etc.; each group was required to provide possible design ideas within the prescribed $2 \mathrm{~h}$. The arrangement of the comparative study is shown in Table 9.

Table 9. The arrangement of the comparative experiment.

\begin{tabular}{|c|c|c|}
\hline Group & Arrangement & Data Collection and Metrics \\
\hline No-method aided group & $\begin{array}{l}30 \text { min: description of the task; } \\
2 \text { h: design problem clarification and idea } \\
\text { generation. }\end{array}$ & \multirow{4}{*}{$\begin{array}{l}\text { The ideas generated could be recorded by } \\
\text { sound and sketch. } \\
\text { Each method was measured by } \\
\text { evaluating the ideas generated with two } \\
\text { process-based criteria: quantity and } \\
\text { variety, and two result-based criteria: } \\
\text { novelty and quality. }\end{array}$} \\
\hline Eco-design strategy wheel group & $\begin{array}{l}2 \mathrm{~h} \text { : training students in this group for the } \\
\text { eco-design strategy wheel method; } \\
30 \text { min: description of the task; } \\
2 \mathrm{~h} \text { : design problem clarification and idea } \\
\text { generation. }\end{array}$ & \\
\hline TRIZ group & $\begin{array}{l}1 \text { day: training students in this group for TRIZ } \\
\text { method; } \\
30 \text { min: description of the task; } \\
2 \text { h: design problem clarification and idea } \\
\text { generation. }\end{array}$ & \\
\hline Extenics group & $\begin{array}{l}1 \text { day: training students in this group for } \\
\text { Extenics; } \\
30 \text { min: description of the task; } \\
2 \text { h: design problem clarification and idea } \\
\text { generation. }\end{array}$ & \\
\hline
\end{tabular}

After completing the experiment, we analyzed the collected data to obtain the results of four criteria for each group. Figure 19 shows the number of cumulated ideas generated in $2 \mathrm{~h}$ by different groups; it illustrates that the number of ideas generated by the no-method aided group and eco-design strategy wheel group was greater than that of the TRIZ group and Extenics group in $60 \mathrm{~min}$, but it was hard for the former groups to generate new ideas after $60 \mathrm{~min}$, and then the number of ideas was no longer increasing. In contrast, the number of ideas in the TRIZ group and Extenics group was increasing nearly at a constant rate in this phase, which indicated that the TRIZ method and Extenics could effectively stimulate their group students to generate ideas with the analysis tools and knowledge base tools. 


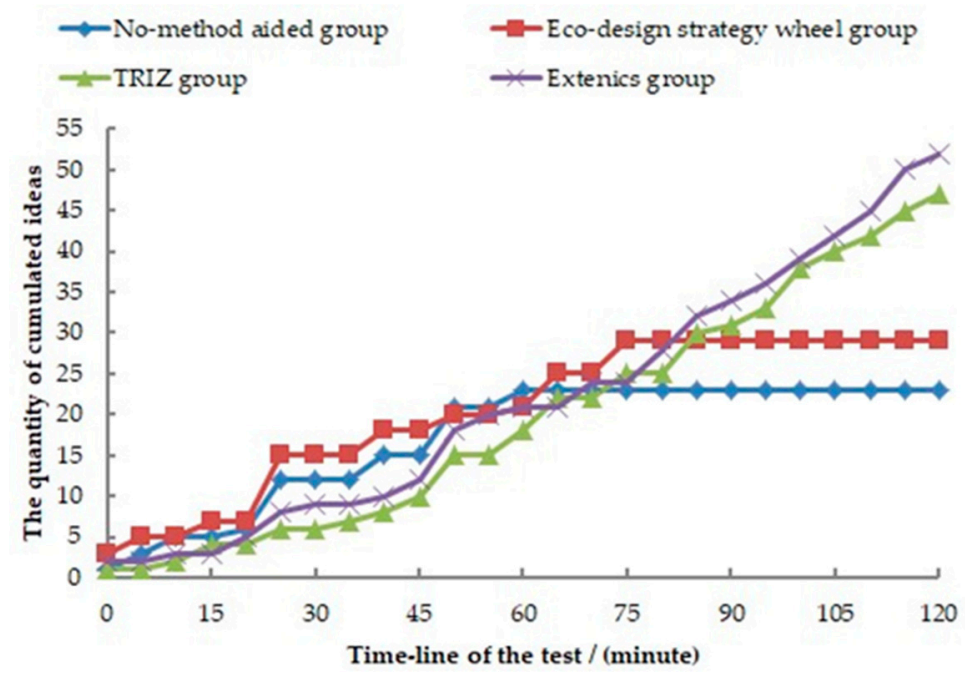

Figure 19. The number of ideas generated in each test group.

To measure the variety of ideas generated, we proposed four levels to explore the design space: the functional principle, structure layout, structure parameter, and low-carbon related strategy. The use of different principles to satisfy the same function makes two ideas more distinct than those that only differ in structure layout level or structure parameters. Table 10 represented the distribution of ideas generated in each group associated with four levels; although the ideas mainly focused on the structure layout level and structure parameter level in each group, the TRIZ group and Extenics group were able to generate more ideas on the functional principle level, namely, they could explore the design space in depth.

Table 10. The distribution of generated ideas on different levels.

\begin{tabular}{lcccc}
\hline Levels of Generated Ideas & $\begin{array}{c}\text { No-Method Aided } \\
\text { Group }\end{array}$ & $\begin{array}{c}\text { Eco-Design Strategy } \\
\text { Wheel Group }\end{array}$ & TRIZ Group & Extenics Group \\
\hline Functional principle & 2 & 3 & 8 & 6 \\
Structure layout & 7 & 6 & 12 & 21 \\
Structure parameter & 11 & 12 & 19 & 16 \\
Low-carbon related strategy & 3 & 8 & 8 & 9 \\
\hline
\end{tabular}

Considering the novelty and quality of ideas, three eco-design experts were required to score each idea generated in each group; Table 11 describes the scoring rule. For the novelty scoring, experts should identify whether the generated idea adopted a novel principle to realize the main functions of the vacuum pump, including the power transmission function, suction and exhaust function, and sealing function, and whether the idea was beneficial to environmental protection. If the generated idea adopted the conventional principles and structure layout to realize the main functions, then the score was equal to 1 , which indicated that the novelty of the idea was low; if the main functions were achieved with novel principles and structure layout by the generated idea, then the score was equal to 2 , which indicated the novelty of the idea was moderate; furthermore, if the generated idea adopted a novel principle and structure to realize the main functions, and the design scheme also had good environmental performance, then the score was equal to 3 , which indicated the novelty of the idea was high. 
Table 11. Scoring rule for novelty and quality of the generated idea.

\begin{tabular}{clll}
\hline Criterion & \multicolumn{1}{c}{ Score $=\mathbf{1}$} & \multicolumn{1}{c}{ Description of the Scoring Rule } \\
\cline { 2 - 5 } Novelty & $\begin{array}{l}\text { Function realization with } \\
\text { conventional principle and } \\
\text { structure layout. }\end{array}$ & $\begin{array}{l}\text { Function realization with novel } \\
\text { principle and structure layout. }\end{array}$ & $\begin{array}{l}\text { Function realization with novel } \\
\text { principle and structure layout, } \\
\text { and the design scheme has good } \\
\text { environmental improvement } \\
\text { potential. }\end{array}$ \\
\hline Quality & $\begin{array}{l}\text { Specifications of low-carbon } \\
\text { related quality characteristics } \\
\text { were satisfied, but the } \\
\text { specifications of the basic } \\
\text { quality characteristics could not } \\
\text { be met. }\end{array}$ & $\begin{array}{l}\text { Specifications of basic quality } \\
\text { characteristics were satisfied, } \\
\text { but specifications of low-carbon } \\
\text { related quality characteristics } \\
\text { could not be met. }\end{array}$ & $\begin{array}{l}\text { Both specifications of basic } \\
\text { quality characteristics and } \\
\text { low-carbon related quality } \\
\text { characteristics were satisfied. }\end{array}$ \\
\hline
\end{tabular}

For quality scoring, experts were required to evaluate whether the initial specifications of basic quality characteristics (the rate of suction and exhaust, ultimate pressure, and cost) and the specifications of low-carbon related quality characteristics (environmental impact and carbon footprint) were satisfied by the generated ideas. If the generated idea could satisfy specifications of low-carbon related quality characteristics, but the specifications of basic quality characteristics could not be met, then the score was equal to 1 ; if the specifications of basic quality characteristics could be satisfied in the generated idea, and the specifications of low-carbon related quality characteristics were not satisfied, then the score was equal to 2; and if the design specifications of basic quality characteristics and low-carbon related quality characteristics both could be satisfied, then the score was equal to 3 .

To obtain the final result, the score of one idea about one certain criterion was the sum of three experts' scores, and the score for the idea could only be was 7,8 , or 9 if only one certain criterion could be taken into account. Figure 20 shows the number of ideas that met the condition about the novelty and quality.

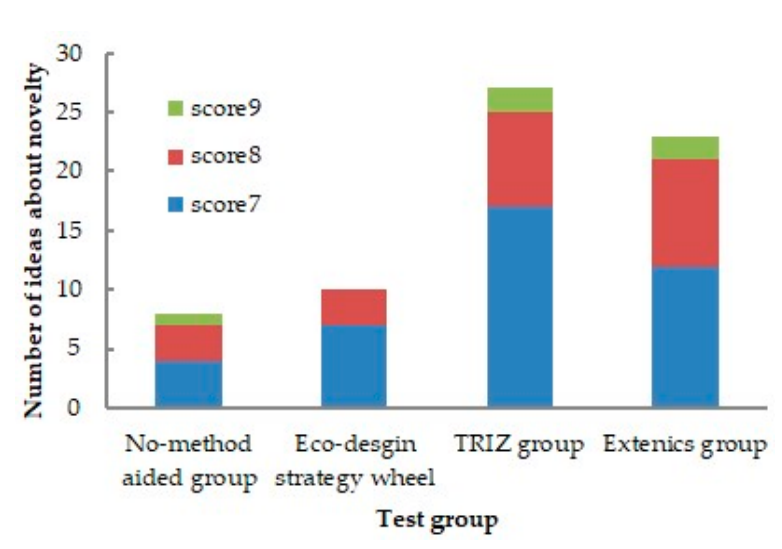

(a)

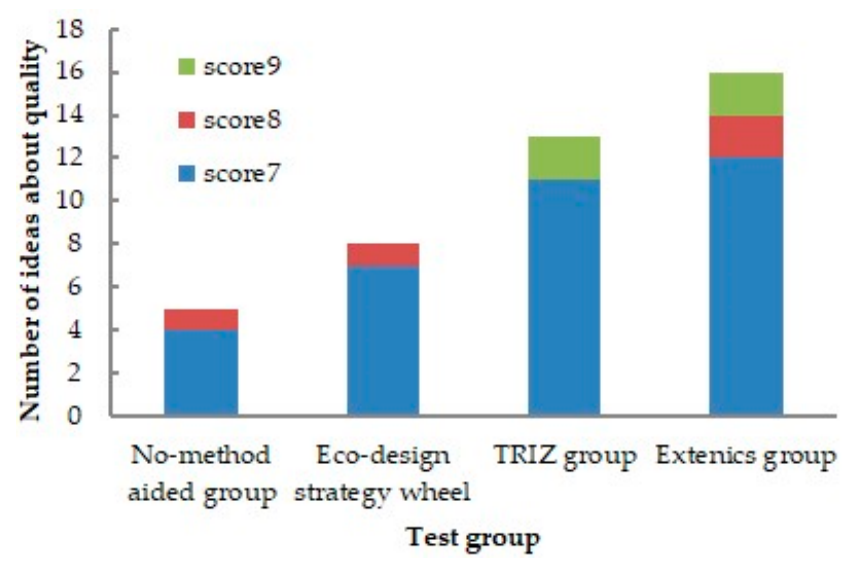

(b)

Figure 20. Comparative analysis of the result-based criteria: (a) number of ideas with the score was 7, 8, and 9 for novelty; (b) number of ideas with the score 7, 8, and 9 for the quality.

Figure 20 illustrates that the proportions of the generated ideas for which the score was greater than or equal to 7 regarding the novelty in the no-method aided group, eco-design strategy wheel group, TRIZ group, and Extenics group were, respectively, 34.78\%, 34.48\%, $57.45 \%$, and $44.23 \%$, and $21.74 \%, 27.59 \%, 27.66 \%$, and $30.77 \%$ regarding the quality. It could be observed that the TRIZ group generated the most ideas that were considered novel, and the Extenics group generated the most ideas that were considered quality. 
In conclusion, the effective design problem-solving method Extenics has good performance both on process-based criteria quantity and variety and the result-based criteria novelty and quality in our comparative study, which verifies that Extenics can help designers generate creative ideas to solve contradictory problems in low-carbon product design.

\section{Discussion}

Low-carbon product design incorporates the low-carbon indicators into the original design system; it not only involves the parametric design problem, but also the design concept generation problem. However, the current literature of low-carbon product design is largely silent on the systematic methodology that provides strategies and ideas for conceptual scheme generation through design contradiction solving. In this paper, a low-carbon product design configuration methodology that integrates the configuration tasks sequencing model and Extenics-based contradictory problem-solving method into a comprehensive framework is proposed. A case study of an academic example concerning the vacuum pump low-carbon design along with a comparative study is conducted to verify the feasibility of the proposed methodology, and the implications of our research work are discussed below.

(1) The contribution of this paper

The purpose of this paper is to address two issues associated with low-carbon product design mentioned in the introduction section. The contribution of this study is the novel combination of a configuration tasks sequencing model based on the GA-DSM method and the Extenics theory; it is also novel in some methodology steps. In the configuration tasks sequencing model, the contribution is that we designated the configuration tasks and corresponding configuration parameters through quality characteristics and proposed the estimation model of associated values of correlated configuration tasks. In the Extenicsbased contradiction-solving method, the contribution is that we clarified and formulated the low-carbon design incompatibility problem LCD-IP and two types of low-carbon design antithetical problems, LCD-AP(I) and LCD-AP(II), and provide two strategy models for LCD-AP(I) and LCD-AP(II), respectively.

(2) The information flow diagram and the Gantt chart

The information flow diagram is constructed for the configuration tasks, while the Gantt chart is built for the measures that were included in the corresponding CTs.

This study constructs the information flow diagram of CTs to help designers effectively coordinate the configuration parameters among CTs and reduce the number of trial-and-error iterations in backtracking analysis; for coupled CTs, configuration tasks $\mathrm{CT}_{i}$ and $\mathrm{CT}_{j}$ are interdependent, as $\mathrm{CT}_{i}$ depends on the output configuration parameter of $\mathrm{CT}_{j}$, and $\mathrm{CT}_{j}$ also depends on the output configuration parameter of $\mathrm{CT}_{i}$, and thus the necessary backtracking analysis is still needed for coupled CTs even if the information flow diagram is provided. Therefore, when only considering the coordination for configuration parameters, the iteration in this study has a similar meaning to the classical iteration in general design research.

However, the iteration in this study is also associated with design contradiction solving; based on the information flow diagram of CTs, the Gantt chart of measures execution is constructed to solve the contradictory problems in each configuration task with a reasonable sequence. In order to reduce the iterations for design contradiction solving, contradictory problems in $\mathrm{CT}_{i}$ may be mapped to $\mathrm{CT}_{j}$ for solving, as $\mathrm{CT}_{i}$ and $\mathrm{CT}_{j}$ are dependent or interdependent. For example, for the Gantt chart in Figure 15, contradictory problems $P_{11}-P_{16}$ in $\mathrm{CT}_{8}<$ consideration of CFP, environmental impact> should be mapped onto the $\mathrm{CT}_{7}<$ control the volume and mass $>$, that is, the modification for the problematic parts should be conducted in $\mathrm{CT}_{7}$. In this aspect, the iteration associated with contradictory problem solving is different from the classical iteration.

In addition, the definition of configuration tasks is different from the definition in the reference [63], where configuration tasks are defined as the special type of design activities to design an artifact only by assembling the predefined components together. In 
our study, we make the assumption that there are not predefined components that can be directly used to replace the problematic components with high carbon emissions; thus, configuration tasks in this paper not only refer to the reuse of predefined components that are satisfied with low-carbon demand, but also involve measures to improve the environmental impact of the problematic components in four aspects, functional principle, structure layout, structure parameter, and low-carbon related strategy.

(3) Explanation for the comparative study

In the comparative experiment, the ideas proposed by each group of students are conceptual schemes, and no specific configuration tasks are involved to realize these schemes, that is, students only used the contradiction-solving methods to put forward possible design ideas for the design requirements.

The proposed low-carbon configuration method is mainly to solve two issues; for the issue about configuration task arrangement, this study constructs the information flow diagram for configuration tasks to reduce the trial-and-error iterations during the configuration process. We consider that the implementation of low-carbon configuration in which all configuration tasks are well scheduled would be more effective and efficient than the implementation of the configuration process where configuration tasks are not well arranged; thus, we do not make the comparative analysis for the constructed information flow model.

For another issue about low-carbon design contradictions, the Extenics-based contradictory problem-solving model is presented to help designers generate innovative design strategies and ideas for addressing low-carbon design incompatibility and antithetical problems. In order to make the research more solid and valid, we conducted a comparative study between the Extenics, TRIZ, and eco-design strategy wheel; the result shows that Extenics has good performance both on the process-based criteria and result-based criteria.

In addition, the comparative study is a team study; five students in each group work together to solve the vacuum pump low-carbon design problem, and we obtained the obvious results to verify the performance of the Extenics. However, if there were more students in each group, such as thirty students in each group, or there were more teams in each condition, then the experimental results would be more reasonable.

(4) Application of proposed methodology

In low-carbon product optimization design, the optimization model and algorithm can be used to obtain the optimal design parameters, and then low-carbon product design is considered as a parametric design problem; however, low-carbon product design also belongs to the design concept generation problem, and designers are required to put forward innovative design schemes to reconfigure the design requirements that are considering the low-carbon demand. The current research on low-carbon product design lacks systematic design theories and methods to help designers produce innovative ideas to solve the design concept generation problem. The commonly used creative method is TRIZ, which provides designers with innovative principles to solve technical and physical contradictions for generating novel design schemes. This study presents an Extenics-based design-contradiction-solving method, which helps designers produce strategies and ideas to address low-carbon design incompatibility and antithetical problems; on the other hand, the information flow diagram of the configuration tasks is constructed along with the Gantt chart of measures execution for design contradiction solving, which improves the efficiency of the low-carbon configuration.

In terms of the product design and development, design activities need to be carried out according to different design purposes such as product redesign and adaptive design, design schemes need to be adjusted quickly according to user requirements, and design contradictions and design changes with iterations will also arise in this process. Thus, the proposed methodology could also be applicable to these design activities; Extenics is used to solve the design contradictions, and design activities could be reasonably scheduled based on the information flow model to reduce the trial-and-error iterations. 


\section{Conclusions}

The low-carbon demand requires designers to conduct the reconfiguration tasks for the original equilibrium design system. However, the low-carbon design incompatibility and antithetical problems are emerging from the configuration process; designers need to solve design contradictions and put forward new principle solutions. On the other hand, the input and output configuration information of each configuration task in the configuration process greatly depends on each other; it is essential to make an arrangement for the implementation of CTs with minimum feedback. For these problems, this paper proposes an Extenics-based scheduled configuration methodology to support low-carbon product design by providing the sequencing model for CTs and the effective design-contradictionsolving method.

Low-carbon requirements are mapped to QCs and ECs through the QFD method, and accordingly, CTs and configuration parameters are designated. The directed network along with associated values of CTs are mapped onto an activity-based DSM to construct the IFD of CTs. The Extenics-based contradictory problem-solving model in this methodology is introduced, the low-carbon incompatibility problem and two types of low-carbon antithetical problems are clarified and formulated with basic-element model, and two strategy models for antithetical problems are established; extensible and conjugate analysis tools are used to provide feasible measures. Based on the information flow diagram of CTs, the Gantt chart of measures execution could be established, which helps designers effectively complete configuration tasks for the low-carbon requirements. The proposed methodology is used for the vacuum pump low-carbon design; the results show that the improved design scheme of the vacuum pump is more environmentally friendly than the previous one, and the comparative analysis indicates that Extenics has good performance based on both the process-based criteria for generated ideas, quantity and variety, and the result-based criteria, novelty and quality.

This paper presents an IFD construction model for CTs, which is useful for reducing the number of trial-and-error iterations in the reconfiguration process. However, considering the complex configuration tasks that need to be decomposed according to the configuration parameters, it is necessary to integrate the component-based DSM and activity-based DSM to construct the IFD for fine-grained CTs. For the contradictory problem solving, it is also essential to develop a knowledge management platform to share and reuse the basic-element model knowledge obtained from the contradiction-solving process by means of computer-aided design technologies.

Author Contributions: Conceptualization, S.R. and Y.Z.; methodology, S.R. and F.G.; validation, S.R.; data curation and software, F.G. and M.Z.; visualization, F.G. and J.Z.; formal analysis, W.W. and M.Z.; investigation, S.R. and J.Z.; writing—original draft preparation, S.R. and M.Z.; writing—review and editing, S.R., Y.Z. and J.Z.; supervision, S.R; project administration, S.R. and W.W.; funding acquisition, Y.Z. and S.R. All authors have read and agreed to the published version of the manuscript.

Funding: This research was supported by National Natural Science Foundation of China (51875524, 52005444), Zhejiang Province Public Welfare Technology Application Research Project (LGG19F020005), and Zhejiang Province Postdoctoral Research Foundation (zj2019130).

Institutional Review Board Statement: Not applicable.

Informed Consent Statement: Not applicable.

Data Availability Statement: The data used to support the results of this study is available from the corresponding author by request.

Conflicts of Interest: The authors declare no conflict of interest. 


\section{Abbreviations and Symbols}

$\begin{array}{ll}\text { CFP } & \text { Carbon footprint } \\ \text { CTs } & \text { Configuration tasks } \\ \text { DSM } & \text { Design structure matrix } \\ \text { ECs } & \text { Engineering characteristics } \\ \text { FI } & \text { Feedback information } \\ \text { IFD } & \text { Information flow diagram } \\ \text { LCD-AP(I) } & \text { Low-carbon design antithetical problem (I) } \\ \text { LCD-AP(II) } & \text { Low-carbon design antithetical problem (II) } \\ \text { LCD-IP } & \text { Low-carbon design incompatibility problem } \\ \text { MA } & \text { Configuration Matrix } \\ \text { QCs } & \text { Quality characteristics } \\ \text { QFD } & \text { Quality function deployment } \\ \text { TRIZ } & \text { Theory of inventive problem solving, a Russian acronym } \\ \text { Symbols } & \\ d_{i, j} & \text { Associated value that } \mathrm{CT}_{i} \text { depends on } \mathrm{CT}_{j} \\ \omega_{k} & \text { Relative weight of } \mathrm{EC}_{\mathrm{k}} \\ x_{i, j} & \text { The input configuration parameter for } \mathrm{CT}_{i} \text { provided by } \mathrm{CT}_{j} \\ \gamma_{j, k} & \text { Relational strength of } \mathrm{QC}_{j} \text { and } \mathrm{EC}_{k} \\ \text { Symbols in Extenics } & \end{array}$

(1) Symbols for problems clarification and formulation

$\begin{array}{ll}M(\mathrm{~m}) & \text { Matter-element model } \\ R(\mathrm{r}) & \text { Relation-element model } \\ A(\mathrm{a}) & \text { Affair-element model } \\ \mathrm{Z}(\mathrm{O}) & \text { Compound-element model } \\ P & \text { Design problem } \\ g & \text { Design goal } \\ l & \text { Design condition }\end{array}$

(2) Symbols for extensible analysis
$A \dashv\left\{A_{1}, A_{2}, \ldots\right\}$
$A_{1}, A_{2}, \ldots$ are generated by the divergent analysis for $A$
$\mathrm{A} \sim \mathrm{B}$
$A$ and $B$ have correlative relationship
$\mathrm{A} \Rightarrow \mathrm{B}$
$\mathrm{A}$ is the lower-level design goal of $\mathrm{B}$ in implication analysis
$\mathrm{A} \oplus \mathrm{B}, \mathrm{A} \otimes \mathrm{B}, \mathrm{A} / /\left\{\mathrm{A}_{1}, \mathrm{~A}_{2}, \ldots\right\}$
In opening-up analysis, put A and B together with symbol $\oplus$, integrate $A$ and $B$ into an unit with symbol $\otimes, A$ is decomposed into $A_{1}, A_{2}, \ldots$ with symbol//

(3) Symbols for conjugate analysis
$\operatorname{im}\left(O_{\mathrm{m}}\right), \operatorname{re}\left(O_{\mathrm{m}}\right)$
$\operatorname{sf}\left(O_{\mathrm{m}}\right), \operatorname{hr}\left(O_{\mathrm{m}}\right)$
Nonmaterial part and material part of object $O_{\mathrm{m}}$
$\operatorname{ng}_{\mathrm{c}}\left(O_{\mathrm{m}}\right), \operatorname{ps}_{\mathrm{c}}\left(O_{\mathrm{m}}\right)$
Soft part and hard part of object $O_{\mathrm{m}}$
$\operatorname{lt}\left(O_{\mathrm{m}}\right), \operatorname{ap}\left(O_{\mathrm{m}}\right)$
Negative and positive part of object $O_{\mathrm{m}}$ about characteristic c
Latent part and apparent part of object $O_{\mathrm{m}}$

\section{Appendix A}

Table A1. Conclusion of the design problems for $\mathrm{CT}_{8}, \mathrm{CT}_{9}$, and $\mathrm{CT}_{10}$.

\begin{tabular}{ccll}
\hline $\mathbf{C T}_{\boldsymbol{i}}$ & Design Problem & \multicolumn{1}{c}{ Design Goal of the Problem } & \multicolumn{1}{c}{ Design Condition of the Problem } \\
\hline & $P_{11}=g_{11} \uparrow l_{11}$ & reduce the volume and mass of part 1 & design information of part 1 \\
$P_{12}=g_{12} \uparrow l_{12}$ & reduce the volume and mass of part 2 & design information of part 2 \\
$P_{13}=g_{13} \uparrow l_{13}$ & reduce the volume and mass of part 15 & design information of part 15 \\
& $P_{14}=g_{14} \uparrow l_{14}$ & reduce the volume and mass of part 24 & design information of part 24 \\
& $P_{15}=g_{15} \uparrow l_{15}$ & reduce the volume and mass of part 18 & design information of part 18 \\
& $P_{16}=g_{16} \uparrow l_{16}$ & reduce the volume and mass of part 6 & design information of part 12 \\
$P_{21}=g_{21} \uparrow l_{21}$ & reduce the inner power consumption & working state of the vacuum pump \\
$\mathrm{CT}_{8}$ & $P_{22}=g_{22} \uparrow l_{22}$ & enhance the work efficiency & design information of part $1,2,6,12,15,18,24$ \\
& $P_{31}=g_{31} \uparrow l_{31}$ & improve the reusability of the parts & design information of part 12,24 \\
& $P_{32}=g_{32} \uparrow l_{32}$ & improve the adaptability of the parts & \\
\hline
\end{tabular}


Table A1. Cont.

\begin{tabular}{|c|c|c|c|}
\hline $\mathrm{CT}_{i}$ & Design Problem & Design Goal of the Problem & Design Condition of the Problem \\
\hline & $P_{01}=\left(\left(g_{11}, g_{12}\right)^{\wedge} g_{22}\right) \uparrow l_{01}$ & $\begin{array}{l}\text { reduce the volume and mass of part } 1,2 \\
\text { enhance the work efficiency }\end{array}$ & $\begin{array}{l}\text { design information of part } 1,2 \\
\text { working state of the vacuum pump }\end{array}$ \\
\hline & $P_{02}=\left(g_{211} \hat{g} g_{212}\right) \uparrow l_{21}$ & $\begin{array}{l}\text { reduce the working chamber air pressure } \\
\text { increase the working chamber air pressure }\end{array}$ & $\begin{array}{l}\text { design information of the suction and } \\
\text { exhaust disc }\end{array}$ \\
\hline \multirow[t]{2}{*}{$\mathrm{CT}_{9}$} & $P_{1}=g_{1} \downarrow l_{1}$ & maintenance of the continuous working parts & $\begin{array}{l}\text { design information of continuous } \\
\text { working parts }\end{array}$ \\
\hline & $P_{2}=g_{2} \downarrow l_{2}$ & maintenance of the sealing parts & design information of sealing parts \\
\hline $\mathrm{CT}_{10}$ & $\begin{array}{l}P_{11}=g_{11} \uparrow l_{11} \\
P_{12}=g_{12} \uparrow l_{12} \\
P_{21}=g_{21} \uparrow l_{21} \\
P_{22}=g_{22} \downarrow l_{22}\end{array}$ & $\begin{array}{l}\text { material selection of the transmission shaft } \\
\text { material selection of the impeller } \\
\text { improve the recycling methods for parts } \\
\text { improve the disposal methods for parts }\end{array}$ & $\begin{array}{l}\text { design information of the transmission shaft } \\
\text { design information of the impeller } \\
\text { current recycling measures for the parts } \\
\text { current disposal measures for the parts }\end{array}$ \\
\hline
\end{tabular}

“ $\uparrow$ " denotes design condition $l$ cannot satisfy design goal $g$; “ $\downarrow$ ” denotes design condition $l$ can satisfy design goal $g$. part 1: pump cover, part 2: pump body, part 6: transmission shaft, part 12: suction and exhaust disc, part 15: impeller, part 18: bearing seat, part 24: suction and exhaust pipeline.

\section{References}

1. Mesa, J.A.; Esparragoza, I.; Maury, H. Trends and perspectives of sustainable product design for open architecture products: Facing the circular economy model. Int. J. Precis Eng. Manuf. Green Technol. 2019, 6, 377-391. [CrossRef]

2. Cagno, E.; Neri, A.; Howard, M.; Brenna, G.; Trianni, A. Industrial sustainability performance measurement systems: A novel framework. J. Clean. Prod. 2019, 230, 1354-1375. [CrossRef]

3. Kellens, K.; Dewulf, W.; Overcash, M.; Hauschild, M.Z.; Duflou, J.R. Methodology for systematic analysis and improvement of manufacturing unit process life cycle inventory (UPLCI) CO2PE! initiative (cooperative effort on process emissions in manufacturing). Part 2: Case studies. Int. J. Life Cycle Assess. 2011, 17, 242-251. [CrossRef]

4. Ceschin, F.; Gaziulusoy, I. Evolution of design for sustainability: From product design to design for system innovations and transitions. Design Stud. 2016, 47, 118-163. [CrossRef]

5. He, B.; Li, F.F.; Cao, X.Y.; Li, T.Y. Product sustainable design: A review from the environmental, economic, and social aspects. J. Comput. Inf. Sci. Eng. 2020, 20, 040801. [CrossRef]

6. Kuo, T.C.; Chen, H.M.; Liu, C.Y.; Tu, J.C.; Yeh, T.C. Applying multi-objective planning in low-carbon product design. Int. J. Precis. Eng. Manuf. 2014, 15, 241-249. [CrossRef]

7. He, B.; Wang, J.; Huang, S.; Wang, Y. Low-carbon product design for product life cycle. J. Eng. Des. 2015, 26, 321-339. [CrossRef]

8. Vukelic, D.; Boskovic, N.; Agarski, B.; Radonic, J.; Budak, I.; Pap, S.; Turk Sekulic, M. Eco-design of a low-cost adsorbent produced from waste cherry kernels. J. Clean. Prod. 2018, 174, 1620-1628. [CrossRef]

9. Ahmad, S.; Wong, K.Y.; Tseng, M.L.; Wong, W.P. Sustainable product design and development: A review of tools, applications and research prospects. Resour. Conserv. Recycl. 2018, 132, 49-61. [CrossRef]

10. Qureshi, M.I.; Rasiah, R.A.l.; Al-Ghazali, B.M.; Haider, M.; Jambari, H.; Iswan; Sasmoko. Modeling work practices under socio-technical systems for sustainable manufacturing performance. Sustainability 2019, 11, 4294. [CrossRef]

11. Yang, C.Y.; Cai, W. Extenics: Theory, Method and Application; Science Press: Beijing, China, 2013.

12. Chandrasegaran, S.K.; Ramani, K.; Sriram, R.D.; Horváth, I.; Bernard, A.; Harik, R.F.; Gao, W. The evolution, challenges, and future of knowledge representation in product design systems. Comput. Aided Des. 2013, 45, 204-228. [CrossRef]

13. Tong, C.; Sriram, R.D. Artificial Intelligence in Engineering Design; Academic Press: Boston, MA, USA, 1992.

14. Kusiak, A.; Wang, J. Decomposition of the design process. J. Mech. Des. 1993, 115, 687-695. [CrossRef]

15. Browning, T.R. Applying the design structure maxtrix to system decomposition and integration problems: A review and new directions. IEEE Trans. Eng. Manag. 2001, 48, 292-306. [CrossRef]

16. Wang, Q.; Tang, D.B.; Yin, L.L.; Salido, M.A.; Giret, A.; Xu, Y.C. Bi-objective optimization for low-carbon product family design. Robot. Cim. Int. Manuf. 2016, 41, 53-65. [CrossRef]

17. Su, J.C.P.; Chu, C.H.; Wang, Y.T. A decision support system to estimate the carbon emission and cost of product designs. Int. J. Precis. Eng. Manuf. 2012, 13, 1037-1045. [CrossRef]

18. Branker, K.; Jeswiet, J.; Kim, I.Y. Greenhouse gases emitted in manufacturing a product-A new economic model. CIRP Ann. Manuf. Technol. 2011, 60, 53-56. [CrossRef]

19. He, B.; Pan, Q.J.; Deng, Z.Q. Product carbon footprint for product life cycle under uncertainty. J. Clean. Prod. 2018, 187, 459-472. [CrossRef]

20. De Koning, A.; Schowanek, D.; Dewaele, J.; Weisbrod, A.; Guinée, J. Uncertainties in a carbon footprint model for detergents; quantifying the confidence in a comparative result. Int. J. Life Cycle Assess. 2009, 15. [CrossRef]

21. Anand, A.; Wani, M.F. Product life-cycle modeling and evaluation at the conceptual design stage: A digraph and matrix approach. J. Mech. Des. 2010, 132, 091010. [CrossRef] 
22. Ren, S.D.; Gui, F.Z.; Zhao, Y.W.; Xie, Z.W.; Hong, H.H.; Wang, H.W. Accelerating preliminary low-carbon design for products by integrating TRIZ and Extenics methods. Adv. Mech. Eng. 2017, 9, 1-18. [CrossRef]

23. Peng, J.; Li, W.Q.; Li, Y.; Xie, Y.M.; Xu, Z.L. Innovative product design method for low-carbon footprint based on multi-layer carbon footprint information. J. Clean. Prod. 2019, 228, 729-745. [CrossRef]

24. Pigosso, D.C.A.; Ferraz, M.; Teixeira, C.E.; Rozenfeld, H. The deployment of product-related environmental legislation into product requirements. Sustainability 2016, 8, 332. [CrossRef]

25. He, B.; Tang, W.; Huang, S.; Hou, S.C.; Cai, H.X. Towards low-carbon product architecture using structural optimization for lightweight. Int. J. Adv. Manuf. Technol. 2015, 83, 1419-1429. [CrossRef]

26. Lu, Q.; Zhou, G.H.; Xiao, Z.D.; Chang, F.T.; Tian, C.L. A selection methodology of key parts based on the characteristic of carbon emissions for low-carbon design. Int. J. Adv. Manuf. Technol. 2017, 94, 3359-3373. [CrossRef]

27. ISO. ISO 14040 Environmental Management-Life Cycle Assessment-Principles and Framework; International Organization for Standardization: Geneva, Switzerland, 2006.

28. BSI. The Guide to PAS 2050: 2011 How to Carbon Footprint Your Products, Identify Hotspots and Reduce Emissions in Your Supply Chain; British Standards Institution: London, UK, 2011.

29. Song, J.S.; Lee, K.M. Development of a low-carbon product design system based on embedded GHG emissions. Resour. Conserv. Recycl. 2010, 54, 547-556. [CrossRef]

30. Zhang, X.F.; Zhang, S.Y.; Hu, Z.Y.; Yu, G.; Pei, C.H.; Sa, R.N. Identification of connection units with high GHG emissions for low-carbon product structure design. J. Clean. Prod. 2012, 27, 118-125. [CrossRef]

31. Gui, F.Z.; Ren, S.D.; Zhao, Y.W.; Zhou, J.Q.; Xie, Z.W.; Xu, C.; Zhu, F. Activity-based allocation and optimization for carbon footprint and cost in product lifecycle. J. Clean. Prod. 2019, 236, 117627. [CrossRef]

32. Xu, Z.Z.; Wang, Y.S.; Teng, Z.R.; Zhong, C.Q.; Teng, H.F. Low-carbon product multi-objective optimization design for meeting requirements of enterprise, user and government. J. Clean. Prod. 2015, 103, 747-758. [CrossRef]

33. Zhang, C.; Huang, H.H.; Zhang, L.; Bao, H.; Liu, Z.F. Low-carbon design of structural components by integrating material and structural optimization. Int. J. Adv. Manuf. Technol. 2018, 95, 4547-4560. [CrossRef]

34. Hu, L.K.; Tang, R.Z.; He, K.Y.; Jia, S. Estimating machining-related energy consumption of parts at the design phase based on feature technology. Int. J. Prod. Res. 2015, 53, 7016-7033. [CrossRef]

35. Zhang, Y.; Wang, H.P.; Zhang, C. Green QFD-II: A life cycle approach for environmentally conscious manufacturing by integrating LCA and LCC into QFD matrices. Int. J. Prod. Res. 1999, 37, 1075-1091. [CrossRef]

36. Bereketli, I.; Erol Genevois, M. An integrated QFDE approach for identifying improvement strategies in sustainable product development. J. Clean. Prod. 2013, 54, 188-198. [CrossRef]

37. Puglieri, F.N.; Ometto, A.R.; Salvador, R.; Barros, M.V.; Piekarski, C.M.; Rodrigues, I.M.; Diegoli Netto, O. An environmental and operational analysis of quality function deployment-based methods. Sustainability 2020, 12, 3486. [CrossRef]

38. Devanathan, S.; Ramanujan, D.; Bernstein, W.Z.; Zhao, F.; Ramani, K. Integration of sustainability into early design through the function impact matrix. J. Mech. Des. 2010, 132, 081004. [CrossRef]

39. Sakao, T. A QFD-centred design methodology for environmentally conscious product design. Int. J. Prod. Res. 2007, 45, 4143-4162. [CrossRef]

40. Cai, W.; Yang, C.Y. Basic theory and methodology on Extenics. Chin. Sci. Bull. 2013, 58, 1190-1199. [CrossRef]

41. Rittel, H.W.J.; Webber, M.M. Dilemmas in a general theory of planning. Policy Sci. 1973, 4, 155-169. [CrossRef]

42. Feng, Y.X.; Hao, H.; Tan, J.R.; Hagiwara, I. Variant design for mechanical parts based on extensible logic theory. Int. J. Mech. Mater. Des. 2010, 6, 123-134. [CrossRef]

43. Li, J.; Zhong, S.S.; Jin, L.; Lin, L. Research on modular design methods based on extension theory. Comput. Integ. Manuf. Syst. 2006, 12, 641-647. [CrossRef]

44. Li, W.J.; Song, Z.H.; Mao, E.R.; Suh, S. Using Extenics to describe coupled solutions in Axiomatic design. J. Eng. Des. 2018, 30, 1-31. [CrossRef]

45. Tang, L.; Yang, C.Y.; Li, W.H. Adopting gene expression programming to generate extension strategies for incompatible problem. Neural Comput. Appl. 2016, 28, 2649-2664. [CrossRef]

46. Chen, A.L.; Dong, L.; Liu, W.; Li, X.S.; Sao, T.M.; Zhang, J. Study on the mechanism of improving creative thinking capability based on Extenics. In Procedia Computer Science, Proceedings of the 3rd International Conference on Information Technology and Quantitative Management, Rio De Janeiro, Brazil, 21-24 July 2015; Gomes, L., Colcher, R., Wolcott, P., HerreraViedma, E., Shi, Y., Eds.; Elsevier Ltd.: Amsterdam, The Netherlands, 2015; pp. 119-125.

47. Zhao, Y.W.; Su, N. Extension Design; Science Press: Beijing, China, 2010.

48. Chen, J.; Zhao, Y.W.; Li, F.Y.; Li, J.F. Transforming bridge-based conflict resolution for product green design. J. Mech. Eng. 2010, 46, 132-142. [CrossRef]

49. Olaru, A.; Olaru, S. Solving of the contradictory problem of the precision-stability by using the extenics theory. In MATEC Web of Conferences, Proceedings of the 7th International Conference on Mechanical, Industrial, and Manufacturing Technologies, Cape Town, South Africa, 1-3 February 2016; Abou, E.I., Hossein, K., Eds.; EDP Sciences: Cedex A, France, 2016; pp. 1-8.

50. Zhao, Y.W.; He, L.; Hong, H.H.; Huang, X. Study on the innovation of integrating TRIZ-Extenics. J. Guangdong Univ. Technol. 2015, 32, 1-10. [CrossRef] 
51. Zhou, X.Y. Research on the Technological Innovation Theory and Method Based on TRIZ and Extenics. Ph.D. Thesis, Southwest Jiaotong University, Chengdu, China, 2012.

52. Yang, C.Y.; Cai, W. Extenics and intelligent processing of contradictory problems. Sci. Technol. Rev. 2014, 32, 15-20. [CrossRef]

53. Yang, C.Y.; Cai, W. Study on extension engineering. Eng. Sci. 2000, 2, 90-96.

54. Masui, K.; Sakao, T.; Kobayashi, M.; Inaba, A. Applying quality function deployment to environmentally conscious design. Int. J. Qual. Reli. Manag. 2003, 20, 90-106. [CrossRef]

55. Ren, S.D.; Gui, F.Z.; Zhao, Y.W.; Zhan, M.; Wang, W.L. An effective similarity determination model for case-based reasoning in support of low-carbon product design. Adv. Mech. Eng. 2020, 12, 1-24. [CrossRef]

56. Suh, N.P. Axiomatic design theory for systems. Res. Eng. Des. 1998, 10, 189-209. [CrossRef]

57. Meier, C.; Yassine, A.A.; Browning, T.R. Design process sequencing with competent genetic algorithms. J. Mech. Des. 2007, 129, 566-585. [CrossRef]

58. Pahl, G.; Beitz, W.; Feldhusen, J.; Grote, K.-H. Engineering Design-A Systematic Approach, 3rd ed.; Sprinter: Berlin, Germany, 2007.

59. Ilevbare, I.M.; Probert, D.; Phaal, R. A review of TRIZ, and its benefits and challenges in practice. Technovation 2013, 33, 30-37. [CrossRef]

60. Chou, J.R. An ARIZ-based life cycle engineering model for eco-design. J. Clean. Prod. 2014, 66, 210-223. [CrossRef]

61. Tyl, B.; Legardeur, J.; Millet, D.; Vallet, F. A comparative study of ideation mechanisms used in eco-innovation tools. J. Eng. Des. 2015, 25, 325-345. [CrossRef]

62. Shah, J.J.; Smith, S.M.; Vargas-Hernandez, N. Metrics for measuring ideation effectiveness. Design Stud. 2003, 24, 111-134. [CrossRef]

63. Mittal, S.; Frayman, F. Towards a generic model of configuration tasks. In Proceedings of the 11th International Joint Conference on Artificial Intelligence, Detroit, MI, USA, 20-25 August 1989; Morgan Kaufmann: San Mateo, CA, USA, 1989; pp. $1395-1401$. 